\title{
The Challenges of Transition:
}

\section{Essays on Nutrition and Climate Change}

Dissertation by Iris Butzlaff 


\section{The Challenges of Transition: Essays on Nutrition and Climate Change}

Dissertation to obtain the Ph.D. degree at the Faculty of Economics Sciences

Georg-August-University of Goettingen, Germany

Presented by:

Iris Butzlaff

born in Rotenburg/Wuemme, Germany

Date of submission: January 22, 2016

Date of disputation: April 21, 2016 
Supervision and examination committee:

$1^{\text {st }}$ supervisor: Prof. Stephan Klasen, PhD.

$2^{\text {nd }}$ supervisor: Prof. Dr. Matin Qaim

$3^{\text {rd }}$ supervisor: JProf. Dr. Sebastian Vollmer 


\section{Summary}

Transition processes are a concomitant feature of economic growth. The transition that many countries (especially developing and transition countries) undergo when they experience economic growth has manifold characteristics. The nutrition transition, which is understood as a rapid change of diets towards more energy-dense, often (highly) processed and convenience foods and beverages that tend to be rich in sugar, fat, and salt and a more sedentary lifestyle, leads to increasing rates of overweight and obesity. These nutritional statuses are known to be risk factors for nutrition related non-communicable diseases such as diabetes, cardiovascular diseases, and certain types of cancer.

Two essays of this Ph.D. thesis analyze determinants of the nutrition transition in middleincome countries. Using recent individual level data from the Russia Longitudinal Monitoring Survey (RLMS) from 1994 to 2012, in the first essay we scrutinize the influence of transitional processes, particularly economic transitions on nutritional and health outcomes. We test the hypothesis that the income gradient of individual body weight growth (i.e. the relationship between income and BMI growth) follows an inverted U-shape and thus changes its sign from positive to negative in the process of economic development. For the case of Russia, we could not find clear evidence that the income-BMI-growth gradient has already shifted. Turning points have not yet been reached. Expenditure increases have significant positive effects on BMI levels and on BMI growth rates. Furthermore, better educated women have lower BMI levels than women with less than secondary education whereas men who completed tertiary education have higher BMI levels than men with less than secondary education.

The second essay uses longitudinal data from South Africa to reveal short-term and long-term effects that socio-economic and cultural factors have on the probability of becoming obese. The concept of "benign" obesity seems to influence people's perceptions of an ideal body shape and thus they model the preference for a higher body weight. Women are more affected by increasing body weights than men. We find that time invariant characteristics and long-term effects have the largest influence on the probability of becoming obese. To address the problems of obesity, we suggest implementing programs that change people's attitudes and behavior regarding food intake and physical activity.

The third essay investigates how regional climate agreements potentially can contribute to reducing greenhouse gas emissions and gives an overview of the nature of those agreements. We classify 16 agreements by their subject (technology/R\&D, trade and finance) and examine their record to date. Although most of the agreements were established with lofty motivations, in all of them clear reduction targets or compliance mechanism were missing. Since most countries share the same climate-related risks (e.g. rising sea levels, water scarcity, flooding) and necessities, states were probably expecting to reduce a competitive disadvantage by implementing climate change mitigation efforts. The main potential outcome may be found in the field of information sharing. A stronger commitment to reporting tools, quantifiable goals, compliance mechanism and accountability towards these goals would clearly be necessary to quantify the effects of actual and potential policies. 


\section{Acknowledgements}

The present thesis was written under the supervision of Prof. Stephan Klasen, Ph.D. and as part of the Research Training Group "GlobalFood" at the Georg-August University of Göttingen. First, my deepest thanks go to my first supervisor Prof. Stephan Klasen for his continuous support, guidance, and scientific and practical advice. I have started as student assistant at his chair and was employed as a research associate at the chair during the time I was working on this dissertation. Prof. Klasen was always able to motivate me and to give me inspiring ideas for continuing my research. I would also like to thank my second supervisor Prof. Matin Qaim for his readiness and his availability to comment on my research with stimulating questions and valuable suggestions. As a speaker of the Research Training Group "GlobalFood", he also provided me support regarding equipment and interesting courses. I thank JProf. Sebastian Vollmer for serving at my supervision committee and for keeping an open door. I am grateful for his valuable comments.

To conduct my research would not have been possible without the RLMS-HSE (Russia Longitudinal Monitoring Survey-Higher School of Economics) data; I acknowledge the provision of the data.

I am thankful to my co-authors Dr. Dimitrios Minos and Dr. Nicole Grunewald. We had fruitful discussions on our papers and the collaboration with them has always been fun.

My thanks also go to my 'mentor' Dr. Melanie Grosse who drove me into the "GlobalFood" program because she seemed to have been convinced that it was a great idea if I would write a dissertation. Thanks for joining my way in the academic world for so many years.

I am very grateful to my colleagues from "GlobalFood" and from Prof. Klasen's chair for the many productive discussions, meetings and talks we shared. Thanks in particular to Dr. Ramona Rischke who gave me so much support and trust.

I am lucky to have always been surrounded by people who believed in my ability to be successful and who have pushed me to the end. I owe my friends and my family a lot because they showed me that life is (also) good outside of university. They filled my life with joy, happiness and strength that helped me to continue. Thanks to my parents and to my sisters for all their support, their encouragement and for their love.

Thanks to my beloved husband Felix and to my children. I am deeply thankful for your love, patience and support at any time. I love you back. 


\section{Table of Contents}

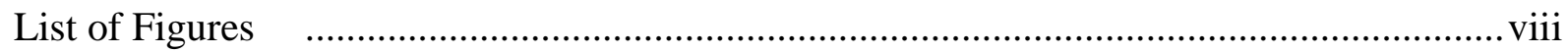

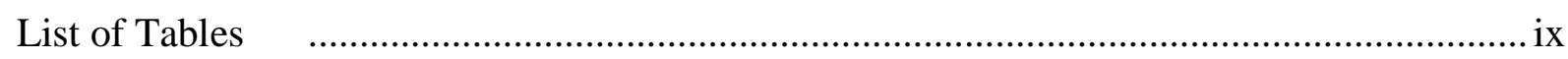

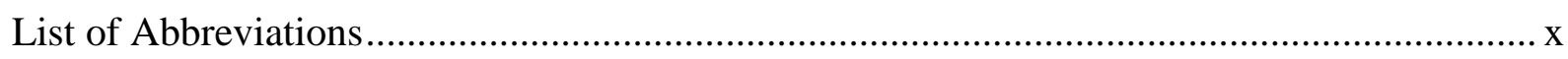

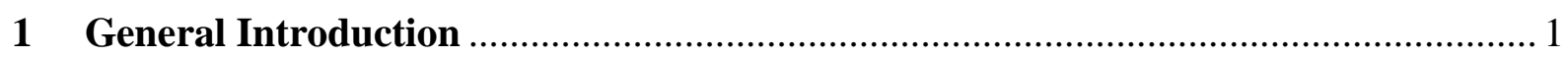

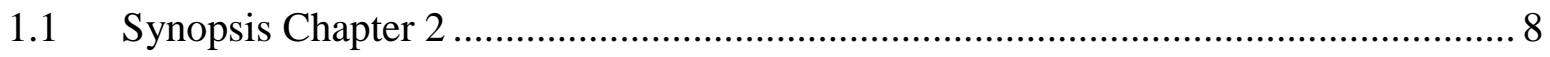

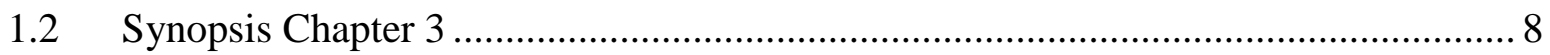

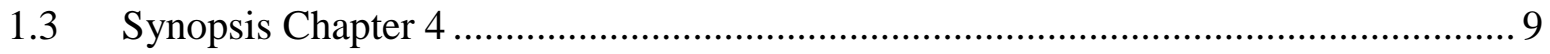

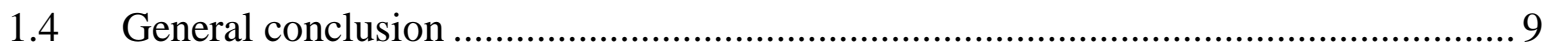

2 BMI Growth Rates and the Nutrition Transition: The Role of Income, Inequality

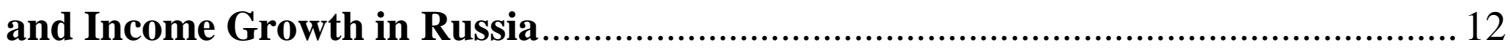

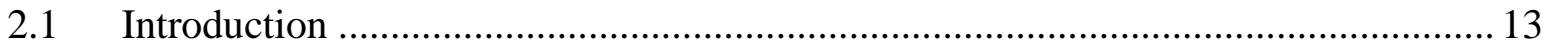

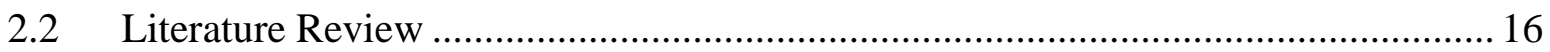

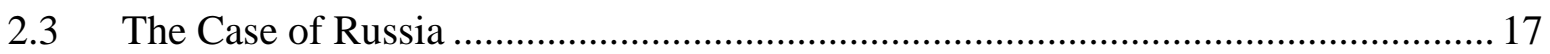

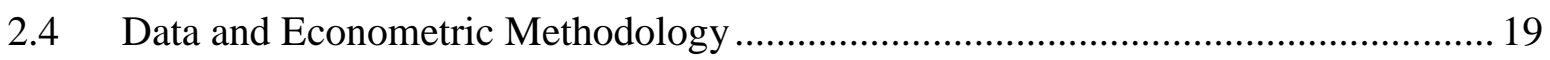

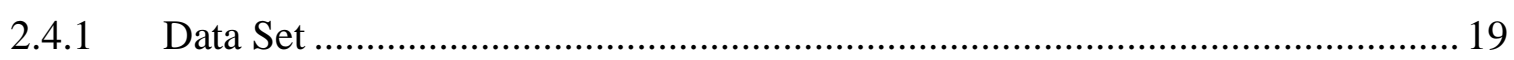

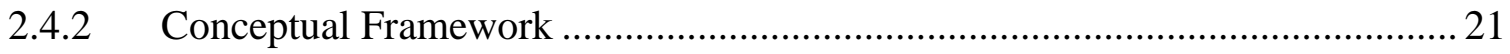

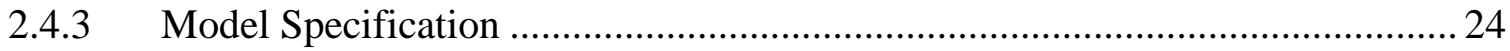

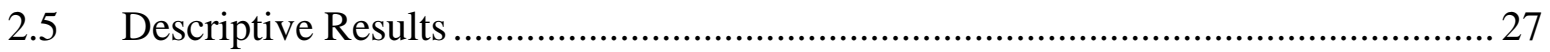

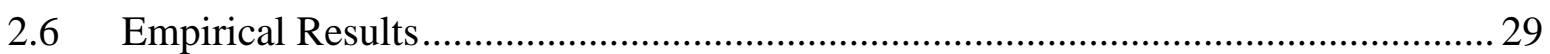

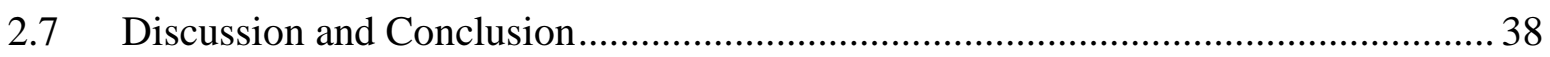

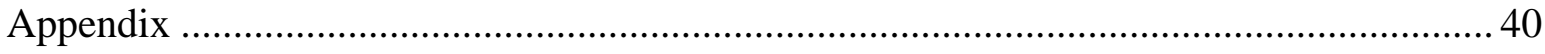

3 Understanding the Drivers of Overweight and Obesity in Developing Countries:

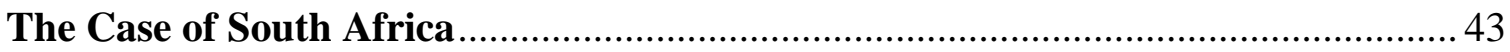

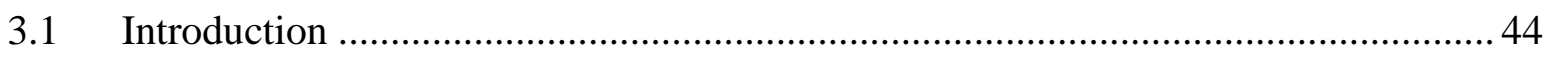

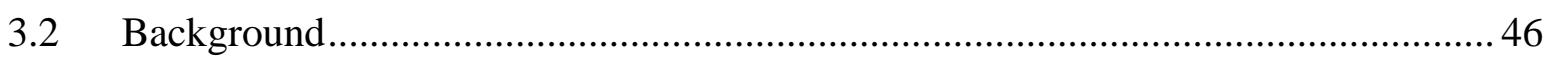

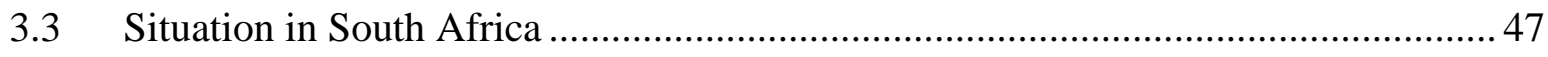

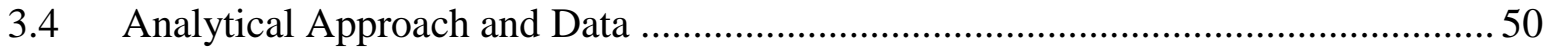

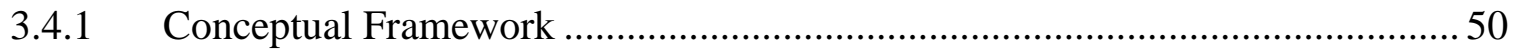

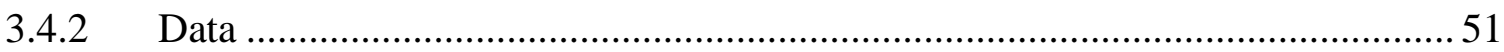




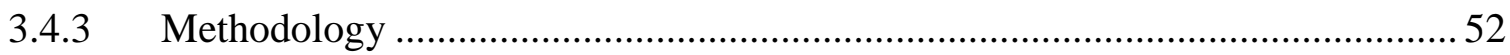

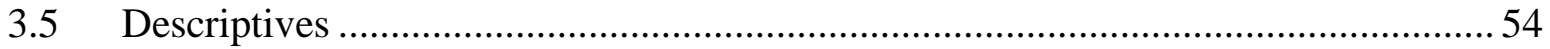

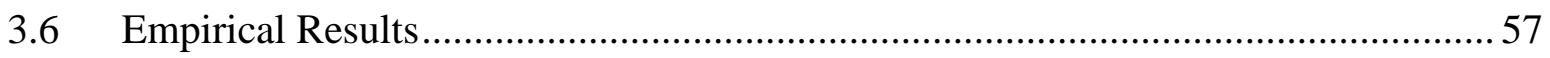

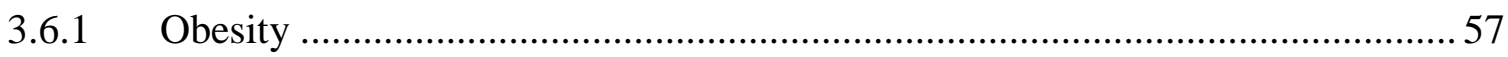

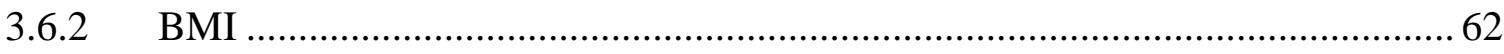

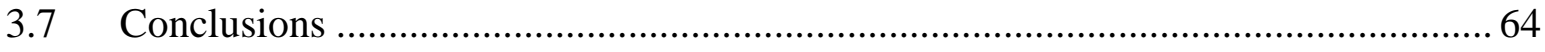

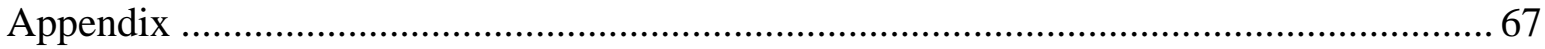

4 Regional Agreements to Address Climate Change: Scope, Promise, Funding,

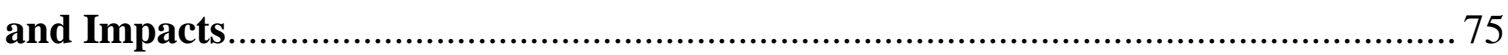

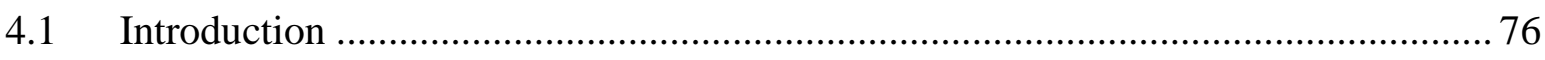

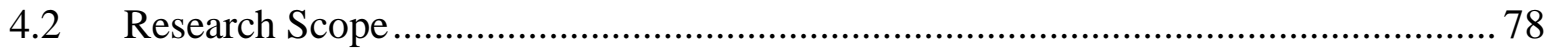

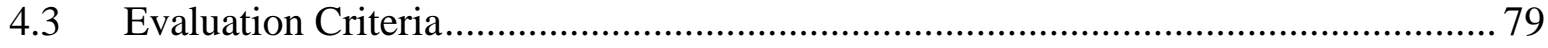

4.3.1 Type, Member Size and Age of the Initiative ................................................... 79

4.3.2 Goals and Compliance/Reduction Mechanisms.............................................. 80

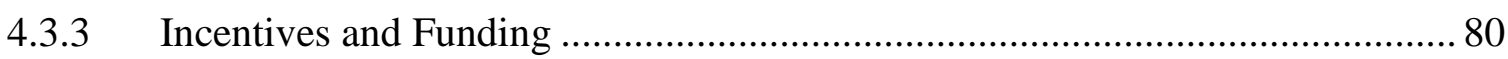

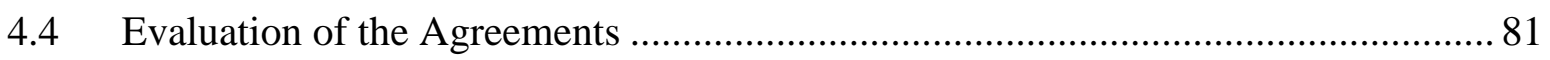

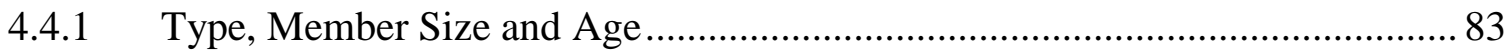

4.4.1.1 Technology and Research \& Development Agreements ............................ 83

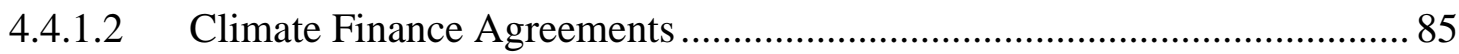

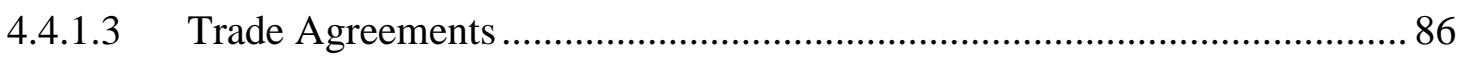

4.4.2 Goals and Compliance/Reduction Mechanism ............................................. 87

4.4.2.1 Technology and Research \& Development Agreements ............................ 87

4.4.2.2 Climate Finance Agreements …............................................................... 89

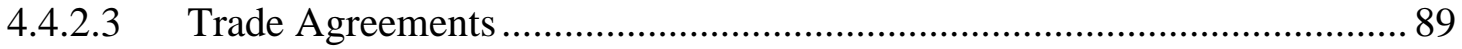

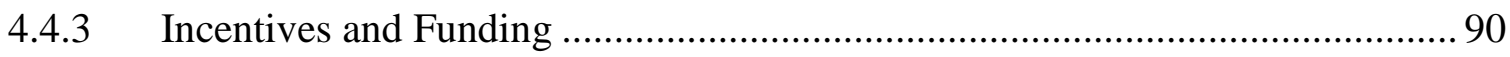

4.4.3.1 Technology and Research \& Development Agreements ........................... 90

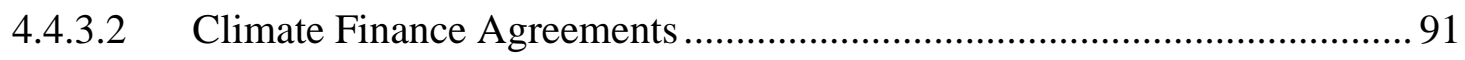

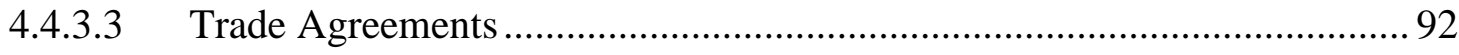

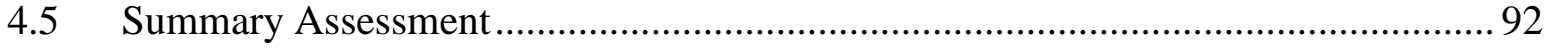

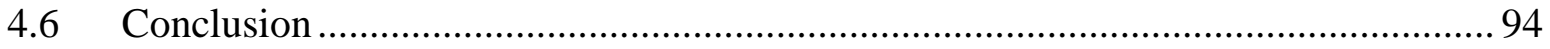

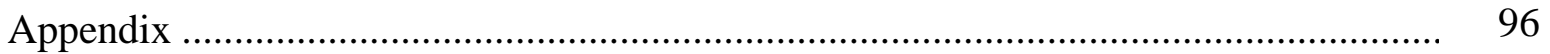

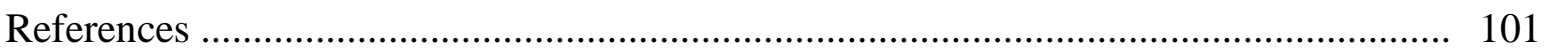




\section{List of Figures}

\section{Chapter 2}

Figure 2.1: Conceptual Framework of Determinants of Nutritional Status ................... 21

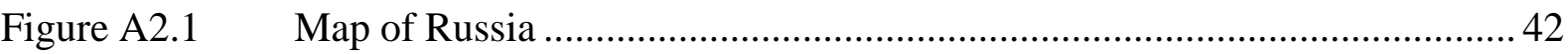

\section{Chapter 3}

Figure 3.1: Overweight and Obesity in Urban and Rural Areas ....................................55

Figure 3.2: $\quad$ Mean Total Expenditure per capita across quintiles .................................... 56

Figure 3.3: Share of BMI $>30$ over expenditure quintiles.............................................57

Figure A3.1 Total and Food Expenditure (2008-2012)................................................... 68

Figure A3.2 Expenditure on high- and low-fat food (2008-2012) ................................... 69

Figure A3.3 Total and Food Expenditure for the lowest quintile ……............................. 70 


\section{List of Tables}

\section{Chapter 1}

Table 1.1: $\quad$ Millennium Development Goals ............................................................ 2

Table 1.2: $\quad$ Sustainable Development Goals ................................................................ 4

Chapter 2

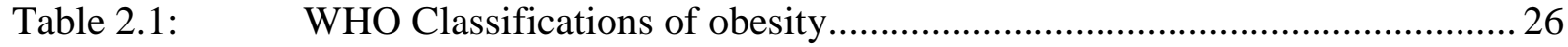

Table 2.2: $\quad$ Descriptive Statistics for RLMS Sample, 1994-2012 _................................ 27

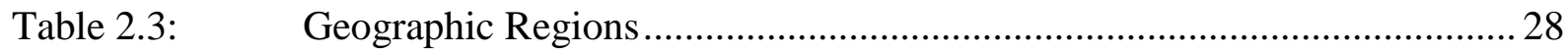

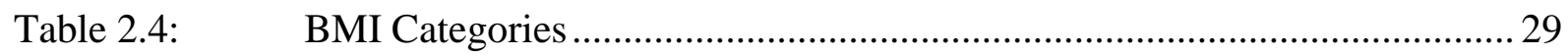

Table 2.5: $\quad$ Impact of income variables on BMI for selected years, base models Pooled OLS regression results ................................................................. 30

Table 2.6: $\quad$ Impact of income variables on BMI for selected years, extended models Pooled OLS regression results .............................................................. 32

Table 2.7: $\quad$ Fixed Effects Regression Results (BMI) .................................................. 35

Table 2.8: $\quad$ BMI growth per period, Pooled OLS regression ….................................... 37

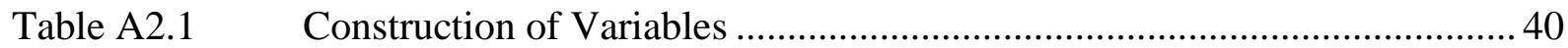

Table A2.2 Distribution of Observations among Years (1994 to 2012) ........................ 41

Table A2.3 Transition Matrix for Income Quintiles ..................................................... 41

Chapter 3

Table 3.1: $\quad$ BMI Categories for males and females in 2008, 2010, and 2012 2.............. 54

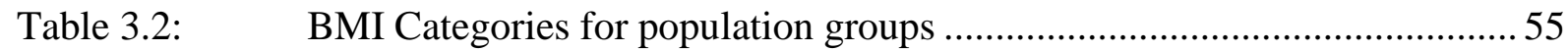

Table 3.3: $\quad$ Regressions on the probability of a person being obese ...............................58

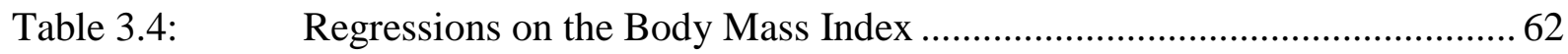

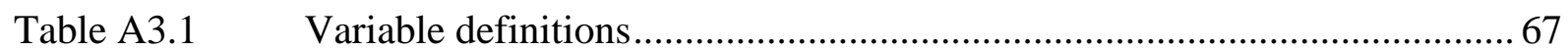

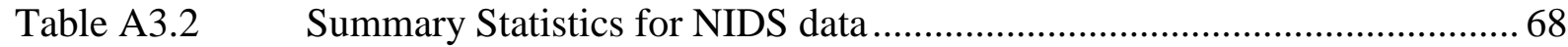

Table A3.3 Regressions on the probability of a person being obese (Exp. squared) ..... 71

Table A3.4 Regressions on the natural logarithm of the Body Mass Index .................. 73

\section{Chapter 4}

Table 4.1: Overview of the Analyzed Agreements

Table A4.1a-e Overview on Regional Technology and R\&R Agreements Concerning Climate Change 


\section{List of Abbreviations}

ACCI

ACRI

AFCC

AIDS

AIFS

APEC FFSEA

APEC

APPCDC

ASEAN

BMI

CAGR

CEC

$\mathrm{CO} 2$

COMESA

CSIRO

CSLF

DALYs

DPAD

ECPCA

ETF-IW

ETS

EU

FAO

FE

G-20 FFSEA

G-20

GCCA

GDP

GEEREF

GEF

GHG

GIZ

GMI

GNP

HIV

ICCAI

ICI

IDB

IEA

IHD

IMF
ASEAN Climate Change Initiative

Arab Climate Resilience Initiative

ASEAN Multi-Sectoral Framework on Climate Change

Acquired Immune Deficiency Syndrome

ASEAN Integrated Food Security

APEC Fossil Fuel Subsidies Elimination Agreement

Asia-Pacific Economic Cooperation

Asia Pacific Partnership on Clean Development and Climate

Association of Southeast Asian Nations

Body Mass Index

Compound Annual Growth Rate

Commission for Environmental Cooperation

Carbon Dioxide

Common Market for Eastern and Southern Africa

Commonwealth Scientific and Industrial Research Organization

Carbon Sequestration Leadership Forum

Disability Adjusted Life Years

Development Policy and Analysis Division

Energy and Climate Partnership for the Americas

Environmental Transformation Fund, International Window

Emission Trading System

European Union

Food and Agriculture Organization

Fixed Effects

G-20 Fossil Fuel Subsidies Elimination Agreement

Group of Twenty

Global Climate Change Alliance

Gross Domestic Product

Global Energy Efficiency and Renewable Energy Fund

Global Environmental Facility

Greenhouse Gas

Gesellschaft für Internationale Zusammenarbeit

Global Methane Initiative

Gross National Product

Human Immunodeficiency Virus

International Climate Change Adaptation Initiative

International Climate Initiative

Inter-American Development Bank

International Environmental Agreements

Ischaemic Heart Disease

International Monetary Fund 


\begin{tabular}{|c|c|}
\hline IPCC & Intergovernmental Panel on Climate Change \\
\hline IPHE & International Partnership for the Hydrogen Economy \\
\hline kcal & kilocalories \\
\hline LDCF & Least Developed Countries Fund \\
\hline LPM & Linear Probability Model \\
\hline $\mathrm{M} 2 \mathrm{M}$ & Methane to Markets \\
\hline MCCI & Mediterranean Climate Change Initiative \\
\hline NAAEC & North American Agreement on Environmental Cooperation \\
\hline NAFTA & North American Free Trade Agreement \\
\hline NIDS & National Income Dynamics Study \\
\hline NR-NCDs & Nutrition-Related Non-Communicable Diseases \\
\hline NSR & Non-Self Representing \\
\hline NTC & National Technical Certificates \\
\hline OLS & Ordinary Least Squares \\
\hline PCCSP & Pacific Climate Change Science Program \\
\hline POLS & Pooled Ordinary Least Squares \\
\hline PPS & Probability Proportional to Size \\
\hline PSU & Primary Sampling Unit \\
\hline R\&D & Research \& Development \\
\hline RE & Random Effects \\
\hline REDD & Reducing Emissions from Deforestation and Forest Degradation \\
\hline RLMS & Russia Longitudinal Monitoring Survey \\
\hline RUB & Russian Ruble \\
\hline SADHS & South African Demographic and Health Survey \\
\hline SALDRU & Southern Africa Labor and Development Research Unit \\
\hline SCCF & Special Climate Change Fund \\
\hline SDC & Swiss Agency for Development and Cooperation \\
\hline SR & Self-Representing \\
\hline SSA & Sub-Saharan Africa \\
\hline SSU & Second Stage Unit \\
\hline UN & United Nations \\
\hline UNDP & United Nations Development Programme \\
\hline UNEP & United Nations Environment Programme \\
\hline UNFCCC & United Nations Framework Convention on Climate Change \\
\hline UNOPS & United Nations Office for Project Services \\
\hline VAT & Value Added Tax \\
\hline WHO & World Health Organization \\
\hline
\end{tabular}




\section{General Introduction}

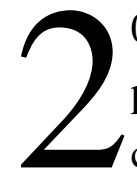

015 was the year when long-lasting development strategies affecting the world population, the Millennium Development Goals (MDGs), have been evaluated and culminated in far-ranging, international resolutions. One famous policy event was the resolution of the Sustainable Development Goals (SDGs) as a successor of the MDGs in September 2015, and another the Paris Agreement dealing with climate change in December 2015. But getting to these milestones in the field of development, involving scientists, political stakeholders, and civil societies worldwide was a long way.

Many years of attempting different development strategies to help developing countries fight poverty have elapsed and sometimes fell short of expectations. In the 1970s, concepts mostly were implemented as "economic development by growth"-strategy (Cabello et al., 2008). But although most of the developing countries registered economic growth poverty rates did not significantly fall. Hence, it became clear that elementary human needs must explicitly be taken into consideration for implementing growth strategies that benefit the whole society. Shelter, housing, food security, access to drinking water as well as health and education indicators were put forward, e.g. by the World Bank (Buckley and Kalarickal, 2006). In the 1980s political stakeholders shifted their attention more on economic topics again, focusing on neoliberalism and integration of developing countries into the world market (Cabello et al., 2008). This was seen as a good way to help developing countries on the same 'well-proven' track as industrialized countries have been. Nevertheless, most countries in the global South had to struggle with macroeconomic hardships, such as decreasing prices for oil (mainly true for oil-exporting countries), low economic growth and huge outstanding debts nourishing continued microeconomic hardships (Ocampo and Vos, 2008; Levine and Renelt, 1991; Fischer, 1991; Montiel and Servén, 2004). In the 1990s - according to the "Washington Consensus" ${ }^{1}$ the established instruments to meet these problems were trade liberalization, deregulation and privatization. But all these strategies have in common that they followed a "top-down" approach. A common perception was that the industrialized countries or BrettonWoods institutions like the International Monetary Fund (IMF) or the World Bank, respectively, tried to impose their ideas of what would be best for economic development on the developing countries. Real identification with the implemented measures and acceptance within the developing countries often were missing. At the same time, starting in the early 1990s, first ideas of a global partnership between the industrialized countries and developing countries arose.

\footnotetext{
1 "Washington Consensus" covers a set of policy measures that the US government, the International Monetary Fund and the World Bank promoted to help economically instable developing countries. The main goal was macroeconomic stabilization, economic opening with respect to trade and investment, and the expansion of market forces within the domestic country (WHO, 2016).
} 
The Earth Summit from 1992 held in Rio de Janeiro was the major UN conference that attracted more attention than previous summits. More than 172 governments attended, with 116 head of states sent plus 17,000 people at the parallel NGO "Global Forum". This summit addressed several environmental issues, such as water supply, air pollution, climate change topics, and poverty. Some far-reaching documents resulted from this meeting: the Rio Declaration on Environment and Development, Agenda 21, and the Framework Convention on Climate Change (UNFCCC), among others. The Agenda $21^{2}$ covers a social and economic section focusing on combating poverty, promoting sustainable consumption patterns, improving health, and increasing the standard of living of their populations through sustained economic development. So, this conference can be interpreted as an important precursor to the Millennium Summit in 2000.

The Millennium Development Goals (MDGs) (see Table 1.1) have been developed at the Millennium Summit in 2000 in New York City where many world leaders met to discuss the role of the United Nations (UN) at the turn of the $21^{\text {st }}$ century; the UN Millennium Declaration was adopted. The main goal of this meeting was to reduce extreme poverty and setting out a series of time-bound targets - with a deadline of 2015. The MDGs covered the topics of poverty reduction; health for children and mothers; gender equality; HIV/AIDS, malaria and other disease; environmental sustainability; and global partnership for development. In September 2001 the MDGs, based upon the Millennium Declaration, were presented by the UN and adopted by 189 independent states.

Table 1.1 Millennium Development Goals

\begin{tabular}{l|l}
\hline Goal 1 & Eradicate extreme poverty and hunger \\
\hline Goal 2 & Achieve universal primary education \\
\hline Goal 3 & Promote gender equality and empower women \\
\hline Goal 4 & Reduce child mortality \\
\hline Goal 5 & Improve maternal health \\
\hline Goal 6 & Combat HIV/AIDS, malaria and other diseases \\
\hline Goal 7 & Ensure environmental sustainability \\
\hline Goal 8 & Develop a global partnership for development \\
\hline
\end{tabular}

Source: (United Nations, 2015c)

The UN Millennium Declaration was seen as a turning point away from neoliberal development theory towards a viewpoint more oriented towards socioeconomic (including health and education), ecologic and human rights perspectives. Human beings moved to 'the center of development' (United Nations, 1995). Reasons are manifold: structural adjustment programs have not been evaluated to be successful (Kingston et al., 2011). Also, the many

\footnotetext{
${ }^{2}$ The number 21 denotes $21^{\text {st }}$ century.
} 
conferences held in the 1990s and 2000s clearly put their focus on social and sustainable topics and on joint efforts of industrialized and developing countries, e.g. the World Conference on Education for All in Thailand in 1990; the World Summit for Social Development in Copenhagen in March 1995; the Platform for Action in Beijing in September 1995 which put its emphasis on women empowerment and gender equality; and in 2002 the World Summit on Sustainable Development in Johannesburg; to just name a few.

Five years after the Millennium Summit, in September 2005, the World Summit was held as a first follow-up summit in New York City to assess the progress of the UN in achieving the MDGs. Another five years later, in 2010, the UN Summit on the MDGs concluded with the adoption of a global action plan to achieve the eight anti-poverty goals by their 2015 target date. Not only among the community of development economists the evaluation of the Millennium Development Goals (MDG) and the necessity of the logical successor - the SDGs (see Table 1.2) - have been discussed (Klasen and Lange, 2012; Easterly, 2009). Several of the MDGs are evaluated as successful (UN, 2015) but some scientists criticized the measurement criteria as inconsistent. Thomas Pogge made a severe criticism based on relative versus absolute gains in reducing the number of the poor in the world (Grefe, 2015). Others say developing countries in Africa are disadvantaged because they have to make much bigger efforts to reach MDGs like e.g. reducing child mortality than other countries (Easterly, 2009; Klasen and Lange, 2012). Country-specific goals would have been a 'fairer' solution for the world's poorest countries (Klasen, 2012). Another criticism referred to the fact that developing countries were imposed upon the phrasing of the goals by the industrialized countries (and mainly by a small team).

In 2012, at the Rio+20 Summit in June 2012 (named after the landmark 1992 Earth Summit in Rio de Janeiro), it was clear that the world still faces many challenges in feeding the hungry, lifting people out of poverty, and provide access to sanitation and water. The MDG expired in 2015 but still many needs are not met. So, establishing post-2015 goals was an outcome of the Rio+20 Summit, which led to a creation of an open working group to come up with a draft agenda (in comparison to the MDGs that have been drafted by a small homogenous group of persons) (Tran, 2012).

The SDGs are a new, universal set of goals, targets and indicators. The UN member states will be expected to use them to frame their agendas and political policies over the next 15 years (Ford, 2015). Discussing possible SDGs, in 2012 already Loewe (2012) raised concerns that goals that refer to the preservation or establishment of global public goods (such as limiting climate change) are preconditions for sustainable development that for reasons of consistency should not enter into one agenda with final goals. Sachs (2012) emphasizes that accurate data is essential to measure progress, a legally binding framework for the SDGs 
would be helpful since a high commitment could increase the probability to engage in the SDGs.

Table 1.2 Sustainable Development Goals

\begin{tabular}{|c|c|}
\hline Goal 1 & End poverty in all its forms everywhere \\
\hline Goal 2 & $\begin{array}{l}\text { End hunger, achieve food security and improved nutrition and promote } \\
\text { sustainable agriculture }\end{array}$ \\
\hline Goal 3 & Ensure healthy lives and promote well-being for all at all ages \\
\hline Goal 4 & $\begin{array}{l}\text { Ensure inclusive and equitable quality education and promote lifelong learning } \\
\text { opportunities for all }\end{array}$ \\
\hline Goal 5 & Achieve gender equality and empower all women and girls \\
\hline Goal 6 & Ensure availability and sustainable management of water and sanitation for all \\
\hline Goal 7 & Ensure access to affordable, reliable, sustainable and modern energy for all \\
\hline Goal 8 & $\begin{array}{l}\text { Promote sustained, inclusive and sustainable economic growth, full and } \\
\text { productive employment and decent work for all }\end{array}$ \\
\hline Goal 9 & $\begin{array}{l}\text { Build resilient infrastructure, promote inclusive and sustainable } \\
\text { industrialization and foster innovation }\end{array}$ \\
\hline Goal 10 & Reduce inequality within and among countries \\
\hline Goal 11 & Make cities and human settlements inclusive, safe, resilient and sustainable \\
\hline Goal 12 & Ensure sustainable consumption and production patterns \\
\hline Goal 13 & Take urgent action to combat climate change and its impacts* \\
\hline Goal 14 & $\begin{array}{l}\text { Conserve and sustainably use the oceans, seas and marine resources for } \\
\text { sustainable development }\end{array}$ \\
\hline Goal 15 & $\begin{array}{l}\text { Protect, restore and promote sustainable use of terrestrial ecosystems, } \\
\text { sustainably manage forests, combat desertification, and halt and reverse land } \\
\text { degradation and halt biodiversity loss }\end{array}$ \\
\hline Goal 16 & $\begin{array}{l}\text { Promote peaceful and inclusive societies for sustainable development, provide } \\
\text { access to justice for all and build effective, accountable and inclusive } \\
\text { institutions at all levels }\end{array}$ \\
\hline Goal 17 & $\begin{array}{l}\text { Strengthen the means of implementation and revitalize the Global Partnership } \\
\text { for Sustainable Development }\end{array}$ \\
\hline
\end{tabular}

Source: (United Nations, 2015a)

Therefore, effective enforcement mechanisms are needed. Sachs (2012) also highlights the necessity of intermediate milestones which would ensure closer feedback between policies and outcome. In March 2013 the open working group (consisting of representatives from 70 countries) had its first meeting and published its final draft in July 2014.

The SDGs (also called Agenda 2030) cover 17 goals with a total of 169 targets and were finally adopted in September 2015 (Ford, 2015; United Nations, 2015b). The MDGs have been considered as too narrow so the SDGs were elaborated with more regard for environmental issues and women empowerment among other topics. Nevertheless, different opinions on the number of goals exist. Some NGOs prefer to have less goals, but others believe it is better to have 17 goals that include targets on good governance, and peace and 
security, than fewer goals that do not address these points (Ford, 2015). Indicators for measuring the goals - developed by the UN Statistical Commission - are due to be finalized in March 2016. One big difference between the MDGs and the SDGs is that all countries are affected by the SDGs, not only the developing countries (as has been the case for the MDGs). Main criticism on the SDGs is related to the too high number of goals and targets, and the narrowness of the goals (The Economist, 2015).

Another publicly well-noticed event in 2015 was the Paris Agreement from December that year: for the first time representatives of 195 nations agreed on an accord that will commit nearly every country to lowering planet-warming greenhouse gas emissions (GHG) to help lower the most drastic effects of climate change (Davenport, 2015). Getting there has been a long process for which several obstacles had to be overcome, e.g. the refusal of some countries including the US to sign a binding agreement regarding the reduction of GHG emissions or the request of Japan, Russia, the US and Canada for implementing more exceptional rules (Hovi et al., 2003; Hovi et al., 2010). It is also the first time that emerging countries commit to the goals.

As mentioned before, the UNFCCC was a legally binding agreement achieved at the Earth Summit in 1992. In December 1997 the Kyoto Protocol was adopted in Kyoto, as extended protocol to the UNFCCC. It entered into force in February 2005 after the adoption of its detailed rules in Morocco in 2001 at the Seventh Conference of the Parties (COP7). Russia's ratification made this possible since at least 55 states of the UNFCCC with an amount of 55\% GHG emissions of all emissions from industrialized countries from 1990, by rule, must have ratified the agreement. Countries that committed to the protocol were 37 industrialized countries and the European Community (UNFCCC, 2016). Three market-based mechanisms were implemented to reduce GHG (Greenhouse Gas) emissions to an average of five percent against 1990 levels; International Emissions Trading, Clean Development Mechanism (CDM), and Joint Implementation (JI). The Emissions Trading allows countries that have emission units to spare to sell this excess capacity to countries that are over their targets. The European Union Emissions Trading System (EU ETS) is the biggest trading system worldwide and works on the 'cap and trade' principle, a certain amount of certificates (allowances related to GHG emissions) can be traded. In short, the EU ETS is working technically, but not working very well economically because there are too many certificates out, so the price is too low which in turn reflects a too low price for carbon (Bel i Queralt and Joseph, 2015; Reyes, 2011; Sinclair, 2009). The incentive to mitigate GHG emissions is hence very small. One reason is the economic crisis which has lowered emissions more than expected (European Commission, 2016). The CDM allows a country committed to the Kyoto Protocol to implement an emission-reduction project in developing countries. By the implementation of these projects saleable certified emission reduction (CER) credits can be earned and finally can be counted towards meeting Kyoto targets (UNFCCC, 2016). While indirectly so, this is the first and 
only system which involves developing countries in GHG emissions reductions under the UNFCCC. Song (2010) evaluates the CDM mechanism as performing relatively well in general (especially in China and India) but one should be aware that a stable investment environment and the existence of appropriate technologies in the host countries is essential for most investors from industrialized countries. Therefore, poor-performing countries like countries in Sub-Saharan Africa (SSA) might need extra policy support. The JI mechanism on the other hand, allows a country that committed to the Kyoto Protocol (Annex B Party) to earn emission reduction units (ERUs) from an emission-reduction or emission removal project in another Annex B Party (UNFCCC, 2016). The first commitment period of the Kyoto Protocol started in 2008 and ended in 2012, the second period was agreed on in 2012 and ends in 2020 (Doha Amendment) (United Nations, 2016). The outcome of the Kyoto Protocol has always been critically under supervision (McKibbin and Wilcoxen, 2002; Böhringer, 2003; Prins and Rayner, 2007) although some of the mechanisms have performed quiet well (Michaelowa and Müller, 2009). The main reason was the acceptance of the Protocol. In the second period Japan, New Zealand and Russia e.g. have not taken on new targets. Also Canada withdrew from the Kyoto Protocol in 2013; the USA and Australia have not even ratified it. The literature on climate change policy was reviewed by Gupta et al. (2007) who concluded that the implementation of the UNFCCC and the Kyoto Protocol are only first steps towards the implementation of an international response strategy to combat climate change (Böhringer, 2003). Nevertheless, several countries have implemented CDM and JI projects. The outcome of these has been evaluated controversially. Recently - in December 2015 - the Paris Agreement has been called 'historic breakthrough that has foiled decades of international efforts to address climate change' (Davenport, 2015). Legally, it is a separate instrument under the UNFCCC rather than an amendment of the Kyoto Protocol. However, this agreement might not save the world from global warming, but GHG emissions can be cut by about half of what is considered to be necessary to stave off an increase in global temperature of 2 degrees Celsius. Additionally, it is more than unclear whether all countries will ratify the agreement, and it will not become binding on its member states until 55 parties who produce $55 \%$ of the world's GHG have ratified the agreement. For its first year from April 22, 2016 the agreement will be opened for signature at the UN in New York.

Takeaways messages from the introduction so far are the following: in the development strategies a shift toward environmental issues alongside economic development could be noticed. Individual well-being still is high ranked on political agendas; nevertheless global inequality is still a 'popular' topic after many years of measures to reduce poverty in the developing world.

Yet, the relevance of the above described development strategies is very high. Assisting countries to establish growth paths that put their populations into circumstances of high wellbeing, free from economic hardships and health problems as well as meeting the global 
problem of a warming climate is still of highest importance. All essays of this dissertation deal with the aforementioned development problems. The first two essays (Chapter 2 and 3) cover health topics that also are reflected in the SDGs. Especially Goal 3 (Ensure healthy lives and promote well-being for all at all ages) ${ }^{3}$ is relevant for the current political debate. In particular, the focus of the first two essays is on the rise of non-communicable diseases (NCDs) that affect countries in transition. NCDs are expanding and affect all countries but the burden of death and disease is heavily concentrated in low- and middle-income countries (WHO, 2014). "Loss of productivity due to premature deaths, and the individual and national costs of addressing NCDs, act as important barriers to poverty reduction and sustainable development" (WHO, 2014). Worldwide NCDs are estimated to account for $60 \%$ of all deaths and obesity seems to be an important driver of NCDs; around 42 million children under the age of 5 years were estimated to be overweight in 2013 (WHO, 2014). The likelihood of diabetes, hypertension, coronary heart disease, stroke, certain cancers, obstructive sleep apnea and osteoarthritis increases as people become obese (WHO, 2014). But through multisectoral population-based interventions that promote physical activity and consumption of a healthy diet, throughout the life course, obesity can be prevented. Therefore, the WHO implemented a Global NCD Action Plan which includes voluntary global targets for prevention and control of NCDs to be attained by 2025. Goal 7 is called 'Halt the rise in diabetes and obesity' (WHO, 2014). To know how strongly countries are affected by increasing prevalence rates of overweight and obesity is of significance for governments, policymakers and health organizations (in addition to the individuals affected) (Chapter 2). The identification of determinants of overweight and obesity, especially in transition countries, is of high relevance and addressed in Chapters 2 and 3.

The third essay (Chapter 4) is related to SDG 13 (Global urgent action to combat climate change and its impacts). Since the Kyoto Protocol has been the only legally binding international agreement with not always successfully operating mechanisms, many (especially developing) countries did not solely rely on it. As developing countries are most strongly affected by the consequences of climate change, several states have identified the potential opportunities of cooperation on the regional level. Benefits could be cost-effectiveness and the reduction of competitive disadvantages of national action. Chapter 4 evaluates the

\footnotetext{
${ }^{3}$ Target 3.b: Support the research and development of vaccines and medicines for the communicable and noncommunicable diseases that primarily affect developing countries, provide access to affordable essential medicines and vaccines, in accordance with the Doha Declaration on the TRIPS Agreement and Public Health, which affirms the right of developing countries to use to the full the provision in the Agreement on TradeRelated Aspects of Intellectual Property Rights regarding flexibilities to protect public health, and, in particular, provide access to medicines for all.

Target 3.c: Substantially increase health financing and the recruitment, development, training and retention of the health workforce in developing countries, especially in least developed countries and small island developing states.

Target 3.d: Strengthen the capacity of all countries, in particular developing countries, for early warning, risk reduction and management of national and global health risks.

Source: (United Nations, 2015a)
} 
potential that regional climate agreements could have for mitigation of climate change. The Paris Agreement is not yet into force but one can already identify one feature that this agreement and the regional climate agreements we evaluate in Chapter 4 have in common: both can be seen as "name-and-shame-systems" which could potentially be a very powerful kind of monitoring and reporting mechanism because probably no country would like to be identified as free-rider on other country's efforts to combat climate change.

\subsection{Synopsis Chapter 2}

In chapter two, for the case of Russia, we analyze the extent to which nutritional status in terms of weight and weight change has been affected by the income distribution as the economy grows. We investigate, whether BMI growth is varying at different tails of the income distribution. Health and nutritional outcomes are not normally expected to be uniform across the income distribution and over time (Monteiro et al., 2004). Using recent individual level data from the Russia Longitudinal Monitoring Survey (RLMS) from 1994 to 2012 with almost 170,000 observation points, we scrutinize the influence of transitional processes, particularly economic transitions on nutritional and health outcomes. The case of Russia is of special interest because of its transition from a centrally planned to a free market economy at the beginning of the 1990s. We test the hypothesis that the income gradient of individual body weight growth (i.e. the relationship between income and BMI growth) follows an inverted $U$-shape and thus changes its sign from positive to negative in the process of economic development. For the case of Russia, we could not find clear evidence that the income-BMI-growth gradient has already shifted. Turning points - which mean that BMI growth is decreasing after a certain economic threshold - have not yet been reached. Expenditure increases have significant positive effects on BMI levels and on BMI growth rates. Investigating determinants of BMI and BMI growth our results give deeper insights on how peoples' body weight is influenced. Better educated women have lower BMI levels than women with less than secondary education whereas men who completed tertiary education have higher BMI levels than men with less than secondary education. Looking at income quintiles we find that all quintiles from second to fifth show higher BMI levels compared to the lowest quintile. Again, this gives evidence to the conclusion that the Russian population has not yet reached a peak or a turning point regarding body weight and body weight gain.

\subsection{Synopsis Chapter 3}

In chapter three, we investigate how high prevalence rates of overweight and obesity have evolved in South Africa. The rise in obesity prevalence rates in South Africa was first noticed already in the early 1990s. Since then, several articles have explored the drivers that have affected people's body weights in the country. This article is the first one that uses longitudinal data from South Africa to reveal the short- and long-term effects that socio- 
economic and cultural factors have on the probability of becoming obese. The concept of "benign" obesity - that is a kind of 'resistance' to health problems caused by obesity - seems to influence people's perceptions of an ideal body shape and thus model the preference for a higher body weight. The concept of "benign" obesity assumed that overweight and obesity does not negatively affect a person with high body weight in terms of non-communicable diseases. In addition, high body weight has been considered to reflect a high social status and wealth. Both arguments hold true for the South African population. Analyzing panel data collected by the Southern Africa Labor and Development Research Unit (SALDRU) with almost 14,000 individuals, we conclude the following: women are more affected by increasing body weights than men. Expenditure has a significant positive effect on body weight in all estimated models but we can rule out a significant effect of food expenditure rise. We find that time invariant characteristics and long-term effects have the largest influence on the probability of becoming obese.

\subsection{Synopsis Chapter 4}

In chapter four, we assess the potential of regional climate agreements on climate change measures by analyzing several evaluation criteria. There are several regional climate agreements which either focus directly on reducing GHG emissions (climate change mitigation) or which were embedded in other agreements. Although many of them are familiar to climate researchers and the public, little is known about the type, the design or funding of those agreements or effectiveness in reducing GHG. We therefore shed light on the potential contribution those agreements could have in reducing GHG emissions and give an overview of the nature of those agreements when evaluating their success. We classify 16 agreements by their subject (technology/research and development, trade and finance) and examine their record to date. Although most of the agreements were established with lofty motivations, in all of them clear reduction targets or compliance mechanism were missing. Since most countries share the same climate-related risks (e.g. rising sea levels, water scarcity, flooding) and necessities, states were probably expecting to reduce a competitive disadvantage by implementing climate change mitigation efforts. The main potential outcome may be found in the field of information sharing. A stronger commitment to reporting tools, quantifiable goals, compliance mechanism and accountability towards these goals would clearly be necessary to quantify the effects of actual and potential policies.

\subsection{General conclusion}

This dissertation investigates the effects of income, income growth and other determinants on the development of overweight and obesity in two transition countries, Russia and South Africa. The results are shown in Chapter 2 and Chapter 3. Chapter 4 examines regional 
climate agreements by evaluating their type and dimension, their goals and compliance mechanisms, and their incentives and funding.

The studies on drivers of overweight and obesity provide evidence that excess body weight is influenced by long-term factors. In general, for both countries, for a set of socioeconomic variables, our findings are in accordance with previous research: Women are (relative to their height) heavier compared to men, age and living with a partner are positively associated with body weight, whereas physical activity and smoking are negatively associated with BMI. Education is positively associated with rising BMIs in both countries, but for Russia we find that women with tertiary education have a significantly lower BMI compared to women with less than secondary education. Hence, education might be one channel to address high obesity rates. It seems to be clear - from both studies on Russia and South Africa - that income positively affects BMI. Hereby, different transmission channels play a role. For the case of South Africa, our findings suggests that a high BMI is still perceived as "healthy" potentially because being thin in some people's minds is related to HIV/AIDS (the "slim" disease), a disease which heavily affects the South African society. Additionally, a visible high body weight still seems to be perceived as a sign of wealth and power which supports the assumption that it is the preferred body status. For the case of Russia we establish that the rise of prevalence rates of obesity will likely continue with growing incomes since the turning point of the income BMI gradient has not yet been reached. Nevertheless, transmission channels of rising incomes that lead to rising BMI rates are not fully revealed.

Chapter 2 and Chapter 3 provide evidence on long-term effects which can be explained by daily behavior. At the same time, the factors that influence people's lifestyle decisions (healthy versus unhealthy nutrition and physical activity versus inactivity) must be taken into consideration from different perspectives, such as cultural, political, economic, and psychological perspectives. As obesity is a byproduct of other lifestyle choices (at least in most westernized countries) such as sedentary lifestyles and changed cooking behavior, effective strategies to reduce excess body weight should rely on a mixture of strategies. Instead of focusing (blames and policies) on the individual (and blaming him), it would be preferable that policies and programs need to readjust their approach. Health programs to prevent overweight and obesity already in childhood could be one way. Since it is mostly the mothers that prepare meals for the children (and the whole family) and therefore make nutritional choices (and since obesity is more prevalent among women), women and children should be in the focus of prevention programs. So, schools should adopt measures to offer "healthy" food, education programs are needed and maybe also worksites could be changed towards an environment that fosters nutritious food and opportunities for being physically active. From the political perspective, we can think of food labelling, such as multiple traffic light systems to inform people about the fat and sugar content of food to influence their shopping behavior. Since we find that long-term factors seem to matter a lot, we conclude 
that a cultural change from the bottom up holds promise, so people need to be involved. Relevant social theories are needed to design intervention programs and to include the issue of overweight related health issues that highly increase the risk of non-communicable diseases.

Chapter 4 evaluates the potential contribution of regional climate agreements on mitigation of climate change. By classifying 16 agreements by their subject and evaluating several criteria such as compliance and reduction mechanisms, as well as budget, we assess the potential effect of the agreements that they might have on the reduction of GHG emissions. The incentives to join an agreement often stem from the fact that neighboring countries are equally negatively affected by consequences of climate change. Furthermore, the implementation of advanced technologies that might result from technology and $R \& D$ agreements promises a competitive advantage that countries do not want to miss. Trade-related agreements originate from existing collaboration with partners (in other fields) and oftentimes do not mention clear goals. Finance agreements are of special interest for developing countries that do not have the financial capacities to fund mitigation projects. None of the evaluated agreements names clear and quantifiable goals or compliance mechanisms. A powerful measure seems to be an implemented monitoring mechanism (as implemented by the APEC FSSEA) which can serve as a "name-and-shame" system. Lately - in December 2015 - the Paris Agreement has been adopted by 195 governments, which is (or would be - when ratified by its member states) the first-ever universal, legally binding global climate deal. To avoid dangerous climate change by limiting global warming to below $2^{\circ} \mathrm{C}$ it sets out a global action plan to put the world on track. The Paris Agreement hopefully results in the implementation of various programs and measures to prevent the climate from further warming. In consequence, after some time it will not be easy to identify impacts of different agreements. However, if the goal of limiting global warming to $2^{\circ} \mathrm{C}$ comes within the range of vision it might be less important to identify the individual most successful strategy. 


\title{
2 BMI Growth Rates and the Nutrition Transition: The Role of Income, Inequality and Income Growth in Russia
}

\begin{abstract}
This study analyzes the extent to which nutritional status in terms of weight change has been affected by the income distribution as the economy has grown. Is BMI growth different at different tails of the income distribution? Health and nutritional outcomes are not normally expected to be uniform across the income distribution and over time. Using recent individual level data from the Russia Longitudinal Monitoring Survey (RLMS) from 1994 to 2012, we scrutinize the influence of transitional processes, particularly economic transitions on nutritional and health outcomes. We test the hypothesis that the income gradient of individual body weight growth (i.e. the relationship between income and BMI growth) follows an inverted U-shape and thus changes its sign from positive to negative in the process of economic development. For the case of Russia, we could not find clear evidence that the income-BMI-growth gradient has already shifted. Turning points have not yet been reached. Expenditure increases have significant positive effects on BMI levels and on BMI growth rates. Better educated women have lower BMI levels than women with less than secondary education whereas men who completed tertiary education have higher BMI levels than men with less than secondary education.
\end{abstract}

JEL classifications: H51, I15, O15, P36

Keywords: Overweight, obesity, health, transition economy, Russia 


\section{$2.1 \quad$ Introduction}

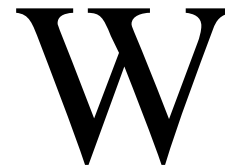

hile the first millennium development goal - halving the share of people suffering from hunger by 2015 - has not yet been reached, a quite different nutrition-related phenomenon has arisen on political agendas in several developing and transition countries. Overweight and obesity are emerging in many countries in transition and even in developing countries that were traditionally more associated with hunger and underweight than with obesity (Doak et al., 2004; Doak et al., 2000; Drewnowski and Popkin, 1997; Subramanian et al., 2009). The onset of the nutrition transition in developing countries was in the 1990s and led to the World Health Organization (WHO) discussing an obesity epidemic already in 2000 in their report "Obesity: Preventing and Managing the Global Epidemic" (WHO, 1998).

The transition process is a broad concept that can occur in several dimensions. In the context of overweight and obesity, the topic of the nutrition transition is crucial. Nutrition transition has been described as the shift in dietary composition - from traditional foods high in cereals and fiber to more processed (and animal sourced) foods, sugar, and fats, and hence more kilocalories (kcal) and less energy expenditure (e.g. a more sedentary lifestyle) (Popkin, 1993). As Popkin and Gordon-Larsen (2004) point out, such a nutrition transition is manifested among others things- in a shift from a high prevalence of infectious diseases to a high prevalence of chronic and degenerative diseases. In this paper, we investigate how the nutrition transition has affected the Russian Federation after the fall of the Iron Curtain. Russia's economy has taken a steep downturn at the beginning of the 1990s and recovered after 1997 (with a short interruption in 1998 due to the Ruble crisis). Since Russia is on its way from a developing country to a highly developed country it is interesting to see where Russia stands regarding the nutrition transition.

In the early 1990s, several authors find that some long-standing patterns about overweight and obesity have been reversed: Traditionally, positive correlation between (female) body fat and socioeconomic status were regarded as stylized fact (Smuts, 1992). For industrialized countries in 1991 Jeffery et al. find that BMI (Body Mass Index) was inversely related to socioeconomic status (Jeffery et al., 1991), i.e. lower income groups were bigger than richer income groups. Several studies since then have found higher prevalence rates for overweight in poorer income groups in industrialized countries, and in richer income groups in developing countries (Popkin, 1999; Popkin and Gordon-Larsen, 2004; Ball and Crawford, 2005; Asfaw, 2007; Fernald, 2007). Monteiro et al. (2004) showed that this seems to be an oversimplified picture of the story. First, they find that overweight is becoming an issue also in developing countries for groups with lower socioeconomic status, secondly, women seem to become overweight at an earlier stage of economic development than men. Philipson and Posner (2003) did a cross-country investigation to show evidence of how the relationship 
between income and body weight changes sign at a certain stage of economic development, which implies an inverted U-shape as an economy is growing. Some other studies have since shown this switch of sign in the income-BMI-gradient using cross-country regressions. Due to scarce panel data, however, hardly any research has been undertaken to show such a relationship empirically for one country even though within-country evidence is required to rule out that country level contextual factors drive the income-BMI relationship. Tafreschi (2014) shows that income growth is associated with higher individual's body weight in less developed areas, whereas it is associated with lower weight growth in more developed areas in China.

Some of the biggest structural changes in societies and economies took place during the transition from a centrally planned to free market economy in the former Soviet Union at the beginning of the 1990s. Price liberalization, the elimination of food subsidies, and privatization of state enterprises led to an enormous transition in the society and structure of the former socialist countries (Mroz and Popkin, 1995; Zohoori et al., 1998). The fraction of the ultra-poor increased significantly in the region between 1989 and 1992 - from less than $5 \%$ to $27.1 \%$ between 1991 and 1992 (Cornia, 1994). Consequences included an increase in unemployment and poverty, household income loss and lifestyle changes (increased alcohol consumption, higher stress levels) that led to a significant decline in life expectancy. The substitution of expensive food products to more quantity but less expensive sources of nutrients helped to reduce hunger in the region (more bread and cereals, less meat and milk) (Cornia, 1994; Mroz and Popkin, 1995). The increased consumption of food low in nutrients but high in kilocalories had long-lasting consequences (probably including micronutrient deficiencies). From 1980 to 1990 the Russian Federation only faced minor increases in overweight prevalence rates ( $\mathrm{Ng}$ et al., 2014). However, overweight and obesity became such a serious problem during the transition that after only two decades more than $50 \%$ of the adults were affected (Huffman and Rizov, 2007). As non-communicable diseases (NCDs) are estimated to account for $82 \%$ of all deaths in Russia (in comparison to $63 \%$ worldwide) (WHO, 2011b) and overweight and obesity seem to be important drivers of NCDs, it is important that the Russian government pays more attention to lower these prevalence rates. The Russian health care system does not adequately respond to the epidemiological transition. ${ }^{4}$ The economic recession in the 1990s led to a sharp decline in public expenditures on health; at the same, indirect costs rose due to the fact that mainly working age people were affected by premature death (Petrukhin and Lunina, 2012).

Whereas households' responses to Russia's economic transition after the collapse of the socialist economy in 1991 (e.g. for children's energy intake see Dore et al., 2003) are well covered in the empirical literature, the extent to which health outcomes are associated with

\footnotetext{
${ }^{4}$ Epidemiologic transition is defined as the shift from a predominance of infectious to noninfectious diseases.
} 
changes in the income distribution poses an important gap in the literature. We focus on health outcomes in terms of BMI. The switching income gradient hypothesis of Philipson and Posner (2003) is empirically tested in this paper. For this hypothesis we analyze the long-run effects of income, income growth, and the income distribution on BMI and BMI growth. The primary contribution of our paper is that we examine the impact of economic growth on people's health outcomes (here BMI and BMI change) at different parts of the income distribution. We also test the effect of gender to establish if men and women react differently to the same determinants of income growth. For the case of Russia, we could not find clear evidence that the income-BMI-growth gradient has already shifted. Expenditure increases have significant positive effects on BMI levels and on BMI growth rates. Regarding expenditure quintiles, higher quintiles have higher BMI levels compared to the poorest quintile.

Not every overweight or obese person suffers from health difficulties, but on an aggregate level obesity can cause many health-related problems. As Chopra et al. (2002) point out, NCDs will become the main cause of morbidity and mortality in the world. The consequences of a higher consumption of animal source food, saturated fats, and sugar on people's health status are diverse nutrition-related non-communicable diseases (NR-NCDs) such as diabetes, heart diseases, cardiovascular diseases (CVD) and some of the most common cancers (Popkin et al., 2001; Montonen et al., 2005). NR-NCDs imply high treatment costs, high expenses for government prevention programs, and high opportunity costs for the people who are affected (Bleich et al., 2008). Dropping out of the labor market results in a loss of income to the laborers and also a loss in productivity to the enterprises and hence a negative effect for the economy as a whole. This adds up to high governmental and even gross domestic product (GDP) reducing costs (Suhrcke et al., 2007; Philipson and Posner, 2008; Rtveladze, 2012).

More than 2.8 million people worldwide die each year as a result of overweight and obesity (WHO, 2011a). Since 1980 the prevalence of obesity has nearly doubled worldwide (WHO, 2014). To confront these diseases, policymakers need to know how many people are affected and who these people are, although it is not easy to successfully implement mechanisms that encourage people to adopt healthier lifestyles (Chopra et al., 2002). It would be even more promising to prevent overweight and obesity in developing and transition countries from reaching high levels so that large costs could be avoided. As obesity and overweight can also reduce the quality of life, this topic should not only be regarded as an economic issue, but as an indicator of subjective well-being as well. Independent of health outcomes, in a few countries, however, being overweight or obese is still considered to be an indication of wealth and wisdom, e.g. in some small South-Pacific islands (Prentice, 2006). Among developing countries, there is huge heterogeneity in the patterns, trends, and onset of substantial levels of obesity. Several countries in Latin America began their transition earlier in the past century 
and hence, entered the NR-NCDs stage of the nutrition transition far earlier than other developing countries (Popkin and Gordon-Larsen, 2004).

Caballero (2007) emphasizes that political leaders should no longer regard obesity as a "disorder of individual behavior" but consider the rising obesity epidemic as highly influenced by the socioeconomic environment (p. 4). A change in the perception of this problem could lead to a change in the strategies implemented to prevent NCDs. Adler and Stewart investigate a public health model that focuses on the prevention of obesity as well as interventions that can modify environmental forces. This could be done through social policies so that the individual is not blamed for not managing his or her weight through diet and exercise (Adler and Stewart, 2009).

The paper continues as follows. We will proceed with a literature review in section 2.2. In section 2.3 , we shortly describe the Russian background. Then, we introduce the data and the econometric methodology in section 2.4. Section 2.5 includes a descriptive analysis of the data. In section 2.6 we present our empirical results and finally conclude in section 2.7 .

\subsection{Literature Review}

Popkin and other epidemiologists have empirically identified the nutrition transition in the 1990s for the developing world (Mroz and Popkin, 1995; Drewnowski and Popkin, 1997). The possibility of there being a difference between how obesity is associated with income in developed and developing societies has already been emphasized by Sobal and Stunkard (1989) in a meta-study. They identified an inverse relationship between socioeconomic status and obesity - at least for women in developed societies - which is driven by the influence of attitudes toward obesity and thinness, respectively. However, not only attitudes but also the availability and affordability of healthy food differ across the income distribution. In westernized countries, overweight is considered to be a reflection of bad health whereas thinness is favored. Popkin and Gordon-Larsen (2004), Mendez et al. (2005) as well as Caballero (2007) find that already in low- and moderate-income countries overweight and obese people (especially women) are more likely to live in lower-income households than in higher-income households. Popkin and Gordon-Larson (2004) even further argue that for low-income countries, belonging to the lower socio-economic group grants protection against obesity, because people cannot afford to become obese, which may be different for lowermiddle income countries. For upper-middle countries, in contrast, belonging to the lower socio-economic group implies a systematic risk factor for obesity. In sum, obesity is seen as a "global epidemic" (Caballero, 2007), and through the channel of NCDs as a "silent killer" (Mbanya et al., 2011).

To make it more specific, Popkin and Ng (2007) explain how the above mentioned factors drive a "westernization of the global diet", associated with increased consumption of animal 
source foods, more added caloric sweeteners, and more sedentary lifestyles. The shift from labor-intensive occupations and leisure activities toward more capital-intensive, less strenuous work and leisure is occurring faster worldwide (Popkin, 2004). Drewnowski (2003) points out how technological advances have led to decreased energy costs for sugar and fat. For many (poor) people, the lowest cost dietary options available are refined grains, added sugars, and fats. This, in turn, leads to the hypothesis that it is very cheap to become obese. The cheap world market price of the energy-dense food - such as fat and sugar - encourages high consumption and high energy intake. Although there is a strong overlap between poverty and food insecurity, we cannot treat these two terms synonymously. Food insecure people face a $20 \%$ to $40 \%$ higher risk of obesity than people who are not food insecure, which has been consistently observed across the US, Europe, and Australia. However, this is only true for women and is regardless of income, lifestyle behaviors or education (Burns, 2004). Some authors find an inverse relationship of energy density and energy costs; they assume that people who attempt to limit food costs will first select less expensive but more energy-dense foods to maintain energy needs. If food costs then further decrease, the total energy intake may actually increase (Drewnowski and Specter, 2004). It has been further shown that fat consumption is less dependent on the Gross National Product (GNP) than ever before because vegetable oils and fats have become globally available at cheap prices. Hence, dietary transitions in accordance with the nutrition transition can occur at lower levels of GNP than previously in the past (Drewnowski and Popkin, 1997).

Prentice (2006) additionally describes a "psychological brake" to rising BMI levels in the western world, social stigmatism against obese people is high, that it so this has probably helped to limit the rise in obesity, at least to some extent.

\subsection{The Case of Russia}

For Russia, the WHO reports alarming numbers for NCD mortality (WHO, 2011b). In total numbers $1,718,300$ deaths are related to NCDs $(827,900$ males and 890,400 females in a population of $142,958,164$ ) which account for $82 \%$ all deaths (all numbers, also the following are related to Russia and 2008 estimates). Of these, a total of $11 \%$ are related to CVDs and diabetes $(7.7 \%$ for males and $4.14 \%$ for females). These are $62 \%$ of total deaths for all ages (66.4\% males and $33.6 \%$ females). Cancers were calculated separately and had a proportion of $13 \%$ of total deaths. Behavioral risk factors identified for NCDs are tobacco smoking (estimated prevalence: $40.5 \%$ ) and physical inactivity (estimated prevalence: $22.6 \%$ ); tobacco smoking and excessive alcohol consumption present other important risk factors for CVDs and NCDs. Metabolic risk factors identified by the WHO (among others) are overweight (estimated prevalence: 59.8\%) and obesity (estimated prevalence: 26.5\%) (WHO, 2011). The health care system of the former Soviet Union did not adequately respond to the epidemiological transition that began in the 1960s, as total mortality and CVDs increased 
from 1965 to 1990 (Tulchinsky and Varavikova, 1996; Petrukhin and Lunina, 2012). The reduction in public expenditures, due to a sharp recession in the early 1990 s, coincides with the deterioration of the health of the Russian population (Petrukhin and Lunina, 2012). But since the high numbers of mortality due to CVDs and NCDs have been known for some years already, the Russian government has set up several programs to address and respond to NCDs. These include programs to address physical inactivity, unhealthy diets, diabetes, and cardiovascular diseases (as reported by the Ministry of Health). A worrying feature of NCD mortality in Russia is that most deaths occur in the working age group (under the age of 60 here).

According to Cornia (1994), the average reported levels of food intake have been considerably higher in Eastern Europe than in most other middle-income countries. In urban areas and among low-income groups, the eating habits of Russians have been characterized by a high proportion of animal fats (cholesterol-rich products), sugar, salt, bread, alcohol - with doses often higher than what is recommended by the WHO - and a low consumption of vegetables, fruits, and berries (which partly can be explained by the severe climate) for several years. Whereas poor families consumed less food per capita, their diet consisted to a higher degree of bread and fats (in relative and absolute terms) and a lower proportion of more diverse food high in micronutrients. This has led to high prevalence rates of overweight, CVDs, micronutrient deficiencies, and anemia (Cornia, 1994). At the same time, Cornia (1994) only finds a weak relationship between food expenditure and caloric intake (elasticity below 0.4). The relationship between household income and caloric intake is even weaker (below 0.15 in the case of Russia).

Engel's Law states that food's budget share is inversely related to household real income (Houthakker, 1987). For Russia, Manig and Moneta (2009) compare income elasticities of quantity with income elasticities of quality of food consumption and conclude that Russian households tend to choose higher quality food items as income rises. Staudigel and Schröck (2015) confirm this finding using RLMS data. The latter article concludes that demand for food is far from satiated in Russia and future growth in expenditures is to be expected, following Engel's Law. The authors furthermore find that Russians will increase their food demand of high-value products such as meat products, sugar and confectionery, alcohol and beverages, while starchy staples such as bread and bakery, and cereals may lose ground. This finding is in accordance with Bennett's Law (Bennett, 1941), which predicts considerable shifts in the composition of food baskets away from starchy food as an economy is rising. Staudigel (2011) finds that in Russia it is mainly high-income households that significantly react with weight changes to food prices. Regarding determinants of obesity Huffman and Rizov (2010) find that expenditure shares of fats and sugars in consumption drive the rising obesity rates, and better education protects from obesity. Both latter articles use RLMS data. 
The collapse of the Soviet Union in December 1991 has affected the food economy strongly. Structural and economic reforms led to a significant decrease in food subsidies (particularly meat products) in the region, high unemployment rates, and increasing poverty rates. The economy had already recovered by 1998 , when the Ruble crisis caused the economy to totter again and caused high inflation rates. Poverty rates were increasing up until 1999 and then falling afterwards. A slightly different picture is drawn by Gibson et al. (2008). They emphasize that the Russian population has been able to cope with the 1998 shock and buffer their nutrition because of the preceding years of economic growth. In our analysis we will see whether different income quintiles had different health outcomes. Has the Russian society experienced changes in their nutritional status as they have developed economically? Have poorer income groups been affected differently from richer income groups?

\subsection{Data and Econometric Methodology}

\subsubsection{Data Set}

This study is based on phase II of the Russian Longitudinal Monitoring Survey of the Higher School of Economics (RLMS-HSE). ${ }^{5}$ The RLMS is a household survey (including individual survey data) designed to measure the effects of Russian reforms on the health and economic welfare of households and individuals across time. It is based on stratified three-stage ${ }^{6}$ clustered samples of residential addresses. Households were repeatedly interviewed and individuals were followed after they had moved to another place and established a new family in 1996, thus observation numbers have been increasing from 1998 onwards. Individuals moving out of the geographical coverage of the surveys (i.e. primary sampling units (PSU)) were not followed. New household members living at the sample dwelling unit (in households interviewed before) were included in the sample. According to the Carolina Population Center at the University of North Carolina and the Demoscope team in Russia this measure of replenishment does not harm the representativeness of the data assuming that new entrants are exchangeable (at least in socioeconomic terms) with those who have left. The annual samples from 1994 to 2012 (excluding 1997 and 1999) each have data for more than 4,000 households and their members. It consists of 38 randomly selected primary sampling units (municipalities) which are representative of the Russian Federation. The collected data include a wide range of information concerning household characteristics such as

\footnotetext{
${ }^{5}$ Source: "Russia Longitudinal Monitoring survey, RLMS-HSE», conducted by National Research University "Higher School of Economics" and ZAO "Demoscope" together with Carolina Population Center, University of North Carolina at Chapel Hill and the Institute of Sociology RAS. (RLMS-HSE web sites: http://www.cpc.unc.edu/projects/rlms-hse, http://www.hse.ru/org/hse/rlms)

${ }^{6} 1$. One modified raion (county) was drawn as Primary Sampling Unit (PSU) from each NSR (non-self representing) stratum. The random selection employed the probability-proportional-to-size (PPS) procedure. Each NSR-PSU was assigned 108 dwelling units on average to be drawn in the next steps. 2. Second-stage Units (SSU) were drawn from the 35 NSR-PSU as well as from the SR (self-representing) strata. 3. Household dwellings were selected from the SSU chosen in Stage 2 (Zohoori et al., 1998; Staudigel, 2011; Swafford and Kosolapov, 2002).
} 
demographic composition, income, expenditures/consumption, education, health, nutrition, medical problems, occupation, and region of residence (Zohoori et al., 1998). The following geographic regions are covered in the sample: Moscow and St. Petersburg as the metropolitan areas, Northern and North Western, Central and Central Black-Earth, Volga-Vaytski and Volga Basin, North Caucasian, Ural, Western Siberian, Eastern Siberian and Far Eastern.

One advantage of this data set is that it can be used as a repeated cross-sectional sample but also shows a panel structure (note, however, that it is an unbalanced panel data set). In combination with the long time period covered (1994-2012), these rich data allow us to analyze drivers and patterns of the transition processes, such as economic or nutritional changes, and their effects on health outcomes of households and individuals.

For the model estimation, we restrict the sample to respondents who were at least 18-years old (for each year), and exclude pregnant women from the sample. BMI is only a suitable indicator of nutritional status for individuals who have reached their final body height. ${ }^{7}$ Our sample includes individuals from the period of 1994-2012. ${ }^{8}$ We need to exclude observations with missing anthropometric data (weight and height) because this information is essential for measuring BMI. We keep extreme cases in our sample (BMI $<18$ and $\mathrm{BMI}>40)$ since several checks indicated that these were not outliers in the sense of erroneously reported anthropometric information, but rather trustworthy in their dimension. Some few very extreme outliers were dropped as they did not seem plausible (BMI $<13$ and $B M I>60)$. Inconsistent observations, e.g. negative values in real per capita expenditure were dropped from our sample, albeit there were only a few.

By analyzing the long-run effects of income, income growth and income distribution on BMI and BMI growth, we aim to empirically test the switching income gradient hypotheses of Philipson and Posner (Philipson and Posner, 2003). The main contributions of our paper are as follows: we first examine the hypothesis over time, and we examine the impact of economic growth on peoples' health outcomes (here BMI change) at different tails of the income distribution, which to the best of our knowledge has not yet been done for Russia. In addition, we extend our analysis by separating between males and females since gender has been identified as important factor for BMI levels and growth in the literature. Given the longitudinal dimension of the large data set, we can exploit the rich data set and test for $a$ transition country, Russia, whether the switching income gradient on BMI increase hypothesis holds true over time and across income groups for a given point in time.

\footnotetext{
${ }^{7}$ We use self-reported information on weight and height as will be explained in detail in Section 2.4.3.

${ }^{8}$ The RLMS survey was not conducted in 1997 and 1999.
} 


\subsubsection{Conceptual Framework}

Figure 2.1 below shows the conceptual framework which supports our analytical approach. As Stubbs and Lee (2004) point out, the increasing number of obese people in the world cannot be solely reduced due to lower physical activity levels but also to an increase in per capita energy intake. When the energy balance is not in equilibrium there are these two starting points to explain the imbalance. Either energy intake is too high or the physical activity level is too low, both arguments can favor overweight and obesity. Because of the above mentioned consequences of obesity (namely NR-NCDs), too high body weight should not be considered as desirable but also underweight should not be considered as "healthy" equilibrium. Underweight causes bad health consequences as well (Black et al., 2008).

Figure 2.1 Conceptual Framework of Determinants of Nutritional Status ${ }^{9}$

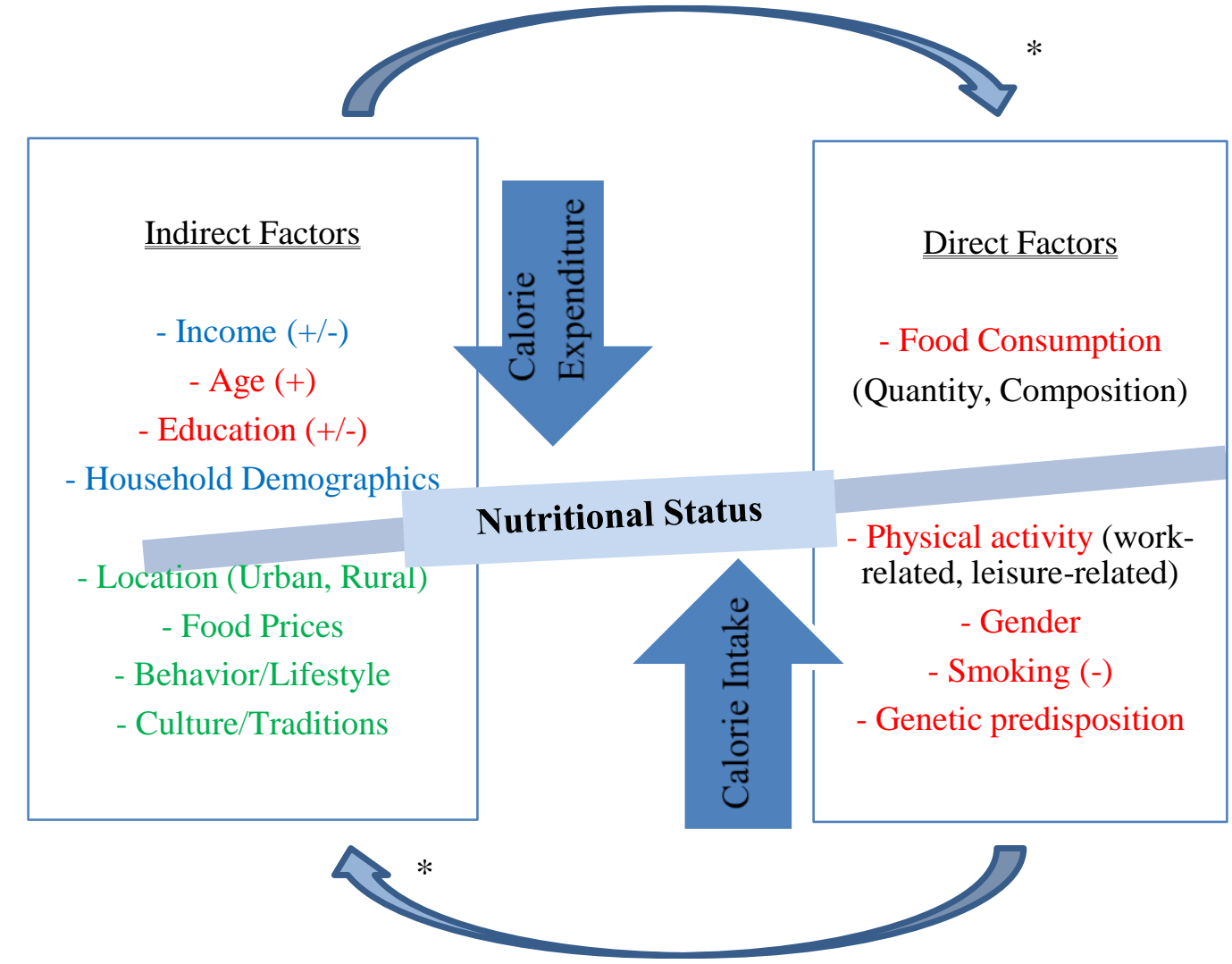

Source: Own composition, *some factors might have an influence on each other.

Several determinants (grouped in the boxes) influence the amount of energy in form of kilocalories that people consume and the extent to which they move their bodies (big arrows that represent calorie intake and calorie expenditure) which finally leads to a certain nutritional status (here: BMI level). Some influencing factors can be measured but have an indirect effect, such as income (expenditure) or age, whereas other factors have a direct effect

${ }^{9}$ Color codes: Individual Level, Household Level, Environmental Level. 
on calorie intake and are directly measurable (e.g. food composition). Some determinants have effects on both directions of the energy balance (e.g. income). The slim arrows indicate that there might occur endogeneity problems due to omitted variable bias or simultaneity. We discuss the expected effects of the influencing factors below. For the construction of the variables, see Table A2.1 in the Appendix.

In order to control for the monetary well-being of a household, we use per capita expenditure as a control variable in our model, following the standard assumption that, collected from survey data, this reflects a household's financial situation better than direct income measures (Deaton and Zaidi, 2002). Indeed there is evidence that in Russia, people might understate their income because they fear disclosure of their responses to tax authorities (Gorodnichenko et al., 2010). This is backed by Stillman and Thomas - also using RLMS - who point out that the use of income measures may lead to biased coefficients and recommend using expenditure data (2008). Sometimes the underreporting of income leads to even smaller absolute values for income compared to expenditure, which cannot be traced back to dissaving to the same extent. We therefore regard per capita expenditure as a more reliable measure for the actual purchasing power of households in our sample and use it as the main measure of their economic situation. Real term, price deflated, per capita household expenditure is used to allow for comparisons across regions and time. All monetary values were deflated using the monthly consumer price index for food $(2005=100)$ in the Russian Federation, separated by region. Income has an effect on calorie intake (whether increasing or decreasing has to be shown here) and on physical activity (car ownership or membership in fitness center might not be affordable for everybody).

BMI is expected to increase with age since the digestive system starts to lose its efficiency and capacity; also activity levels decrease with aging. This has been shown in the literature, we further expect a negative effect from the variable age ${ }^{2}$ (Huffman and Rizov, 2007).

Some articles have shown that females have higher prevalence rates of overweight and obesity compared to men (Monteiro et al., 2004; Crosnoe, 2007; Ball et al., 2011). Hence, we expect a negative sign for the dummy variable male (which is 1 for males and 0 for females).

We use dummy variables for professional education to capture the educational level. Since in Russia school education is relatively important to the society, the average schooling years have been at high levels for several years. ${ }^{10}$ We thus insert the following dummy variables: less than secondary education, completed secondary education, and completed tertiary

${ }^{10}$ Mean Years of Schooling for Adults 25+
\begin{tabular}{|l|l|l|l|l|l|l|l|}
\hline $\begin{array}{l}\text { MEAN YEARS OF SCHOOLING } \\
\text { FOR ADULTS 25+ }\end{array}$ & $\mathbf{1 9 8 0}$ & $\mathbf{1 9 8 5}$ & $\mathbf{1 9 9 0}$ & $\mathbf{2 0 0 0}$ & $\mathbf{2 0 0 5}$ & $\mathbf{2 0 1 0}$ & $\mathbf{2 0 1 3}$ \\
\hline Russia & 7.1 & 8.1 & 9.2 & 11.3 & 11.6 & 11.7 & 11.7 \\
\hline
\end{tabular}

Source: (Human Development Reports, 2013). 
education. The less than secondary education dummy includes simple training programs (e.g. on tractoring and typing). Completed secondary education includes technical, medical, music, pedagogical and art school. Completed tertiary education includes receiving a diploma at institutes, universities, academies, and graduate schools. We expect that higher education is negatively related to body weight and BMI growth because better educated people are more conscious about healthy food and lifestyles and are therefore less likely to be overweight or obese. Additionally, less educated people probably earn less and hence are not able to afford the more expensive healthy food and consume more food items dense in kilocalories. Since we control for per capita expenditure we will not be able to directly identify the latter effect.

The variable household size includes all members living in the household. We did not drop extreme values (in only $1.8 \%$ of all households did the members size exceed 10 people). Since Huffman and Rizov (2010) describe a positive relationship between carbohydrates (bread and potatoes) with household size we expect a positive relationship between household size and BMI.

As a social preference for thinness in some westernized societies exists - which has been argued to be stronger for people who are still searching for their future spouse - we include a dummy variable for living with a partner or not (Sobal et al., 1995; Macdiarmid and Blundell, 1998). We do not rely on the marital status alone because we also want to include people who live with their partner in an "informal marriage". We hence include all persons who live in a registered marriage and those who live together but are not registered and value them as 1 . People receive the value 0 for this dummy when they have never been married, are divorced or widowed. We assume this dummy to be positively correlated with BMI growth.

A dummy for whether the respondent is a smoker or not is included because several studies, including medical studies, have shown a negative effect of smoking on body weight (Wardle and Steptoe, 2003; Williams et al., 2007; Baum and Chou, 2011; Rizov et al., 2012). Smoking tends to increase metabolism and suppress appetite, thus having a negative effect on BMI.

To control for urbanization, we include a binary variable which shows the effect for the location of the respondent's residence in an urban or a rural area on BMI growth. Urbanization has been found to have a positive impact on body weight as living in urban areas tends to increase the intake of processed food, sugar, fat and salt, while reducing physical activity due to better infrastructure and transportation facilities (Drewnowski and Popkin, 1997; Hoffman, 2001; Popkin, 2004; Schmidhuber and Shetty, 2005; Kearney, 2010).

The year dummy variable controls for changes over time related to transition processes, e.g. regarding the organization of the health system. As Huffman and Rizov (2007) point out price 
and income shocks as a result of economic reforms have shifted consumption towards cheaper (and more energy-dense) types of food. So, we expect the year dummy variable to be positive.

We include a dummy variable for whether the respondent was working or not. By inserting this dummy we aim to control for food eaten away from home, which tends to be richer in kilocalories than food prepared at home, as well as control for a higher share of processed food that may be consumed at home due to time constraints (Drewnowski and Popkin, 1997; Popkin and Gordon-Larsen, 2004). Hence, we expect this dummy to be positively correlated with body weight and BMI growth.

Several studies have shown that technological change (including TV watching, fridge and microwave ownership) has led to more sedentary lifestyle, both during work and in leisure time (Philipson and Posner, 2003; Popkin and Gordon-Larsen, 2004; Campbell et al., 2006; Petrukhin and Lunina, 2012). To measure the level of physical activity we include selfreported information (which gives information on activities during leisure time). The value of 0 means the respondent does not engage in physical activity and increases with higher levels of physical activity. Highest is a value of 4 which means the respondent does daily exercise for not less than 30 minutes per day. We know that physical activity reduces BMI growth and therefore expect the variable to show a negative sign.

\subsubsection{Model Specification}

To get a basic overview of how determinants have changed over time, we implement a Pooled OLS (POLS) regression model as shown in Equation (2.1).

$$
Y_{i t}=\alpha_{0}+\beta X_{i t}+u_{i t}
$$

Let $Y_{i t}$ denote the outcome (BMI) of individual $i$ at time $t$, the matrix $X_{i t}$ captures individual and household characteristics and includes a constant term $\alpha_{0} . \beta$ is a vector of parameters to be estimated. $u_{i t}$ is an unobserved random error term. If errors were uncorrelated with the explanatory variables, the above model would allow us to obtain unbiased estimates for $\beta$.

A more robust approach to estimating the parameters of interest is to exploit the panel dimension of our data. A fixed effects (FE) estimator allows us to remove unobserved, timeinvariant components of the error term that may also affect explanatory variables. By using fixed effects regression models it is possible to explore the relationship between explanatory variables and a dependent variable within an individual over time. In contrast to the POLS estimator, the FE estimator results in consistent estimates of $\beta$ even in the presence of timeinvariant, omitted variables.

We hence use fixed-effects regression models (shown in Equation (2.2)) in order to control for time-invariant characteristics that are unique to the individual and are not correlated with 
other characteristics that we control for. Unobserved heterogeneity in individuals or households plays a main role in the formation of overweight and obesity (Staudigel, 2011). Specification tests (Hausman) give us evidence that the assumption that FE models do map our research question accurately, is valid. ${ }^{11}$ Our model of interest is shown in Equation (2.2).

$$
Y_{i t}=\alpha_{i}+\beta X_{i t}+u_{i t}
$$

Where $Y_{i t}$ denotes the outcome (BMI) of individual $i$ at time $t$, the matrix $X_{i t}$ captures individual and household characteristics. $\beta$ is a vector of parameters to be estimated. $\alpha_{i}$ captures time-invariant unobserved effects on the level of individuals, and $u_{i t}$ is an i.i.d. error term.

When estimating the growth regression we use Equation (2.3). In this case BMI_CAGR $i t$ (i.e. the compound annual growth rate, CAGR) as outcome variable denotes the BMI growth of individual $i$ over time period $t$ (see Equation (2.4)), the matrix $X_{i t}$ captures individual and household characteristics. $\beta$ is a vector of parameters to be estimated. $\delta$ is the coefficient that measures the effect of the initial BMI, observed in the first year within the time spell for which data is available. $\gamma$ is the coefficient that captures the impact of time year dummies. $\alpha_{0}$ is the constant term, and $u_{i t}$ is an i.i.d. error term.

$$
B M I_{-} C A G R_{i t}=\alpha_{i}+\delta B M I_{i t}+\beta X_{i t}+\gamma T_{t}+u_{i t}
$$

In our analysis we will focus on the longitudinal component of the data. This unbalanced panel data set provides detailed information on our variables of interest and for several (if not fully overlapping) time periods per individual.

In Equation (2.3) $B M I_{i t-1}$ is represented by the first year with BMI information for each period and hence serves as a lagged variable. Periods are grouped as 1994-1998, 2000-2003, 2004-2007, and 2008-2012. This procedure lowers a possible measurement error and therefore is able to correct the attenuation bias.

To focus on the smoothed growth rate of the individual's BMI is appropriate to address the unbalanced structure of the panel. For some individuals we lack information for some years, i.e. the individuals were followed again after a few years break. Using the compound annual growth rate we do not simply consider the BMI growth of an individual from one period to the next but we generate a smoothed growth rate (which assumes e.g. that an individual we observed 1995 to 2000 grew at the same rate between these years). So, for the compound annual growth rate we take into account the first year with the BMI information $\left(V\left(t_{0}\right)\right)$, the year with the most recent information $\left(V\left(t_{n}\right)\right)$, and the length of the period in between.

\footnotetext{
${ }^{11}$ A FE-Model is also appropriate to use for unbalanced panel data sets. FE models allow attrition to be correlated with $\alpha_{\mathrm{i}}$, the unobserved effect (Wooldridge, 2002).
} 
Below (in Equation (2.4)) we present the equation used to calculate the compound growth rate for BMI:

$$
B M I_{-} C A G R\left(t_{0}, t_{n}\right)=\left(\frac{V\left(t_{n}\right)}{V\left(t_{0}\right)}\right)^{\frac{1}{t_{n}-t_{0}}}-1
$$

with the start value $V\left(t_{0}\right)$, finish value $V\left(t_{n}\right)$, and number of years $t_{n}-t_{0}$.

For calculating the BMI and the dependent variable BMI growth we use self-reported information of the individuals. We are aware that this may lead to biased results as often weight and height are misreported and can hence distort the measured BMI levels (Macdiarmid and Blundell, 1998). To capture the change of BMI, however, we use compound growth rates and assume that the degree of misreporting more or less remains constant over time,${ }^{12}$ so that compound growth rates are likely to be less affected by potential misreporting. ${ }^{13}$ By using self-reported information we can use all waves from 1995 to 2012, thus we must rely on the self-reported weight and height information. T-Tests show us that the means of measured and self-reported data for the growth rates are equal whereas they are significantly different from each other for the BMI levels. We hence conclude that it is appropriate to use BMI_CAGR with self-reported information from an econometric perspective. We additionally used the Wilcoxon signed-rank test to evaluate the median values of the implemented dependent variable because we know of some outlier values in the sample, and our analysis goes beyond analyzing effects for population means. Here as well, we find confirmation that it is better to use BMI_CAGR instead of BMI level values if we want to use self-reported information. Nevertheless, we will use both, BMI and BMI_CAGR, as dependent variables for our empirical analysis to obtain a more detailed understanding of the situation in Russia but use precaution when interpreting the results.

Table 2.1 WHO Classifications of obesity

\begin{tabular}{lll}
\hline Classification & $\begin{array}{l}\text { BMI } \\
\left(\mathbf{k g} / \mathbf{m}^{\mathbf{2}}\right)\end{array}$ & Risk of comorbidities \\
\hline Underweight & $<18.5$ & $\begin{array}{l}\text { Low (but risk of other clinical } \\
\text { problems increased) }\end{array}$ \\
Normal range & 18.5 to 24.9 & $\begin{array}{l}\text { Average } \\
\text { Increased }\end{array}$ \\
Overweight & 25.0 to 29.9 & Moderate \\
Obese Class 1 & 30.0 to 34.9 & Severe \\
Obese Class 2 & 35.0 to 39.9 & Very Severe \\
Obese Class 3 & $\geq 40.0$ &
\end{tabular}

\footnotetext{
${ }^{12}$ If the degree of misreporting does change over time due to e.g. changes in preferences for thinness, then people might systematically underreport their weight, maybe women even more than man. Controlling for gender and time meets this problem.

${ }^{13}$ For the most recent seven years we would have lost information if we had only used measured data because after 2005 only self-reported information were conducted and not measured information any more. Since we clearly want to have up-to-date information we accept this issue.
} 
Table 2.1 shows how WHO classified people of different body stature into four BMI categories (more detailed obese classes were added later to be able to develop more targeted recommendations and strategies). For our analysis we refer to these cut-off points for BMI levels but only use the BMI categories underweight, normal, overweight, and obese. BMI levels change according to individual's energy balances. If people consume more energy (energy input in kilocalories (kcal)) than they spend (energy expenditure in kcal) their body weight increases and accordingly, BMI levels increase as well.

\section{$2.5 \quad$ Descriptive Results}

To get a first impression of the sample characteristics, Table 2.2 presents the means and standard deviations for all variables used in the econometric analysis.

In our sample we have $57 \%$ females and $43 \%$ males (in our pooled sample: $\mathrm{N}=97,140$ versus $\mathrm{N}=72,766$, respectively). The bias towards women most likely stems from the fact that women are more likely to be at home when the enumerators visit the dwelling units and additionally there are more women living in Russia than men (87 males per 100 females; UN, 2015).

Table 2.2 Descriptive Statistics for RLMS Sample, 1994-2012

\begin{tabular}{llllllllll}
\hline & \multicolumn{3}{c}{ Total } & \multicolumn{3}{c}{ Females } & \multicolumn{3}{c}{ Males } \\
\hline Variable & N & Mean & Std.Dev. & N & Mean & Std.Dev. & N & Mean & Std.Dev. \\
\hline BMI (self-reported) & 169,906 & 26.03 & 5.13 & 97,140 & 26.60 & 5.71 & 72,766 & 25.26 & 4.10 \\
Age & 169,906 & 45.53 & 17.63 & 97,140 & 47.33 & 18.35 & 72,766 & 43.11 & 16.31 \\
Gender & 169,906 & 0.43 & 0.50 & 97,140 & 0 & 0 & 72,766 & 1 & 0 \\
Expenditure, p.c.(real) & 169,906 & 3468 & 5825 & 97,140 & 3420 & 5788 & 72,766 & 3530 & 5875 \\
Less Second. Educ. & 169,906 & 0.44 & 0.49 & 97,140 & 0.42 & 0.49 & 72,766 & 0.47 & 0.49 \\
Complet. Second. Educ. & 169,906 & 0.35 & 0.48 & 97,140 & 0.37 & 0.48 & 72,766 & 0.34 & 0.47 \\
Complet. Tertiary Educ. & 196,906 & 0.20 & 0.40 & 97,140 & 0.21 & 0.41 & 72,766 & 0.19 & 0.39 \\
Working & 169,906 & 0.56 & 0.50 & 97,140 & 0.49 & 0.50 & 72,766 & 0.64 & 0.48 \\
Household Size & 169,906 & 4.20 & 2.23 & 97,140 & 4.08 & 2.24 & 72,766 & 4.37 & 2.21 \\
Living with Partner & 169,906 & 0.60 & 0.49 & 97,140 & 0.53 & 0.50 & 72,766 & 0.71 & 0.46 \\
Has Kids & 169,885 & 0.71 & 0.46 & 97,129 & 0.72 & 0.45 & 72,756 & 0.69 & 0.46 \\
Smokes & 169,780 & 0.34 & 0.47 & 97,062 & 0.14 & 0.35 & 72,718 & 0.60 & 0.49 \\
Physical Activity & 166,154 & 0.40 & 1.00 & 95,256 & 0.35 & 0.94 & 70,898 & 0.47 & 1.08 \\
Urban & 169,906 & 0.74 & 0.44 & 97,140 & 0.74 & 0.44 & 72,766 & 0.73 & 0.45 \\
\hline Source: Own & & & & & & & & &
\end{tabular}

Source: Own computation based on RLMS, 1994-2012.

Females are somewhat older than males in our sample (47.3 and 43.1 years, respectively) which to a small extent can explain why females have a higher BMI than males (26.6 and 25.2, respectively). ${ }^{14}$ Women have a smaller income (measured as household real expenditure, per capita, per month) than men (3,420 Russian Rubles (RUB) and 3,530 RUB, respectively).

\footnotetext{
${ }^{14}$ Regressing age on BMI levels we find a positive relationship.
} 
Regarding professional education women and men show comparable numbers for dummy variables: women are more likely to have completed secondary or tertiary education than men. A greater percentage of men are working compared to women (64\% and 49\%, respectively). Household size is 4.2 on average and most of the respondents have children (71\%). Most of the respondents reported that they live together with a partner $(71 \%$ of the men and $53 \%$ of the women). Males report a higher frequency of physical activity compared to women. Around $74 \%$ of the respondents live in urban areas.

Observations are almost equally distributed throughout the years 1994 to 2009, meaning we have around 5\% of observations in these years, from 2010 to 2012 we have higher shares of observations, around $9 \%$ per year. This means that the more recent years are slightly 'overrepresented' in our sample. The main reason lies in the replenishment of the sample, starting in year 1998 (See Table A2.2 in the Appendix).

Table 2.3 gives an overview of the geographic distribution in the sample. Urban areas like Moscow and St. Petersburg are represented with 9.9\%. The regions Northern and North Western, Western Sibirian, and Eastern Sibirian and Far Eastern are less densely populated and therefore, represent a smaller share in the sample $\left(6.2 \%, 9.1 \%\right.$, and $9.3 \%$, respectively). ${ }^{15}$

Table 2.3 Geographic Regions

\begin{tabular}{lll}
\hline Geographic Region & Total & \\
\hline BMI categories & Frequency & Percent \\
\hline Moscow and St. Petersburg & 16,878 & 9.9 \\
Northern and North Western & 10,588 & 6.2 \\
Central and Central Black Earth & 32,297 & 19.0 \\
Volga-Vaytski and Volga Basin & 30,968 & 18.2 \\
North Caucasian & 23,544 & 16.9 \\
Ural & 24,301 & 14.3 \\
Western Sibirian & 15,450 & 9.1 \\
Eastern Sibirian and Far Eastern & 15,880 & 9.3 \\
\hline Total & 169,906 & 100 \\
\hline
\end{tabular}

Source: own calculations using RLMS sample.

Table 2.4 shows the distribution of the population in the BMI categories. ${ }^{16}$ We can see that a much higher share of the women is obese relative to the men $(25.7 \%$ and $12.4 \%$, respectively). As a whole, it is worrying that around one-fifth of the whole sample is obese. For overweight prevalence rates are much higher. Around $30 \%$ of the women are overweight whereas $34 \%$ of

\footnotetext{
${ }^{15}$ An overview of the location of the different regions can be found in the Appendix (Figure A2.1).

${ }^{16}$ The categories are mutually exclusive but jointly exhaustive.
} 
the men are overweight and hence have a BMI between 25 and 30 (obese not included). In total, this means that more than $50 \%$ of the population is either classified overweight or obese. This clearly shows how urgently the Russian government needs to take steps and strategies to raise peoples' awareness about health risks and comorbidities caused by obesity. If we compare these numbers with the measured, rather than self-reported information, we get an even more alarming picture. Measured BMIs show much higher levels and much higher percentage points for overweight and obesity. ${ }^{17}$

Regarding the income distribution and mobility of income groups (here: expenditure quintiles) we can tell that highest 'persistence' is found in the richest and the lowest quintiles; the middle expenditure quintiles are less likely to stay in the same quintile relative to the previous period. $58 \%$ of the respondents of the first quintile remained in the same income quintile as in the previous period, $50 \%$ of the richest quintile had already been rich in the previous period. In the middle quintiles we see less variance (see Table A 2.3 in the Appendix).

Table 2.4 BMI Categories

\begin{tabular}{lllllll}
\hline & Total & \multicolumn{3}{c}{ Females } & Males \\
\hline BMI categories & Frequency & Percent & Frequency & Percent & Frequency & Percent \\
\hline underweight & 5,235 & 3.08 & 3,843 & 3.96 & 1,392 & 1.91 \\
normal & 77,746 & 45.76 & 39,809 & 40.98 & 37,937 & 52.14 \\
overweight & 52,984 & 31.18 & 28,575 & 29.42 & 24,409 & 33.54 \\
obese & 33,941 & 19.98 & 24,913 & 25.65 & 9,028 & 12.41 \\
\hline Total & 169,906 & 100 & 97,140 & 100 & 72,766 & 100 \\
\hline
\end{tabular}

Source: own calculations using RLMS sample.

\subsection{Empirical Results}

Before we implement the fixed effects regression, we first try to get an idea of the relationship between income and BMI by running Pooled OLS regressions, separated by selected years. We chose the first year 1995 (to get the growth expenditure variable we have to allow for a time lag) and then chose steps spanning 5 years when possible. ${ }^{18}$ Hence, we first have a look at OLS regressions for 1995, 2001, 2006, and 2012.

\footnotetext{
${ }^{17}$ Measured information is available until 2005 only: total number for overweight people (BMI>25) is $77.21 \%$, and for obese people (BMI>30) it is $62.19 \%$ in the pooled sample (with measured information).

${ }^{18}$ As already mentioned, the survey has not been conducted in the years 1997 and 1999.
} 
Table 2.5 Impact of income variables on BMI for selected years, base models - Pooled OLS regression results

\begin{tabular}{|c|c|c|c|c|c|c|c|c|c|c|c|c|}
\hline VARIABLES & 1995 & 1995 & 1995 & 2001 & 2001 & 2001 & 2006 & 2006 & 2006 & 2012 & 2012 & 2012 \\
\hline Male & $\begin{array}{l}-1.619 * * * \\
(0.126)\end{array}$ & $\begin{array}{l}-1.619 * * * \\
(0.126)\end{array}$ & $\begin{array}{l}-1.801^{* * * *} \\
(0.140)\end{array}$ & $\begin{array}{l}-1.363 * * * \\
(0.159)\end{array}$ & $\begin{array}{l}-1.362^{* * *} \\
(0.158)\end{array}$ & $\begin{array}{l}-1.609 * * * \\
(0.136)\end{array}$ & $\begin{array}{l}-0.948^{* * *} \\
(0.126)\end{array}$ & $\begin{array}{l}-0.950^{* * *} \\
(0.126)\end{array}$ & $\begin{array}{l}-1.099 * * * \\
(0.138)\end{array}$ & $\begin{array}{l}-0.666^{* * * *} \\
(0.123)\end{array}$ & $\begin{array}{l}-0.666^{* * *} \\
(0.123)\end{array}$ & $\begin{array}{l}-0.786^{* * * *} \\
(0.125)\end{array}$ \\
\hline 2nd Quintile & & $\begin{array}{l}0.0358 \\
(0.176)\end{array}$ & & & $\begin{array}{l}0.370 * * \\
(0.176)\end{array}$ & & & $\begin{array}{l}0.115 \\
(0.132)\end{array}$ & & & $\begin{array}{l}0.249 * \\
(0.134)\end{array}$ & \\
\hline 3rd Quintile & & $\begin{array}{l}0.0761 \\
(0.207)\end{array}$ & & & $\begin{array}{l}0.595 * * * \\
(0.165)\end{array}$ & & & $\begin{array}{l}0.0961 \\
(0.152)\end{array}$ & & & $\begin{array}{l}0.369 * * * \\
(0.129)\end{array}$ & \\
\hline 4th Quintile & & $\begin{array}{l}0.343 \\
(0.224)\end{array}$ & & & $\begin{array}{l}0.548 * * * \\
(0.154)\end{array}$ & & & $\begin{array}{l}0.436 * * * \\
(0.137)\end{array}$ & & & $\begin{array}{l}0.403 * * * \\
(0.144)\end{array}$ & \\
\hline 5th Quintile & & $\begin{array}{l}0.279 \\
(0.214)\end{array}$ & & & $\begin{array}{l}0.692 * * * \\
(0.167)\end{array}$ & & & $\begin{array}{l}0.419 * * \\
(0.186)\end{array}$ & & & $\begin{array}{l}0.441 * * * \\
(0.158)\end{array}$ & \\
\hline Age & $\begin{array}{l}0.406 * * * \\
(0.0142)\end{array}$ & $\begin{array}{l}0.406 * * * \\
(0.0143)\end{array}$ & $\begin{array}{l}0.412 * * * \\
(0.0154)\end{array}$ & $\begin{array}{l}0.406^{* * *} \\
(0.0151)\end{array}$ & $\begin{array}{l}0.406^{* * *} \\
(0.0150)\end{array}$ & $\begin{array}{l}0.427 * * * \\
(0.0153)\end{array}$ & $\begin{array}{l}0.423 * * * \\
(0.0124)\end{array}$ & $\begin{array}{l}0.423 * * * \\
(0.0125)\end{array}$ & $\begin{array}{l}0.423 * * * \\
(0.0160)\end{array}$ & $\begin{array}{l}0.444 * * * \\
(0.0147)\end{array}$ & $\begin{array}{l}0.445^{* * *} \\
(0.0148)\end{array}$ & $\begin{array}{l}0.456^{* * *} \\
(0.0168)\end{array}$ \\
\hline $\mathrm{Age}^{2}$ & $\begin{array}{l}-0.0035 * * * \\
(0.00016)\end{array}$ & $\begin{array}{l}-0.0035 * * * \\
(0.00016)\end{array}$ & $\begin{array}{l}-0.0035^{* * *} \\
(0.00017)\end{array}$ & $\begin{array}{l}-0.0033 * * * \\
(0.00017)\end{array}$ & $\begin{array}{l}-0.0033^{* * *} \\
(0.00017)\end{array}$ & $\begin{array}{l}-0.0035^{* * *} \\
(0.00016)\end{array}$ & $\begin{array}{l}-0.0033 * * * \\
(0.00013)\end{array}$ & $\begin{array}{l}-0.0033 * * * \\
(0.00013)\end{array}$ & $\begin{array}{l}-0.0033 * * * \\
(0.00017)\end{array}$ & $\begin{array}{l}-0.0034 * * * \\
(0.00015)\end{array}$ & $\begin{array}{l}-0.0034 * * * \\
(0.00015)\end{array}$ & $\begin{array}{l}-0.0035 * * * \\
(0.00017)\end{array}$ \\
\hline $\begin{array}{l}\text { Expenditure, } \\
\text { p.c. }(\log )\end{array}$ & $\begin{array}{l}1.627^{*} \\
(0.864)\end{array}$ & & & $\begin{array}{l}1.799 * * \\
(0.793)\end{array}$ & & & $\begin{array}{l}1.207 * * \\
(0.555)\end{array}$ & & & $\begin{array}{l}1.922 * * * \\
(0.599)\end{array}$ & & \\
\hline $\begin{array}{l}\text { Expenditure, } \\
\text { p.c. }(\log )^{2}\end{array}$ & $\begin{array}{l}-0.0907 \\
(0.0554)\end{array}$ & & & $\begin{array}{l}-0.103 * \\
(0.0530)\end{array}$ & & & $\begin{array}{l}-0.0654 * \\
(0.0348)\end{array}$ & & & $\begin{array}{l}-0.105 * * * \\
(0.0372)\end{array}$ & & \\
\hline $\begin{array}{l}\text { Expenditure } \\
\text { growth, p.c. } \\
(\log )\end{array}$ & & & $\begin{array}{l}-0.0082 \\
(0.0754)\end{array}$ & & & $\begin{array}{l}0.114 \\
(0.0912)\end{array}$ & & & $\begin{array}{l}-0.0129 \\
(0.0971)\end{array}$ & & & $\begin{array}{l}0.0391 \\
(0.0741)\end{array}$ \\
\hline Constant & $\begin{array}{l}9.039 * * \\
(3.457)\end{array}$ & $\begin{array}{l}15.95 * * * \\
(0.313)\end{array}$ & $\begin{array}{l}16.09 * * * \\
(0.321)\end{array}$ & $\begin{array}{l}7.922 * * \\
(3.011)\end{array}$ & $\begin{array}{l}15.09 * * * \\
(0.328)\end{array}$ & $\begin{array}{l}15.29 * * * \\
(0.352)\end{array}$ & $\begin{array}{l}9.669 * * * \\
(2.301)\end{array}$ & $\begin{array}{l}14.82 * * * \\
(0.289)\end{array}$ & $\begin{array}{l}15.17 * * * \\
(0.352)\end{array}$ & $\begin{array}{l}5.940 * * \\
(2.484)\end{array}$ & $\begin{array}{l}14.28 * * * \\
(0.314)\end{array}$ & $\begin{array}{l}14.43 * * * \\
(0.374)\end{array}$ \\
\hline $\begin{array}{l}\text { Observations } \\
\mathrm{R}^{2}\end{array}$ & \begin{tabular}{|l|}
7,084 \\
0.141
\end{tabular} & $\begin{array}{l}7,084 \\
0.140\end{array}$ & $\begin{array}{l}5,438 \\
0.125\end{array}$ & $\begin{array}{l}8,580 \\
0.169\end{array}$ & $\begin{array}{l}8,580 \\
0.169\end{array}$ & $\begin{array}{l}7,067 \\
0.152\end{array}$ & $\begin{array}{l}10,716 \\
0.186\end{array}$ & $\begin{array}{l}10,716 \\
0.185\end{array}$ & $\begin{array}{l}8,005 \\
0.161\end{array}$ & \begin{tabular}{|l|}
16,391 \\
0.177
\end{tabular} & $\begin{array}{l}16,391 \\
0.176\end{array}$ & $\begin{array}{l}13,735 \\
0.159\end{array}$ \\
\hline
\end{tabular}


Table 2.5 shows our estimation results for base regressions by inserting different types of variables that represent the monetary well-being of an individual. These base models show us the extent to which expenditure (log), expenditure (log) growth or quintile dummies have an effect on the BMI (level). We analyze these variables to capture the impact that monetary well-being has on the individual BMI. By using these base models, we find that increasing expenditure has significant positive effects on the BMI. The squared term of expenditure (log) shows a negative sign, which reflects diminishing returns of an additional $1 \%$ of expenditure. The growth of expenditure (from one year to the next) does not indicate significant effects, which means that individual expenditure does not affect BMI levels. Inserting quintile dummies (with the poorest quintile as the left out category) shows significant positive effects on BMI levels for the years 2001, 2006, and 2012. Richer quintiles have a significant positive higher BMI than the poorest income quintile.

To illustrate the effect, let's look at a man of average weight and average height that in 2001 belonged to the richest income quintile: this man has a BMI which is $0.692 \mathrm{~kg} / \mathrm{m}^{2}$ higher than that of a man who belonged to the poorest income quintile, it is $2.07 \mathrm{~kg}$ more for a man of average height and weight. The difference of BMI between females and males is becoming smaller over time, so it seems that males gain weight faster than females. The effect of age stays more or less the same over time, around $0.4 \mathrm{~kg} / \mathrm{m}^{2}$ of BMI $(+/-0.03)$.

Turning points for the quadratic regression estimates of expenditure, per capita (first column per year) for the years 1995, 2001, 2006, and 2012 are: 7,856 RUB; 6,234 RUB; 10,716 RUB; and 9,436 RUB, respectively. ${ }^{19}$ Hence, we can expect that rising expenditure will lead to higher BMI levels in the future because turning points are reached at even higher monetary values only, compared to mean expenditure in each year.

To get deeper insights into other factors affecting the BMI level, we ran extended regressions with more explanatory variables, as shown in Table 2.6. Compared to the base model, the coefficient of the gender variable loses in magnitude which means that some of the other variables capture some part of the effect. For example, we have seen before, that smoking habits are correlated with gender. An interesting finding is that living with a partner has a bigger effect on people's BMI than age. Both factors have a significant positive impact on BMI.

\footnotetext{
${ }^{19}$ Mean per capita expenditure for mentioned years are: 2,811 RUB in 1995; 2,398 RUB in 2001; 3,590 RUB in 2006; and 5,184 RUB in 2012.
} 
Table 2.6 Impact of income variables on BMI for selected years, extended models Pooled OLS regression results

\begin{tabular}{|c|c|c|c|c|c|c|c|c|}
\hline VARIABLES & 1995 & 1995 & 2001 & 2001 & 2006 & 2006 & 2012 & 2012 \\
\hline Gender & $\begin{array}{l}-1.114 * * * \\
(0.129)\end{array}$ & $\begin{array}{l}-1.127 * * * \\
(0.122)\end{array}$ & $\begin{array}{l}-0.757 * * * \\
(0.141)\end{array}$ & $\begin{array}{l}-0.757 * * * \\
(0.138)\end{array}$ & $\begin{array}{l}-0.450 * * * \\
(0.109)\end{array}$ & $\begin{array}{l}-0.436 \text { *** } \\
(0.107)\end{array}$ & $\begin{array}{l}-0.405^{* * * *} \\
(0.102)\end{array}$ & $\begin{array}{l}-0.393 * * * \\
(0.101)\end{array}$ \\
\hline $\begin{array}{l}\text { Expenditure, } \\
\text { p.c. }(\log )\end{array}$ & $\begin{array}{l}1.281 \\
(0.839)\end{array}$ & & $\begin{array}{l}2.012 * * \\
(0.797)\end{array}$ & & $\begin{array}{l}1.336^{* *} \\
(0.515)\end{array}$ & & $\begin{array}{l}2.251 * * * \\
(0.590)\end{array}$ & \\
\hline $\begin{array}{l}\text { Expenditure, } \\
\text { p.c. }(\log )^{2}\end{array}$ & $\begin{array}{l}-0.0592 \\
(0.0536)\end{array}$ & & $\begin{array}{l}-0.107 * * \\
(0.0521)\end{array}$ & & $\begin{array}{l}-0.0640 * \\
(0.0322)\end{array}$ & & $\begin{array}{l}-0.115 * * * \\
(0.0357)\end{array}$ & \\
\hline 2nd Quintile & & $\begin{array}{l}0.0529 \\
(0.182)\end{array}$ & & $\begin{array}{l}0.422^{* *} \\
(0.165)\end{array}$ & & $\begin{array}{l}0.171 \\
(0.136)\end{array}$ & & $\begin{array}{l}0.321^{* *} \\
(0.135)\end{array}$ \\
\hline 3rd Quintile & & $\begin{array}{l}0.126 \\
(0.209)\end{array}$ & & $\begin{array}{l}0.699 * * * \\
(0.154)\end{array}$ & & $\begin{array}{l}0.201 \\
(0.155)\end{array}$ & & $\begin{array}{l}0.508 * * * \\
(0.129)\end{array}$ \\
\hline 4thQuintile & & $\begin{array}{l}0.385^{*} \\
(0.226)\end{array}$ & & $\begin{array}{l}0.696 * * * \\
(0.139)\end{array}$ & & $\begin{array}{l}0.581 * * * \\
(0.145)\end{array}$ & & $\begin{array}{l}0.576 * * * \\
(0.150)\end{array}$ \\
\hline 5th Quintile & & $\begin{array}{l}0.430 * \\
(0.225)\end{array}$ & & $\begin{array}{l}0.891 * * * \\
(0.165)\end{array}$ & & $\begin{array}{l}0.575^{* * *} \\
(0.198)\end{array}$ & & $\begin{array}{l}0.671 * * * \\
(0.155)\end{array}$ \\
\hline $\begin{array}{l}\text { Less than } \\
\text { Secondary } \\
\text { Education }\end{array}$ & $\begin{array}{l}1.006^{* * * *} \\
(0.146)\end{array}$ & & $\begin{array}{l}0.603 * * * \\
(0.133)\end{array}$ & & $\begin{array}{l}0.859 * * * \\
(0.134)\end{array}$ & & $\begin{array}{l}0.694 * * * \\
(0.108)\end{array}$ & \\
\hline $\begin{array}{l}\text { Completed } \\
\text { Secondary } \\
\text { Education }\end{array}$ & $\begin{array}{l}0.891 * * * \\
(0.142)\end{array}$ & & $\begin{array}{l}0.504 * * * \\
(0.154)\end{array}$ & & $\begin{array}{l}0.793 * * * \\
(0.0925)\end{array}$ & & $\begin{array}{l}0.785^{* * * *} \\
(0.130)\end{array}$ & \\
\hline Age & $\begin{array}{l}0.383 * * * \\
(0.0162)\end{array}$ & $\begin{array}{l}0.370^{* * * *} \\
(0.0172)\end{array}$ & $\begin{array}{l}0.392 * * * \\
(0.0166)\end{array}$ & $\begin{array}{l}0.383 * * * \\
(0.0166)\end{array}$ & $\begin{array}{l}0.415 * * * \\
(0.0160)\end{array}$ & $\begin{array}{l}0.405 * * * \\
(0.0150)\end{array}$ & $\begin{array}{l}0.432 * * * \\
(0.0164)\end{array}$ & $\begin{array}{l}0.430 * * * \\
(0.0157)\end{array}$ \\
\hline $\mathrm{Age}^{2}$ & $\begin{array}{l}- \\
0.0032 * * * \\
(0.00019)\end{array}$ & $\begin{array}{l}- \\
0.0031 * * * \\
(0.00020)\end{array}$ & $\begin{array}{l}- \\
0.0031 * * * \\
(0.00018)\end{array}$ & $\begin{array}{l}- \\
0.0031 * * * \\
(0.00018)\end{array}$ & $\begin{array}{l}- \\
0.0032 * * * \\
(0.00017)\end{array}$ & $\begin{array}{l}- \\
0.0031 * * * \\
(0.00016)\end{array}$ & $\begin{array}{l}- \\
0.0033 * * * \\
(0.00017)\end{array}$ & $\begin{array}{l}- \\
0.0033 * * * \\
(0.00016)\end{array}$ \\
\hline $\begin{array}{l}\text { Household } \\
\text { Size }\end{array}$ & $\begin{array}{l}0.0915 * * \\
(0.0424)\end{array}$ & $\begin{array}{l}0.0671 \\
(0.0423)\end{array}$ & $\begin{array}{l}0.0970^{* *} \\
(0.0391)\end{array}$ & $\begin{array}{l}0.0826^{* *} \\
(0.0367)\end{array}$ & $\begin{array}{l}0.0728 * * * \\
(0.0233)\end{array}$ & $\begin{array}{l}0.0577 * * \\
(0.0248)\end{array}$ & $\begin{array}{l}0.0615^{* *} \\
(0.0280)\end{array}$ & $\begin{array}{l}0.0513 * \\
(0.0265)\end{array}$ \\
\hline Working & $\begin{array}{l}0.469 * * * \\
(0.138)\end{array}$ & $\begin{array}{l}0.412 * * * \\
(0.137)\end{array}$ & $\begin{array}{l}0.262 * * \\
(0.122)\end{array}$ & $\begin{array}{l}0.209^{*} \\
(0.123)\end{array}$ & $\begin{array}{l}0.360 * * * \\
(0.127)\end{array}$ & $\begin{array}{l}0.299 * * \\
(0.123)\end{array}$ & $\begin{array}{l}0.128 \\
(0.0993)\end{array}$ & $\begin{array}{l}0.0821 \\
(0.0935)\end{array}$ \\
\hline $\begin{array}{l}\text { Lives with } \\
\text { Partner }\end{array}$ & $\begin{array}{l}0.425^{* * * *} \\
(0.140)\end{array}$ & $\begin{array}{l}0.402 * * * \\
(0.139)\end{array}$ & $\begin{array}{l}0.342^{* *} \\
(0.134)\end{array}$ & $\begin{array}{l}0.350^{* *} \\
(0.132)\end{array}$ & $\begin{array}{l}0.244^{*} \\
(0.125)\end{array}$ & $\begin{array}{l}0.248^{*} \\
(0.128)\end{array}$ & $\begin{array}{l}0.303 * * * \\
(0.0825)\end{array}$ & $\begin{array}{l}0.288 * * * \\
(0.0826)\end{array}$ \\
\hline Smokes & $\begin{array}{l}-1.262^{* * * *} \\
(0.116)\end{array}$ & $\begin{array}{l}-1.181 * * * \\
(0.114)\end{array}$ & $\begin{array}{l}-1.496 * * * \\
(0.100)\end{array}$ & $\begin{array}{l}-1.443 * * * \\
(0.101)\end{array}$ & $\begin{array}{l}-1.426 * * * \\
(0.139)\end{array}$ & $\begin{array}{l}-1.342 * * * \\
(0.144)\end{array}$ & $\begin{array}{l}-0.965 * * * \\
(0.132)\end{array}$ & $\begin{array}{l}-0.876^{* * * *} \\
(0.134)\end{array}$ \\
\hline
\end{tabular}




\begin{tabular}{l|ll|ll|ll|ll} 
VARIABLES & $\mathbf{1 9 9 5}$ & $\mathbf{1 9 9 5}$ & $\mathbf{2 0 0 1}$ & $\mathbf{2 0 0 1}$ & $\mathbf{2 0 0 6}$ & $\mathbf{2 0 0 6}$ & $\mathbf{2 0 1 2}$ & $\mathbf{2 0 1 2}$ \\
\hline \hline (continued) & & & & & & & & \\
Physical & -0.0199 & -0.0511 & $-0.154^{* * *}$ & $-0.170^{* * *}$ & -0.0552 & $-0.0795^{* *}$ & $-0.176^{* * *}$ & $-0.191 * * *$ \\
Activity & $(0.0636)$ & $(0.0662)$ & $(0.0469)$ & $(0.0458)$ & $(0.0353)$ & $(0.0375)$ & $(0.0301)$ & $(0.0316)$ \\
Urban & $-0.358^{*}$ & $-0.440^{* *}$ & -0.163 & -0.222 & $-0.325^{*}$ & $-0.389^{* *}$ & $-0.450^{*}$ & $-0.504 * *$ \\
& $(0.195)$ & $(0.197)$ & $(0.224)$ & $(0.220)$ & $(0.164)$ & $(0.168)$ & $(0.238)$ & $(0.244)$ \\
& & & & & & & & \\
Constant & $9.082^{* *}$ & $16.41^{* * *}$ & $6.150^{*}$ & $15.34 * * *$ & $8.015^{* * *}$ & $15.17 * * *$ & 3.824 & $14.73 * * *$ \\
& $(3.435)$ & $(0.413)$ & $(3.121)$ & $(0.454)$ & $(2.127)$ & $(0.296)$ & $(2.487)$ & $(0.331)$ \\
& & & & & & & & \\
\hline Observations & 7,030 & 7,030 & 8,553 & 8,553 & 10,681 & 10,681 & 16,308 & 16,308 \\
R-squared & 0.161 & 0.155 & 0.189 & 0.187 & 0.204 & 0.200 & 0.190 & 0.186 \\
\hline
\end{tabular}

Robust standard errors in parentheses. Left out categories are: $1^{\text {st }}$ Quintile; Completed Tertiary Education.

$* * * \mathrm{p}<0.01, * * \mathrm{p}<0.05, * \mathrm{p}<0.1$. Source: Own calculations using RLMS sample.

The coefficient of household size shows a positive and significant influence on BMI. One factor may be that households with more members buy and prepare food in more efficient ways, so that each family member is able to consume more food. It is also possible that higher numbers of people eating together increase the individual food intake. Interaction terms between expenditure and expenditure quintiles show that only among the richest quintile the richest people have lower BMI levels than the poorest quintile (not shown here).

The coefficient of the factor physical activity is significant and negative. This confirms that more physical activity reduces BMI. The effects of living with a partner, household size, and smoking become smaller over time, whereas the effects of physical activity and urban areas become larger over time.

We know that over time the percentage of people who state that they do not engage in physical activity is clearly decreasing and the percentage of people who state that they do light physical exercise or daily exercise at least $30 \mathrm{~min}$./day is increasing, respectively.

The Pooled OLS regression estimates in Table 2.6 show a significant negative sign for the urban dummy. This is in contrast to previous findings in the nutrition transition literature (Popkin, 2004; Popkin and Ng, 2007; Asfaw, 2007; Hawkes, 2007; Minos, 2015). Our findings show that people in urban areas are not as heavy (have a lower BMI) as people living in rural areas. The effect becomes larger over time. Our hypothesis was that urbanization has a positive effect on BMI due to better transportation and infrastructure and a higher offer of meals eaten outside of the home. One explanation for the negative sign might be that "healthy nutrition" has become modern in the sense that people prefer to eat less meat and less fat. Hence, it is possible that the urban dummy captures other lifestyle factors that lead to lower BMI levels. 
Fixed effects regressions (in Table 2.7) give information on the time-demeaned data on the BMI. Since fixed effects regressions omit time-invariant factors like gender, we run the regressions for both sexes (BMI Total) and separated by gender to get deeper insights. The influence of expenditure is smaller than in the Pooled OLS regressions. There is less within variation (within individuals) of the factors than between (between individuals). This means expenditure has a smaller effect for one particular individual than it has for different individuals. Interestingly, an increase in expenditure only has a positive effect on BMI for females, not for males (with diminishing returns for females). Turning points for the effect of an increase of expenditure are much higher than compared to the pooled sample. Turning points for both, males and females are at 150,704 RUB; and at 34,369 RUB for females (for males Expenditure ${ }^{2}$ is not significant). This means that only after reaching these turning points people are expected to lose weight when increasing their expenditure by $1 \%$. Since this is far more than the average per capita expenditure is, it can be expected that people will gain further weight as their income level increases.

The dummy variable for completed secondary education is not significantly different from less than secondary education (left out category) since there is not much variation in the fixed effects regression. We have another interesting finding for the dummy variable completed tertiary education. Women with completed tertiary education have a significantly lower BMI compared to women with less than secondary education (at $1 \%$ significance level). This finding is in line with Inglis et al. (2005), Dammann and Smith (2009), and Sobal (1991); this holds true if we consider women with completed tertiary education as belonging to a higher socioeconomic group. For men the opposite is true. Men with completed tertiary education have significantly higher BMIs than men with less than secondary education (at 10\% significance level). Age has positive and significant effects on BMI for both, males and females, but has a larger coefficient for women. Household size only has a small positive effect for men, not for women (at the $10 \%$ significance level).

The sign of the work coefficient also depends on the gender: For men the effect of working is positive and for women it is negative (both at the $1 \%$ significance level). Reasons might be that women experience a higher activity level when they are working and have to do the household chores, too, so that they are more active. On the other hand, studies have shown that working is often correlated with higher consumption of food eaten outside the home, which is often regarded as containing more calories than homemade food (Gillis and Bar-Or, 2003; Stewart, 2011). 
Table 2.7 Fixed Effects Regression Results (BMI)

\begin{tabular}{|c|c|c|c|}
\hline VARIABLES & BMI Total & BMI Females & BMI Males \\
\hline \multirow[t]{2}{*}{ Expenditure, p.c. (log) } & $0.310 * * *$ & $0.493 * * *$ & 0.0494 \\
\hline & $(0.0957)$ & $(0.135)$ & $(0.130)$ \\
\hline \multirow[t]{2}{*}{ Expenditure, p.c. $(\log )^{2}$} & $-0.0130 * *$ & $-0.0236 * * *$ & 0.00219 \\
\hline & $(0.00599)$ & $(0.00842)$ & $(0.00821)$ \\
\hline \multirow{3}{*}{$\begin{array}{l}\text { Completed Secondary } \\
\text { Education }\end{array}$} & -0.00380 & -0.0343 & 0.0308 \\
\hline & & & \\
\hline & $(0.0289)$ & $(0.0446)$ & $(0.0360)$ \\
\hline \multirow{3}{*}{$\begin{array}{l}\text { Completed Tertiary } \\
\text { Education }\end{array}$} & -0.0437 & $-0.206^{* * *}$ & $0.140^{*}$ \\
\hline & & & \\
\hline & $(0.0561)$ & $(0.0777)$ & $(0.0796)$ \\
\hline \multirow[t]{2}{*}{ Age } & $0.309 * * *$ & $0.367 * * *$ & $0.233 * * *$ \\
\hline & $(0.0501)$ & $(0.0623)$ & $(0.0691)$ \\
\hline \multirow[t]{2}{*}{$\mathrm{Age}^{2}$} & $-0.00235 * * *$ & $-0.00249 * * *$ & $-0.00233 * * *$ \\
\hline & $(8.58 \mathrm{e}-05)$ & $(0.000115)$ & $(0.000127)$ \\
\hline \multirow[t]{2}{*}{ Household Size } & $0.0276^{*}$ & 0.0196 & $0.0345^{*}$ \\
\hline & $(0.0141)$ & $(0.0202)$ & $(0.0187)$ \\
\hline \multirow[t]{2}{*}{ Working } & $-0.0509 * *$ & $-0.171 * * *$ & $0.0880 * * *$ \\
\hline & $(0.0217)$ & $(0.0306)$ & $(0.0292)$ \\
\hline \multirow[t]{2}{*}{ Lives with partner } & $0.214 * * *$ & $0.234 * * *$ & $0.214 * * *$ \\
\hline & $(0.0323)$ & $(0.0429)$ & $(0.0480)$ \\
\hline \multirow[t]{2}{*}{ Smokes } & $-0.314 * * *$ & $-0.372 * * *$ & $-0.311 * * *$ \\
\hline & $(0.0376)$ & $(0.0590)$ & $(0.0484)$ \\
\hline \multirow[t]{2}{*}{ Physical Activity } & $-0.0160 * *$ & -0.0145 & $-0.0218 * *$ \\
\hline & $(0.00689)$ & $(0.00970)$ & $(0.00969)$ \\
\hline \multirow[t]{2}{*}{ Urban } & 0.147 & 0.461 & -0.298 \\
\hline & $(0.217)$ & $(0.308)$ & $(0.273)$ \\
\hline \multirow[t]{2}{*}{ Constant } & $15.37 * * *$ & $12.79 * * *$ & $18.88 * * *$ \\
\hline & $(1.771)$ & $(2.320)$ & $(2.286)$ \\
\hline Observations & 166,034 & 95,180 & 70,854 \\
\hline R-squared & 0.095 & 0.097 & 0.100 \\
\hline Rho & 0.834 & 0.843 & 0.812 \\
\hline Number of individuals & 34,298 & 18,840 & 15,458 \\
\hline Year FE & YES & YES & YES \\
\hline
\end{tabular}

Robust standard errors in parentheses. Left out categories is: Less than Secondary Education. $* * * \mathrm{p}<0.01, * * \mathrm{p}<0.05, * \mathrm{p}<0.1$. Source: Own calculations using RLMS sample. 
Living with a partner for both sexes increases BMI and smoking decreases BMI. The level of physical activity is only significant and negative for men, which is plausible because men are more likely to report that they engage in physical exercise.

In order to identify drivers of individual BMI growth we ran Pooled OLS as displayed in Table 2.8. We grouped the years into 4 periods $^{20}$ as then we can use the first BMI per period as an explanatory factor (instead of simply using the lagged BMI). This will probably show a more pronounced effect of the other control variables than the lagged BMI. Grouping the years means clustering periods of 4 years. Since the dependent variable is a compound variable which is able to cover different points in time in an unbalanced panel data set, we can rule out attenuation bias.

A higher initial BMI leads to smaller BMI growth rates, which reflects a convergence effect. Note, that we find small marginal effects for most variables because of the structure of the dependent variable (i.e. being a compound annual growth rate). With a higher initial BMI people gain weight less rapidly, hence we can assume that they are closer to their "final weight". From Table 2.8 we can see that males gain weight less rapidly than females; with increasing expenditures people gain weight faster. Calculating turning points again, we find that the turning point (after which increases in expenditure lead to negative BMI growth) is lower for males than for females (at 6,022 RUB and 10,536 RUB, respectively). ${ }^{21}$ It is at 7,641 RUB for both sexes. People that have less than completed tertiary education gain weight faster than persons that have completed tertiary education. This is more relevant for females than for males (in magnitude of coefficients and level of significance). Interestingly, now we see that men do gain weight less rapidly when they become older whereas women gain weight faster as they get older (but only to a certain age). We control for the duration of which we have information of the respondent to make sure that this does not affect the outcome of BMI growth and do not find significant effects for it. Another interesting finding is that we now see significant positive effects of working on BMI growth for both sexes, thus both men and women gain weight faster when they are working.

\footnotetext{
${ }^{20}$ Period 1: 1994 - 1998, Period 2: 1999 - 2003, Period 3: 2004 - 2007, and Period 4: 2008 - 2012.

${ }^{21}$ Mean per capita expenditure for periods are: 2,951 RUB in Period 1; 2,598 RUB in Period 2; 3,564 RUB in Period 3; and 4,863 RUB in Period 4.
} 
Table 2.8 BMI growth per period, Pooled OLS regression

\begin{tabular}{|c|c|c|c|}
\hline VARIABLES & $\begin{array}{l}\text { BMI Growth } \\
\text { Total }\end{array}$ & $\begin{array}{l}\text { BMI Growth } \\
\text { Females }\end{array}$ & $\begin{array}{c}\text { BMI Growth } \\
\text { Males }\end{array}$ \\
\hline $\begin{array}{l}\text { First BMI per Period } \\
\text { Male }\end{array}$ & $\begin{array}{c}-0.0012 * * * \\
(0.0001) \\
-0.0012 * * \\
(0.0005)\end{array}$ & $\begin{array}{c}-0.0011^{* * * *} \\
(0.0001)\end{array}$ & $\begin{array}{c}-0.0017 * * * \\
(0.00016)\end{array}$ \\
\hline Expenditure, p.c. (log) & $\begin{array}{c}0.0125 * * * \\
(0.0040)\end{array}$ & $\begin{array}{c}0.0103 * * \\
(0.0050)\end{array}$ & $\begin{array}{c}0.0149 * * \\
(0.0060)\end{array}$ \\
\hline Expenditure, p.c. $(\log )^{2}$ & $\begin{array}{c}-0.0007 * * * \\
(0.0006)\end{array}$ & $\begin{array}{l}-0.0006^{*} \\
(0.0003)\end{array}$ & $\begin{array}{c}-0.0009 * * \\
(0.0004)\end{array}$ \\
\hline $\begin{array}{l}\text { Completed Secondary } \\
\text { Education }\end{array}$ & $\begin{array}{c}-0.0020 * * * \\
(0.0007)\end{array}$ & $\begin{array}{l}-0.0018 * \\
(0.0009)\end{array}$ & $\begin{array}{c}-0.00243 * * * \\
(0.0009)\end{array}$ \\
\hline $\begin{array}{l}\text { Completed Tertiary } \\
\text { Education }\end{array}$ & $\begin{array}{c}-0.0030 * * * \\
(0.0008)\end{array}$ & $\begin{array}{c}-0.0033 * * * \\
(0.0010)\end{array}$ & $\begin{array}{l}-0.0019 * \\
(0.0010)\end{array}$ \\
\hline Age & $\begin{array}{c}0.0002 * * \\
(0.0001)\end{array}$ & $\begin{array}{c}0.0006 * * * \\
(0.0001)\end{array}$ & $\begin{array}{c}-0.0003 * * \\
(0.0002)\end{array}$ \\
\hline $\mathrm{Age}^{2}$ & $\begin{array}{c}-0.0000 * * * \\
(0.0000)\end{array}$ & $\begin{array}{c}-0.0000 * * * \\
(0.0000)\end{array}$ & $\begin{array}{c}0.0000 \\
(0.0000)\end{array}$ \\
\hline Duration (in each period) & $\begin{array}{c}0.0002 \\
(0.0003)\end{array}$ & $\begin{array}{c}0.0003 \\
(0.0004)\end{array}$ & $\begin{array}{c}0.0000 \\
(0.0004)\end{array}$ \\
\hline Household Size & $\begin{array}{c}0.0002 \\
(0.0002)\end{array}$ & $\begin{array}{c}0.0002 \\
(0.0002)\end{array}$ & $\begin{array}{l}0.00020 \\
(0.0002)\end{array}$ \\
\hline Working & $\begin{array}{c}0.0022 * * * \\
(0.0007)\end{array}$ & $\begin{array}{c}0.00190 * * \\
(0.0009)\end{array}$ & $\begin{array}{c}0.00225^{* *} \\
(0.0011)\end{array}$ \\
\hline Lives with partner & $\begin{array}{c}0.0006 \\
(0.0006)\end{array}$ & $\begin{array}{l}0.0012^{*} \\
(0.0007)\end{array}$ & $\begin{array}{c}0.0023^{* *} \\
(0.0010)\end{array}$ \\
\hline Smokes & $\begin{array}{c}-0.0042 * * * \\
(0.0007)\end{array}$ & $\begin{array}{c}-0.00321 * * * \\
(0.0010)\end{array}$ & $\begin{array}{c}-0.0048 * * * \\
(0.0009)\end{array}$ \\
\hline Physical Activity & $\begin{array}{c}-0.0006^{*} \\
(0.0003)\end{array}$ & $\begin{array}{c}-0.0009 * * \\
(0.0004)\end{array}$ & $\begin{array}{l}-0.0007^{*} \\
(0.0004)\end{array}$ \\
\hline Urban & $\begin{array}{c}-0.0012 * * \\
(0.0006)\end{array}$ & $\begin{array}{c}-0.0018 * * \\
(0.0008)\end{array}$ & $\begin{array}{l}-0.0005 \\
(0.0009)\end{array}$ \\
\hline Constant & $\begin{array}{l}-0.0176 \\
(0.0153)\end{array}$ & $\begin{array}{l}-0.0203 \\
(0.0196)\end{array}$ & $\begin{array}{l}-0.0056 \\
(0.0232)\end{array}$ \\
\hline $\begin{array}{l}\text { Observations } \\
\text { R-squared } \\
\text { Period FE }\end{array}$ & $\begin{array}{c}49,054 \\
0.020 \\
\text { YES }\end{array}$ & $\begin{array}{c}27,893 \\
0.019 \\
\text { YES }\end{array}$ & $\begin{array}{c}21,161 \\
0.029 \\
\text { YES }\end{array}$ \\
\hline
\end{tabular}

Robust standard errors in parentheses. Left out categories is: Less than Secondary Education.

$* * * \mathrm{p}<0.01, * * \mathrm{p}<0.05, * \mathrm{p}<0.1$. Periods are grouped as 1994-1998, 2000-2003, 2004-2007, and 2008-2012.

Source: Own calculations using RLMS sample. 


\subsection{Discussion and Conclusion}

This paper employs different empirical models to enable the understanding of increasing body weight and its influencing factors in Russia at the start of and during the transition from a planned to a market economy. It was of special interest who is most affected in the society by increasing BMI levels as income grows. During the observed time period from 1994 to 2012 overweight and obesity rates significantly increased. At the same time, income growth was much more volatile. By using different measures of economic welfare, such as expenditure per capita (log), and expenditure quintiles, we try to detect the influence of a transitional process in terms of nutritional and health outcomes on different income groups. Since a country's capacity to enhance economic growth depends also on the well-being of its inhabitants, it is imperative to know how a society develops and at whom to address potential health improving strategies. If people are overweight or obese, they are less productive and also cause healthcare costs (Rtveladze, 2012; Hoffman, 2001; Lakdawalla et al., 2005). Since we assume an inverted U-shape relationship of BMI with income, it is essential to find out which people are most affected in the Russian society so that policymakers know which group to address (Tafreschi, 2014). Are the richer income groups more affected by high BMI levels or has this changed and now poorer income groups are bigger? For the case of Russia we could not find clear evidence that the income-BMI gradient has already shifted from a positive to negative sign. Calculating turning points and comparing them with average per capita expenditure for several regression estimates leads to the conclusion that the turning points of the income-BMI gradient have not yet been reached. This means, increasing expenditure still positively influences BMI levels of the respondents in our sample; also BMI growth is significant and positive influenced by rising expenditure (with diminishing returns).

Regarding expenditure quintiles, regression results gave us interesting insights. All quintiles from second to fifth show higher BMI levels compared to the lowest quintile. Expenditure growth did not have significant effects in any of our regressions. Regarding the influence of professional education on BMI, we got a diverse picture. In general, we find that lower educated people had higher BMI levels compared to people who have completed tertiary education, but separated by gender we find that this does not hold true for men. Thus, males that have a higher education are heavier than males with a less than secondary education.

Overweight and obesity can lead to several NCDs, e.g. diabetes, cardiovascular diseases, hypertension, musculoskeletal disorders (especially osteoarthritis), and various cancers. Diabetes is difficult to treat, thus, prevention is critical and can even have multigenerational impact. Some of the undertaken strategies of the Russian government to 
make the population follow dietary recommendations (eat more fruits and vegetables, less salt, fewer sugary and fatty foods and some fish) failed because excess weight does not seem to have high priority for many Russians (Smetanina, 2010). Understanding the drivers of BMI growth is important in order to define what strategies are most likely to be effective in preventing harmful body weight gain. Overweight and obesity is increasing among children in Russia, too, though not as alarming as prevalence rates of childhood obesity are in other countries (UK, Switzerland, Spain, Italy) (Smetanina, 2010).

Since there is not much hope that the problem of rising obesity rates will vanish as income levels increase in the near future, other transmission channels have to be established. High education levels are associated with lower BMI levels for women (though not for men), which gives reason to hope that education measures might be the right path to reduce overweight and obesity. However, these kinds of strategies have to be well-planned. 


\section{Appendix}

Table A2.1 Construction of Variables

\begin{tabular}{|c|c|}
\hline Variable & Description \\
\hline BMI (self-reported) & $\begin{array}{l}\text { Self-reported BMI, defined as weight in kilograms } \\
\text { divided by squared height in meters }\end{array}$ \\
\hline Expenditure (real), per capita & $\begin{array}{l}\text { Total household expenditure, deflated by regional CPI, } \\
\text { divided per household size }\end{array}$ \\
\hline Log Expenditure (real), per capita & Logarithm of Expenditure (real), p.c. \\
\hline Gender (dummy) & 0 for females, 1 for males \\
\hline Age & Age, measured in years \\
\hline $\begin{array}{l}\text { Less than Secondary Education } \\
\text { (dummy) }\end{array}$ & $\begin{array}{l}1 \text { if respondent has no professional education at all, or } \\
\text { less than } 7 \text { years of schooling, or only received simple } \\
\text { training programs; } 0 \text { otherwise }\end{array}$ \\
\hline $\begin{array}{l}\text { Completed Secondary Education } \\
\text { (dummy) }\end{array}$ & $\begin{array}{l}1 \text { if respondent has completed secondary education, or } \\
\text { received a diploma at technical, trade, medical, music, } \\
\text { pedagogical or art school; } 0 \text { otherwise }\end{array}$ \\
\hline $\begin{array}{l}\text { Completed Tertiary Education } \\
\text { (dummy) }\end{array}$ & $\begin{array}{l}1 \text { if respondent received a diploma at institute, } \\
\text { university, academy, or graduate school; } 0 \text { otherwise }\end{array}$ \\
\hline Working (dummy) & 1 if respondent is working; 0 otherwise \\
\hline Household Size & $\begin{array}{l}\text { Number of persons living in the same household as } \\
\text { respondent }\end{array}$ \\
\hline Living with partner (dummy) & $\begin{array}{l}1 \text { if respondent is married or lives with a partner in } \\
\text { same household; } 0 \text { otherwise }\end{array}$ \\
\hline Kids (dummy) & 1 if respondents has children; 0 otherwise \\
\hline Smokes (dummy) & 1 if respondent is smoker; 0 otherwise \\
\hline Physical activity & $\begin{array}{l}\text { Categorical Variable: } \\
0 \text { if respondent does not engage in physical activity } \\
1 \text { if respondent does light physical exercise } \\
2 \text { if respondent does medium/intensive physical } \\
\text { exercise } \\
3 \text { if respondent does intensive physical exercise } \\
4 \text { if respondent does daily exercise at least } 30 \text { min./day }\end{array}$ \\
\hline Urban (dummy) & $\begin{array}{l}1 \text { if respondent lives in urban and small urban } \\
\text { settlement; } 0 \text { if respondent lives in rural areas }\end{array}$ \\
\hline
\end{tabular}


Table A2.2 Distribution of Observations among Years (1994 to 2012)

\begin{tabular}{lll}
\hline Year & Frequency & Percent \\
\hline 1994 & 7,403 & 4.36 \\
\hline 1995 & 7,084 & 4.17 \\
\hline 1996 & 7,212 & 4.24 \\
\hline 1998 & 7,455 & 4.39 \\
\hline 2000 & 7,805 & 4.59 \\
\hline 2001 & 8,580 & 5.05 \\
\hline 2003 & 9,001 & 5.30 \\
\hline 2004 & 9,123 & 5.37 \\
\hline 2005 & 9,114 & 5.36 \\
\hline 2006 & 8,989 & 5.29 \\
\hline 2007 & 10,716 & 6.31 \\
\hline 2008 & 10,555 & 6.21 \\
\hline 2009 & 10,131 & 5.96 \\
\hline 2010 & 10,149 & 5.97 \\
\hline 2011 & 14,379 & 8.46 \\
\hline $\mathrm{N}$ & 15,819 & 9.31 \\
\hline $\mathrm{S} 0 u r c: 0 w n$ & 16,391 & 9.65 \\
\hline
\end{tabular}

Source: own calculations using RLMS sample.

Table A2.3 Transition Matrix for Income Quintiles

\begin{tabular}{l|lllll|l}
\hline \multirow{2}{*}{ Quintile } & $\mathbf{5}$ & $\mathbf{5}$ & Total \\
& $\mathbf{1}$ & $\mathbf{2}$ & $\mathbf{3}$ & $\mathbf{4}$ & $\mathbf{5}$ & \\
\hline $\mathbf{1}$ & 58.19 & 23.84 & 10.41 & 4.85 & 2.71 & 100 \\
$\mathbf{2}$ & 25.90 & 32.27 & 22.68 & 13.15 & 6.00 & 100 \\
$\mathbf{3}$ & 11.72 & 24.67 & 29.98 & 22.16 & 11.47 & 100 \\
$\mathbf{4}$ & 6.29 & 14.09 & 24.40 & 32.00 & 23.21 & 100 \\
$\mathbf{5}$ & 3.37 & 7.25 & 13.27 & 25.99 & 50.12 & 100 \\
\hline Total & 21.33 & 20.55 & 20.18 & 19.53 & 18.40 & 100 \\
\hline
\end{tabular}

Source: own calculations using RLMS sample. 
Figure A2.1 Map of Russia

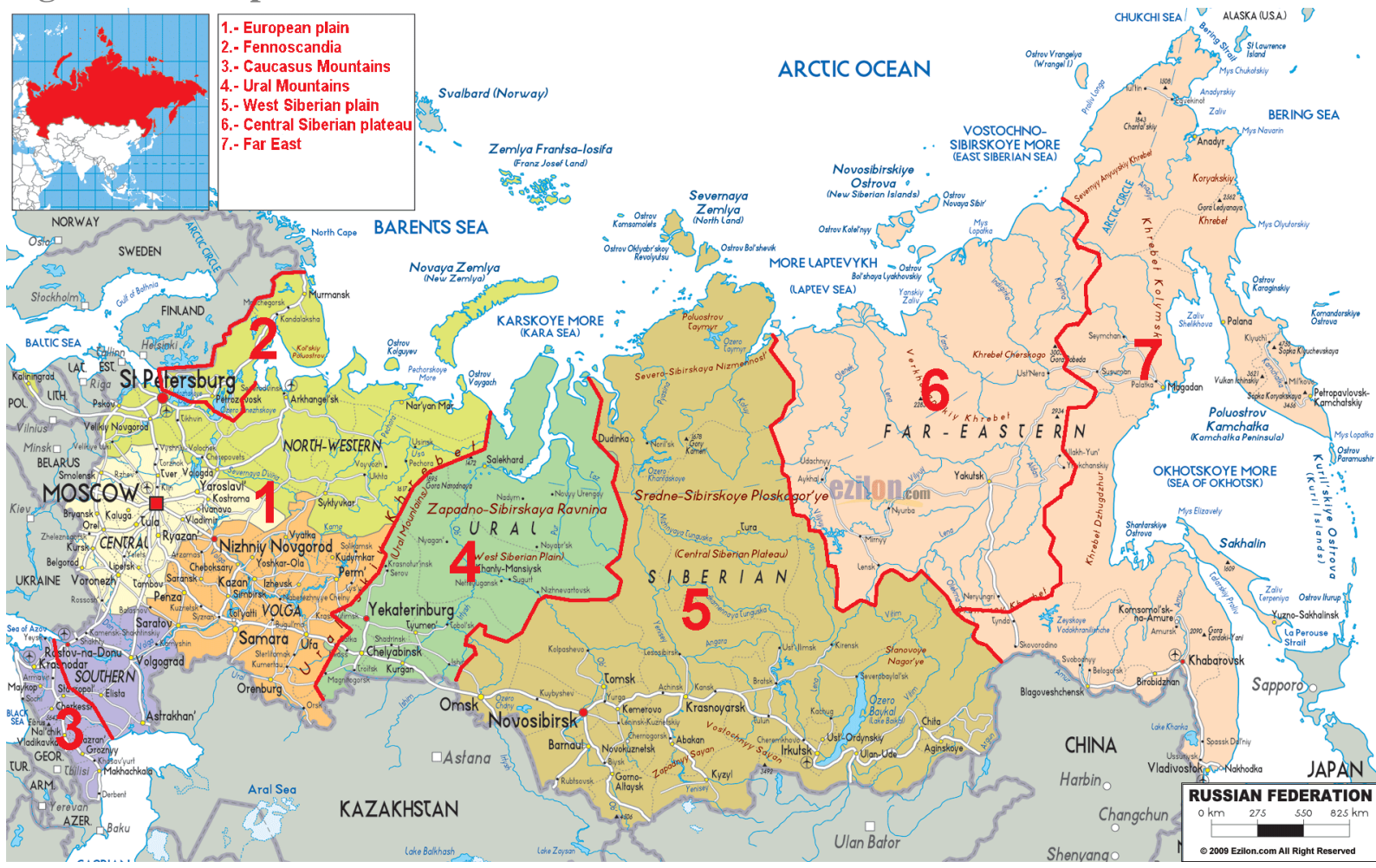

Source: (Russian Geography, 2016) 


\title{
3 Understanding the Drivers of Overweight and Obesity in Developing Countries: The Case of South Africa*
}

\begin{abstract}
This article is the first one that uses longitudinal data from South Africa to reveal the shortand long-term effects that socio-economic and cultural factors have on the probability of becoming obese. The concept of "benign" obesity seems to influence people's perceptions of an ideal body shape and thus model the preference for a higher body weight. Women are more affected by increasing body weights than men. We find that time invariant characteristics and long-term effects have the largest influence on the probability of becoming obese. To address the problems of obesity, we suggest implementing programs that change people's attitudes and behavior regarding food intake and physical activity.
\end{abstract}

JEL code: I12, I18, P46

Key words: obesity, nutrition transition, developing country, South Africa

* This chapter is co-authored with Dimitrios Minos, University of Goettingen. 
Chapter 3: Understanding the Drivers of Overweight and Obesity in Developing Countries: The Case of South Africa

\subsection{Introduction}

$\mathrm{F}$

lor many years one of the most challenging health risks in African countries used to be undernutrition. Although high rates of undernutrition and nutritional deficiencies still prevail, many low and middle income countries face a double burden of malnutrition, where undernutrition and obesity coexist (Popkin et al., 2012; Römling and Qaim, 2012). The obesity pandemic is rising especially among emerging economies. Although industrialized countries still have higher prevalence rates (WHO, 2014), developing countries are catching up fast. Data published by the WHO (2014) reveal that obesity among adults has increased by more than $20 \%$ between 2002 and 2010 to an average of $25 \%$ in middle- and low-income countries. Even in regions like Sub-Saharan Africa we observe an increase in the prevalence of obesity. Rates have increased by over $30 \%$ to an average of almost 10\% in Sub-Saharan Africa (SSA) (WHO, 2014).

The WHO firstly recognized obesity as a chronic disease in 2003 (WHO/FAO, 2003). Obesity is not only a problem in and of itself, but also because it causes comorbidities, such as diabetes, hypertension, higher risk of heart attacks, strokes, and various cancers, the NRNCDs. The WHO measures the damage caused by NCDs in DALYs (Disability Adjusted Life Years), whereas other studies estimate health care costs and loss in productivity to measure the economic impact of NCDs (Grossman and Mocan, 2011; Antipatis and Gill, 2001; Cawley, 2006; Lakdawalla et al., 2005). Starting in the 1990s, scientists have tried to identify the reasons for rising overweight and obesity prevalence rates as well as for NCDs in industrialized and developed countries, respectively (Dowse et al., 1995; Wei et al., 1999; Sobal, 1991). The concept of the "nutrition transition" was utilized by Popkin and Drewnowski to explain the widespread emergence of unhealthy body weights in developing countries (Drewnowski and Popkin, 1997; Popkin, 1999) as already shown in Chapter 2. Some authors have linked this to rising income rates using cross-sectional analysis (Popkin, 2004), but the transmission channels remain unclear.

In South Africa, the nutrition transition goes hand in hand with the concept of "benign obesity" or a kind of "healthy obesity" which gained ground from the 1960s to 1990s. "Benign" obesity means that people with a bigger body size are regarded as healthy despite their increased adiposity because they have normal metabolic features (Phillips et al., 2013).

There is a broad consensus that globally increasing rates of obesity can be attributed to what is called "obesogenic environments", that is "the sum of influences that the surroundings, opportunities, or conditions of life have on promoting obesity in individuals or populations" (Swinburn and Egger, 2002). Several disciplines have investigated the emergence of obesity in human evolutionary history, yet most research is embedded within disciplinary boundaries (Ulijaszek and Lofink, 2006). Our paper aims to add a cultural dimension as this could explain behavior that leads to increasing levels of body weight. Different behavioral 
Chapter 3: Understanding the Drivers of Overweight and Obesity in Developing Countries: The Case of South Africa

patterns in a society are established by cultural perceptions and mentalities within a society. These patterns are developed over the long term and do not change quickly. It is important to distinguish between short-term and long-term factors that influence people's body weights to be able to implement prevention and mitigation strategies. To our knowledge, there are no articles that try to identify long-term and short-term determinants of obesity. Culture has a big influence on people's behavior in the long run, thus it can give more insights to understanding the rise in obesity (Brown, 1991). The concept of "benign" obesity - which we consider to have a cultural and long-term dimension - has been discussed in the literature and appears to be one reason why, among the South African Black population, larger body size seems to be preferred (Van Der Merwe and Pepper, 2006; Walker et al., 2001), see Section 3.3. Perceptions and mentalities shape behavior and have long-term effects.

One novelty of our research paper is that we use longitudinal data from a nationally representative sample in South Africa, which helps us overcome inconsistencies between papers that have identified drivers regarding the variables age, physical activity, urban vs. rural (Van Der Merwe and Pepper, 2006). Furthermore, South Africa is a very diverse country in terms of incomes and ethnicities. The panel structure of the data allows us to control for unobserved heterogeneity, which many of the studies on obesity seem to neglect. We also add to the literature by distinguishing between the short-term and long-term drivers of the ever increasing rates. Time invariant factors are able to reflect the long-term effects that result from the standing of notions such as "benign" obesity in societies. By using the Mundlak approach we are able to reveal long-term effects; namely we are able to reveal the effect that time invariant variables have on the dependent variable. Another advantage of the Mundlak model is that we can estimate both the within estimates and the between estimates. This allows us to identify how much of the variation of the dependent variable can be explained by individual error. It is important to identify certain population groups so that programs aiming to prevent obesity can be targeted in an appropriate manner (Ulijaszek and Lofink, 2006). If the most affected population groups are identified, it is possible to establish prevention programs, such as food or tax programs. The latter is a very common option for several countries, although its effectiveness is debatable (see for instance Schmidhuber, 2004).

The structure of this paper is as follows: In Section 3.2, we shortly describe the development of population trends regarding health outcomes in the last decades and discuss some policy programs. In Section 3.3, we present a literature review reflecting the current state of knowledge with a focus on South Africa. Section 3.4 describes the conceptual framework underlying the research questions, the data and methodology used for the investigation. Section 3.5 looks at the data and Section 3.6 reflects the results of our regressions. In Section 3.7, we conclude the topic and suggest some policy implications. 
Chapter 3: Understanding the Drivers of Overweight and Obesity in Developing Countries: The Case of South Africa

\subsection{Background}

We use the standard WHO/FAO (2003) definitions for overweight (BMI>25) and obesity (BMI>30), despite the well-known shortcomings of these measures (see also Table 2.1 in Chapter $2 .^{22}$

Since overweight and obesity were estimated to account for 3.4 million deaths per year, totaling 93.6 million DALYs in 2010, and the numbers are still increasing in all countries, there is good reason to make this topic a priority on the countries' political agendas. The prevalence of obesity has nearly doubled worldwide between 1980 and 2014 to more than half a billion adults (WHO, 2014). As the income levels of countries increase, the prevalence rates of overweight and obesity increase as well (WHO, 2014), however the transmission channels are not very clear. Moreover, the prevalence rates of overweight preschool aged children are increasing fast, and they are increasing fastest in low- and lowermiddle-income countries. Studies show that around $60 \%$ of overweight children remain overweight later in adulthood, which gives reason to worry about the development of people's health status in the future (Antipatis and Gill, 2001; Stifel and Averett, 2009; Popkin et al., 2006; Halford et al., 2004).

Some studies have tried to detect the impact of policy programs that address the growing obesity problem. Schmidhuber (2004) discusses several policy options in this regard. He finds that food price interventions, which have also been established in some European countries as part of a set of instruments to target the growing obesity epidemic, are more likely to be efficient when they are implemented as consumer price interventions rather than at the producer price level (on fat taxes in European countries see also Holt, 2011; Villanueva, 2011). Fat taxes are implemented to "increase the costs of energy-dense and saturated fat rich foods by adding an extra tax on energy-rich food [...]" so that consumers will avoid these kind of foods (Schmidhuber, 2004). The effect of a tax highly depends on how responsive consumers are to price changes. If income elasticities are negative, then poor consumers are likely to react stronger to a fat tax than rich consumers. Often rich people have inelastic price elasticities for food items which means they react with only small reductions in demand (Schmidhuber, 2004). Guo et al. (1999) examined price policy options theoretically and point out that in China fat taxes would have low effects for rich people but consumption-contracting effects for poor people; in this particular case, pork as source of animal fat would have been taxed. They assume a shift towards substitutes (vegetable oils and fats). The taxation of pork in China would not only reduce the consumption of energy and saturated fatty acids of rich consumers but also cause a decrease in protein consumption by the poor (Guo et al., 1999). So, it would be more helpful to be able to impose taxes on nutrients directly rather than on food items (Schmidhuber, 2004). Mytton et al. (2012) provide a short analysis of health related food taxes and conclude that

\footnotetext{
${ }^{22}$ See Nande et al. (2010) for a more detailed discussion.
} 
Chapter 3: Understanding the Drivers of Overweight and Obesity in Developing Countries: The Case of South Africa

taxes "would need to be at least $20 \%$ to have a significant effect on population health". Finally, Lu and Goldman (2010) predict that a $10 \%$ increase in the price of energy dense food items such as staple oil could lead to a $0.4 \%$ reduction in the BMI in China, which seems to be rather low.

Other countries have implemented more diverse policies to address the obesity problem in their societies. Reducing the consumption of high-fat, energy-dense food has thus reduced the number of deaths from coronary heart diseases in Finland (Puska et al., 1995) and Norway (Norum, 1997). National intervention programs in Singapore were successful in decreasing the levels of some cardiovascular risk factors and of childhood obesity (Cutter et al., 2001). Furthermore, Mauritius has successfully implemented and evaluated a program that has reduced NCDs by means of using the mass media, pricing policy, educational activity in the community, workplaces and schools, and other legislative and fiscal measures (Dowse et al., 1995). In the WHO's status report on NCDs (WHO, 2014) it is stated that school is an important setting for promoting healthy diets. Regarding obesity reduction programs, Sacks et al. (2011) theoretically contrasted nutrition labelling and a junk-food tax. Both were evaluated to be successful, taxes a bit more than labelling at lower costs. A review of 28 studies by Hawley et al. (2013) concludes that a multiple traffic light systems is seen as a trustworthy guide with regard to calorie information and was accepted among the tested people.

\subsection{Situation in South Africa}

For about the past 15 years, articles have been published that describe how even some African countries face the obesity epidemic (WHO, 1998), although undernutrition and malnourishment ${ }^{23}$ still is an important nutrition issue on the African continent.

The general public perception is that many African countries are facing problems with undernourished people, especially underweight children. This is still the case, but in 1998 the WHO has additionally identified another health problem regarding nutrition (WHO, 1998). Obesity prevalence rates were at $8 \%$ for males and $44 \%$ for females for adults in the age group 15-64 in 1990 in South Africa (WHO, 1998). Although South Africa is classified as an upper middle income country by the World Bank (2014), we consider it as being a developing country because it is still on the way to becoming a developed country and not yet industrialized. South Africa faces manifold problems regarding health, inequality, poverty, and infrastructure even though it has achieved noticeable economic development. ${ }^{24}$

\footnotetext{
${ }^{23}$ The Global Nutrition Report (2015) clearly defines the manifold ways of malnutrition. Stunted children, micronutrient-deficient malnourished persons and obese people all count as malnourished. In the above described case we refer to underweight and undernourished persons.

${ }^{24}$ South Africa is classified as an Emerging Industrial Economy by (Upadhyaya, 2013) and sometimes interpreted as somewhere between a developing and developed country (Development Policy and Analysis Division (DPAD), 2012; International Monetary Fund (IMF), 2015).
} 
Chapter 3: Understanding the Drivers of Overweight and Obesity in Developing Countries: The Case of South Africa

The first studies in South Africa on the topic of anthropometric patterns of adults in terms of excess body weight came out in the early 2000s (Puoane et al., 2002; Bourne et al., 2002; Kruger et al., 2005), which confirm the finding that overweight is a problem for people's health and that South Africa has also been affected by several characteristics of the nutrition transition. The health situation of adults in South Africa has become very similar to that of industrialized countries in some aspects. Although the top cause of death is still HIV/AIDS (Human Immunodeficiency Virus/Acquired Immune Deficiency Syndrome) (33.2\%), the second highest number of deaths is caused by strokes $(6.5 \%)$, diabetes $(5.7 \%)$ and ischaemic heart disease (IHD) (4.8\%) (WHO, 2015). Many of the NCDs are caused by individuals' high body weights. Obesity and overweight prevalence rates show increasing rates since the 1990s in South Africa (especially for women), whereas undernutrition rates have remained constant since the early 1990s. Overweight and obesity rates for women aged 15+ are about $68.5 \%$ (WHO, 2010a) and for men 41.3\% (data from 2010, WHO, 2015c). These high prevalence rates for an unhealthy body mass are even higher than the ones for Europe and comparable to the USA, at least for females (Finucane et al., 2011).

The data primarily used to describe this development stems from the South African Demographic and Health Survey (SADHS) which was conducted on a nationally representative sample of the population. In its health section SADHS includes a multiethnic measurement of the anthropometrics of adults (Puoane et al., 2002). Thus, for more than 10 years it has been clear that the worrying direction of malnutrition is predominantly about overnutrition rather than undernutrition (Puoane et al., 2002). Nevertheless, undernutrition still remains a problem in South Africa, especially among children. Households that face overweight and undernutrition among their household members at the same time are known as "double burden" households (Doak et al., 2004; Subramanian et al., 2009; Römling and Qaim, 2012).

In the case of South Africa one has to distinguish between ethnic groups since there are clear differences regarding prevalence rates for Blacks, Whites, Coloureds, and Asian people. Among the South African black population a high body mass has been interpreted as "benign" obesity for almost three decades (Van Der Merwe and Pepper, 2006). "Benign", or "healthy" obesity means that there are people who are not adversely affected from chronic obesity, meaning they did not show worsened metabolic features, also known as "obesity paradox". Only after the 1990s did scientists accept that overweight and obesity have the same harmful effects on African women as it has on white women (Walker et al., 2001). Especially in the long run metabolically healthy obese persons face increased risk for health problems compared with metabolically healthy normal-weight persons. (Kramer et al., 2013). Hence, one may argue that the actual worrying high numbers of black obese people can partly be traced back to the misperception of "healthy" obesity (Van Der Merwe and Pepper, 2006). If one accepts (as in some early papers) that there may be a "healthy" way to be 
Chapter 3: Understanding the Drivers of Overweight and Obesity in Developing Countries:

The Case of South Africa

obese and not suffer from NCDs, and if African or African-American women were considered to more likely face "benign obesity" (Walker and Segal, 1980), then one can follow the argumentation that obesity has not been seen as disadvantageous among the black population. Another argument is that high body weight is considered to reflect a high social status (Puoane et al., 2002; Wittenberg, 2013) as rich people can afford to consume more food. Among South African females, losing weight is often associated with the "slim disease" (which is HIV/AIDS) and hence is not desired (Kruger et al., 2005). This can lead to the view that slimmer individuals are "ill".

Van der Merwe and Pepper (2006) highlight the importance of high body mass for NRNCDs, in particular type 2 diabetes. They argue that the myth of "benign" obesity partly explains the perception that high body weight can be interpreted as healthy and is hence desired (see also Mvo et al., 1999). It therefore seems that obesity is the preferred body status of certain groups in the society, holding true for females more than for males (Van Der Merwe and Pepper, 2006). Obese people that do not have high blood pressure, heart disease or diabetes are regarded as "healthy obese". Several older articles have reported that obese black people seem to suffer less from ischaemic heart disease (IHD), dyslipidaemia, and high blood pressure (Walker et al., 1979; Walker and Segal, 1980; Walker et al., 1988). But still in 2001 some of the above mentioned authors proved that, when compared with white women, African women seem to be less affected by hypertension, coronary heart disease and breast cancer caused by obesity (Walker et al., 2001). By contrast, a metaanalysis from 2013 rebuts this opinion and finds that in the long-term (over 10 years and more) obese people also have a $24 \%$ increased risk for heart attack, stroke and death compared with normal-weight people (Kramer et al., 2013). One reason might be that weight gain as fat in the liver is considered to be more harmful than weight gain in the lower extremities. Suffering from metabolic disease (such as high cholesterol and high blood sugar) regardless of weight implies a higher risk of a heart attack, stroke and death (Kramer et al., 2013).

Case and Menendez (2009) claim that nutritional deprivation in childhood leads to a higher risk of being overweight or obese in later life, especially for women in South Africa. This does not seem to be the case for men. This argumentation is related to the "fetal origin hypothesis", which states that deficits in the nutrition of an expecting mother have severe implications on her children in later life. The metabolism is programmed to manage with less kilocalories, which later on - when food is not scarce any more - leads to an increased body weight ("thrifty phenotype") and a higher probability of suffering from NCDs (Delisle, 2002; Stanner et al., 1997; Osmani and Sen, 2003). Another reason that has been identified is women's perceptions of an "ideal" female body, which are larger than male's perceptions of the "ideal" male body (p. 277ff.). Puoane et al. (2002) discuss the magnitude to which adults of $15+$ years in South Africa underestimate their own body weight. The higher the 
Chapter 3: Understanding the Drivers of Overweight and Obesity in Developing Countries: The Case of South Africa

actual body weight was, the more the self-perception diverged from the true value, thus the amount was completely underestimated (2002). They emphasize that these inaccurate perceptions can be distinguished between population groups. In the next sub-section we describe the data and the methodology used.

\subsection{Analytical Approach and Data}

\subsubsection{Conceptual Framework}

Our analysis is based on a conceptual framework that identifies the drivers of weight and weight gain. For the graphical illustration of the conceptual framework see Figure 2.1 of Chapter 2. Moreover, see Chapter 2 for the discussion of the main variables we also use in this chapter.

Many surveys that have been conducted in the last years include information on the individual level (e.g. anthropometric measures, education, age, sex, job), on the household level (e.g. household size, household income, food consumed at home and assets) and some on the community level (infrastructure, access to health services, recreational facilities). But in general, information that can be interpreted as environmental factors or culture is more difficult to capture. We interpret food prices and food availability, place of residence (urban/rural), ethnicity, and public transport as environmental factors. But there still seem to be more factors that are not easily captured, which can be described with the term culture. Caprio et al. (2008) state that culture is shaped by experience, and that it can be seen as a dynamic construct which changes over time. ${ }^{25}$ As Kleinman and Benson (2006) argue: "Anthropologists emphasize that culture is not a single variable but rather comprises multiple variables, affecting all aspects of experience. Culture is inseparable from economic, political, religious, psychological, and biological conditions." If culture is understood as a set of norms and rules for behavior (either normative, meaning what a person should do or more pragmatic, meaning how to do it) then we can assume that it is learned and can be influenced over time. This change, however, is a rather slow process and can span over decades. Sobal (2001) claims that "acculturation" is often associated with an increase in weight, which at least holds true for the US. In the previously mentioned paper, the author refers to acculturation to Western societies. As people become socialized into another culture this is often due to changes of original cultural patterns and mentalities. People adapt to a "new" culture and change their behavior. Migration and the globalization of Western culture with a strong influence on food, eating and weight is often regarded as social processes which carry along the dilution of geographic borders (Caprio et al., 2008). This means that lifestyle and hence behavior changes lead to a higher body weight. TV and the news, media, and internet could also serve as means of acculturation, as these forms of

\footnotetext{
${ }^{25}$ First researchers that have discussed the long-lasting effects of culture and the relationship to society are Max Weber and Émile Durkheim, for instance.
} 
Chapter 3: Understanding the Drivers of Overweight and Obesity in Developing Countries: The Case of South Africa

media allow people to get in contact with the world and the manifold views of life very easily. Different mentalities are being spread more easily and at a faster rate. The adaption of behavioral patterns according to reformed mentalities takes more time, thus mentality can be considered as having long-term effects. ${ }^{26}$ If the concept of "benign" obesity has settled in South African's minds, then it will take time to change this idea. We assume that in our research we encounter factors that we cannot translate directly into specific variables but that these factors describe a part of the variation in BMI changes. Some of these can be interpreted as cultural factors which can be traced back to people's mentalities and opinions.

We follow a simple framework, where the individual welfare is a function of consumption and health. The health status can in turn be hampered by a high BMI.

$$
W_{t}=f\left(C, H\left(B M I^{h i g h}\right)\right)
$$

A high BMI and subsequently overweight and obesity are caused by an imbalance between calorie intake $(\mathrm{CI})$ and calorie expenditure $(\mathrm{CE})$ over longer periods of time.

$$
C I_{t}>C E_{t}
$$

So, the question is what drives daily intake expenditure. Following a similar framework to Römling and Qaim (2012), one can identify individual, household, and community or environmental characteristics as underlying causes that influence health outcomes.

$$
\begin{aligned}
& C I_{t}=f(I, H, E) \\
& C E_{t}=f\left(I^{\prime}, H^{\prime}, E^{\prime}\right)
\end{aligned}
$$

We distinguish between direct, indirect and environmental factors, as shown in Figure 2.1 in Chapter 2.

We argue that income, education, household demographics, location, food prices, behavior/lifestyle and culture/traditions influence people's body weights in an indirect way. Direct factors are food consumption, physical activity, gender, smoking, and genetic predisposition. Food prices might have an influence on food consumption and physical activity might be influenced by residence area or lifestyle factors. Some factors, especially the indirect ones, can be traced back to culture and traditions. They are not easy to capture and signs are even harder to predict. Some factors have short-term influences and some have long-term effects.

\subsubsection{Data}

The data we use in our study is a three wave panel study from South Africa, the National Income Dynamics Study (NIDS). It is the first national longitudinal study in this country, implemented by the Southern Africa Labor and Development Research Unit (SALDRU)

\footnotetext{
${ }^{26}$ Sociologists talk about "longue durée" when meaning long-term changes in mentalities (Schwaabe, 2006).
} 
Chapter 3: Understanding the Drivers of Overweight and Obesity in Developing Countries: The Case of South Africa

based in the School of Economics at the University of Cape Town. The first wave of the study was conducted in 2008 with a nationally representative sample of over 28,000 individuals in approximately 7,300 households across the country. In order to provide an assessment of income dynamics and its consequences, the survey has continued to be repeated with these same household members every two years and examines the livelihoods of individuals and households over time (Finn et al., 2012). Although the survey has been conducted to track income dynamics, it also includes a comprehensive health section which covers anthropometric measures and information on diseases that are partly nutrition-related, e.g. information on the prevalence and medical treatment of diseases like high blood pressure, diabetes or high blood sugar, stroke and heart problems.

In our sample, after cleaning we include 9,174 females (65.75\%) and 4,779 (34.25\%) males aged 18 to 65 living in 3,266 households. As the BMI and the probability of being overweight or obese is our dependent variable, we excluded observations from our data set when we had missing values for either height or weight ${ }^{27}$ and also pregnant women, because weight gain among pregnant women can be considered as temporary and is not caused by the above mentioned factors. We also excluded individuals who have been diagnosed with HIV/AIDS. Thus, we only kept individuals with available information on weight and height in all 3 waves. The reason for this is to extend the time dimension of the panel as far as possible. However, the final dataset is an unbalanced one, because of several missing values for explanatory variables.

For our model we refer to being overweight as having a BMI greater than 25, being obese as having a BMI greater than 30 and being hyperobese with a BMI of more than 35 . We distinguish between these two forms of adiposity because we assume that it gives a more detailed picture of the health problems in South Africa.

\subsubsection{Methodology}

Following our theoretical model we propose a model using the probability of whether a person (either female or male adult in our case) is obese $(y=1)$ which is explained by a function of vectors of individual, household, and environmental/cultural characteristics.

To get a first impression of the influencing factors we estimate a Pooled Probit model of the following type, as shown in Equation (3.5). ${ }^{28}$

$$
P(y=1)_{i t}=\alpha+\beta X_{i t}+\delta T_{t}+v_{i t}
$$

In this model $\alpha$ is the constant, $\beta$ is the corresponding parameter capturing the impact of a vector of individual, household and environmental/cultural variables, $\delta$ is the parameter

\footnotetext{
${ }^{27}$ Since the NIDS data set has been established to capture income dynamics, the focus has not been on anthropometric measures, which explains the number of missing values for height and weight.

${ }^{28} \mathrm{We}$ also run Pooled OLS regressions with the BMI as our dependent variable as a robustness check.
} 
Chapter 3: Understanding the Drivers of Overweight and Obesity in Developing Countries: The Case of South Africa

capturing the impact of time year dummies, $v_{i t}$ is the error term. The $v_{i t}$ represents the composite error and summarizes the unobserved time fixed effects $c_{i}$ and the idiosyncratic error term $u_{i t}$.

Since both common panel models - namely the Fixed Effects (FE) specification and the Random Effects (RE) specification - have their own shortcomings which we discuss below, we use the Mundlak model to reconcile FE and RE. The so-called incidental parameter problem often occurs in binary choice models with fixed effects that have a relatively short time dimension and produces inconsistent and biased estimates. Another disadvantage of FE is that the model drops time invariant effects from the model, both observed and unobserved, which are often variables of interest. The unlikely assumption of RE, that the omitted heterogeneity is uncorrelated with the regressors, is softened by including additional terms of the time-varying variables in the Mundlak model (Mundlak, 1978). The Mundlak approach includes time means which are able to capture long-term effects and can be interpreted as cumulative effects. This means coefficients are constant across time. The advantage of this model is that we can get the same results as the FE specification for the within variation of the variables and can additionally include more variables and more specific group mean values to account for the between variation in the model. We can obtain the fixed effects estimator by simply adding the time average of our explanatory variables. Another advantage of the Mundlak approach is that "parameters can be estimated by Pooled Probit, greatly conserving on degrees of freedom" (Wooldridge, 2002). Hence, we combine the advantages of both, the FE and the RE model. Furthermore, we are interested in using binary choice models and also model fixed effects. This can be complex, especially if we use several binary variables on the right hand side that show very little variation over time. As we are interested in the coefficients of many time invariant variables (e.g. gender, location, education), this is a good approach. Wooldridge (2006) makes the argument that the approach developed by Mundlak (1978) is also appropriate for unbalanced panels and valid for binary choice models. We estimate a Mundlak model of the following type.

$$
P(y=1)_{i}=\alpha+\beta X_{i t}+\delta T_{t}+\gamma \bar{X}_{l}+v_{i}
$$

The parameters $\alpha, \delta$, and $v$ are the same as those in Equation 3.6. In this equation, $\beta$ is the corresponding parameter capturing the short-term impact of a vector of individual, household and environmental/cultural variables, which can be directly or indirectly related to weight gain. In Equation 3.6, the parameter $\gamma$ describes the coefficient of the set of variables which includes the within-individual mean values, and therefore describe longterm effects. 
Chapter 3: Understanding the Drivers of Overweight and Obesity in Developing Countries: The Case of South Africa

\subsection{Descriptives}

To get a first overview we have a look at Table A3.1 in the Appendix. Both, direct and indirect factor are discussed so that we get a better picture of the determinants of obesity and overweight. We have $65.75 \%$ females and $34.25 \%$ males in our sample. ${ }^{29}$ On average, females are 41.4 years old and males 38.4 years old. Women have a higher BMI (29.15) than men (23.7), on average. Men, on average, have completed more school grades (8.4) than women (8.0). Women smoke to a much smaller degree $(8.0 \%)$ than men $(37.0 \%)$ and do much less exercise ( $11.0 \%$ to $33.0 \%$, respectively). On average, household size is 5.3 members and $40.0 \%$ of the people in our sample live in urban areas.

In our sample, the development of the health status regarding BMI categories is shown in Table 3.1. It becomes clear that being underweight is becoming less and less of a problem; however more and more males and females are becoming overweight and obese instead. Although men are a bit lighter than women, it seems they are gaining weight a bit faster, which can be interpreted as a convergence effect. Note, that in Table 3.1 obese people are included in overweight.

Table 3.1 BMI Categories for males and females in 2008, 2010, and 2012

\begin{tabular}{|c|c|c|c|c|c|c|c|}
\hline \multirow{2}{*}{$\begin{array}{l}\text { BMI } \\
\text { CATEGORIES } \\
\text { in \% }\end{array}$} & \multirow{2}{*}{$\begin{array}{l}\text { All } \\
\text { years } \\
\text { Total }\end{array}$} & \multicolumn{2}{|c|}{2008} & \multicolumn{2}{|c|}{2010} & \multicolumn{2}{|c|}{2012} \\
\hline & & Female & Male & Female & Male & Female & Male \\
\hline underweight & 5.50 & 4.37 & 12.52 & 3.30 & 10.02 & 2.27 & 6.63 \\
\hline normal & 37.87 & 30.75 & 59.86 & 27.08 & 54.61 & 25.49 & 57.15 \\
\hline overweight & 56.63 & 64.88 & 27.62 & 69.62 & 35.28 & 72.24 & 36.22 \\
\hline obese & 31.66 & 39.66 & 8.58 & 43.82 & 10.61 & 44.87 & 11.68 \\
\hline $\mathbf{N}$ & 13,953 & 3,058 & 1,593 & 3,058 & 1,593 & 3,058 & 1,593 \\
\hline
\end{tabular}

Source: Own calculations using NIDS data. Overweight: BMI>25; Obesity: BMI $>30$.

Population groups are heterogeneous in South Africa, so we include Table 3.2 which gives an overview over the health status among the different population groups.

Note, that in Table 3.2 obese people are included in overweight. The largest group is the African group. They exhibit an overweight rate of $56 \%$ and an obesity rate of $31.3 \%$. For

\footnotetext{
${ }^{29}$ There are several reasons why the ratio between males and females is so unbalanced. The primary reason for this has been labor migration (Posel, 2001; Collinson, 2010), also premature death (predominantly occurring for males) brought on by HIV/AIDS (Gilbert et al., 2010). In general, females are less likely to participate in the labor market and in turn are more likely to be at home as the survey is conducted (World Bank, 2012), and are more likely to respond to surveys.
} 
Chapter 3: Understanding the Drivers of Overweight and Obesity in Developing Countries: The Case of South Africa

so-called colored people ${ }^{30}$ the picture is more or less the same, with the figures being only slightly higher.

Table 3.2 BMI Categories for population groups

\begin{tabular}{l|lllll}
\hline \multirow{2}{*}{$\begin{array}{l}\text { BMI } \\
\text { CATEGORIES }\end{array}$} & \multicolumn{5}{c}{ Population Group } \\
\hline in \% & African & Colored & Asian & White & Total \\
\hline underweight & 4.93 & 9.84 & 7.05 & 1.10 & 5.49 \\
Normal & 39.05 & 32.69 & 31.86 & 24.54 & 37.88 \\
overweight & 56.02 & 57.47 & 61.09 & 74.36 & 56.63 \\
obese & 31.31 & 33.85 & 23.53 & 37.36 & 31.66 \\
N & 11,787 & 1,740 & 153 & 273 & 13,963 \\
\hline
\end{tabular}

Source: Own calculations using NIDS data. Overweight: BMI>25; Obesity: BMI>30.

Asians seem to be less likely to be obese (23.53\%), but their share of overweight is higher compared to the other two groups. For whites again we have a different picture. This population group exhibits the highest overweight and obesity rates in the country. However, these results should be viewed with caution, since the unweighted samples for white and Asian are very small and not reflective of the actual size of each population group in South Africa.

Figure 3.1 Overweight and Obesity in Urban and Rural Areas

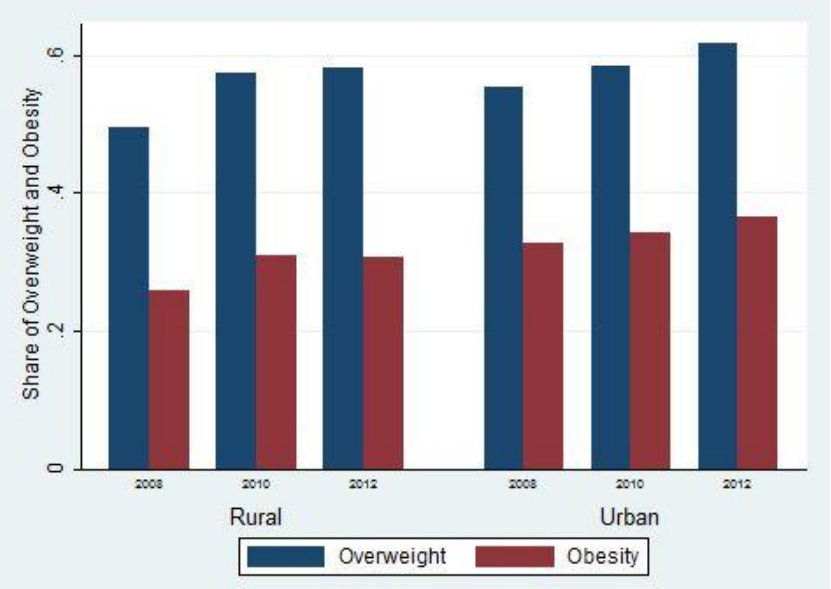

Source: Own calculations using NIDS data. Overweight is defined as BMI $>25$ and obesity as BMI $>30$.

One of the main arguments in the literature is that overweight and obesity are more prevalent in urban areas in developing countries. For the case of South Africa we find a comparable picture, as can be seen in Figure 3.1. We find that there are more overweight

\footnotetext{
${ }^{30}$ Several years ago this term was established and has been used since then. A "colored person" is defined as a person who is not a white person or a native; this definition is based on the principle of exclusion (Patterson, 1953). Colored persons can be seen as mixed race.
} 
Chapter 3: Understanding the Drivers of Overweight and Obesity in Developing Countries: The Case of South Africa

and obese people in urban areas than in rural areas. For both regions prevalence rates are increasing over time.

Moreover, regarding economic growth we observe an increase in incomes during the period 2008-2010, as seen in Figure 3.2. In order to control for the monetary well-being of a household, we use real per capita expenditure ${ }^{31}$ as a control variable into our model because we follow the standard assumption that this reflects a household's financial situation better than income (e.g. Deaton and Zaidi, 2002).

\section{Figure 3.2 Mean Total Expenditure per capita across quintiles}

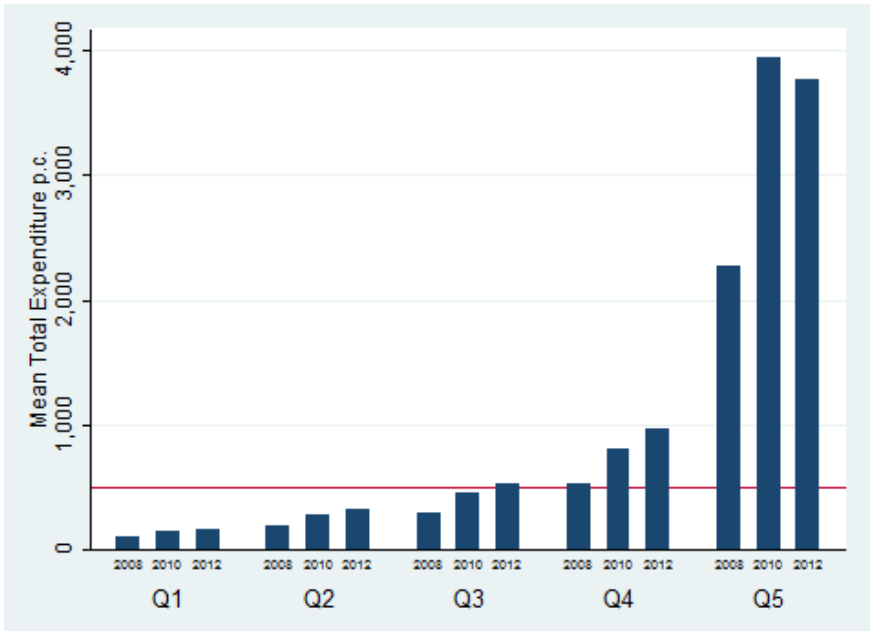

Source: Own calculations using NIDS data. The quintiles are calculated on total household expenditure per capita. The red line represents the 2008 poverty line at 507 Rand per capita per month. ${ }^{32}$

The mean total expenditure per capita almost doubled from 675.88 Rand in 2008 to 1,111.02 Rand in 2010 and ultimately stagnated at 1,112.65 Rand in 2012. However, it is worth noting that total expenditure kept increasing beyond 2010 for all but the richest quintile of the distribution. Even for the poorest $20 \%$ total expenditure per capita increased by another $8.5 \%$ in $2010-2012$ to a total of 167.23 Rand. One notices immediately the huge differences in spending and the income inequality that is prevalent.

We find, however, that an increased body weight is highly prevalent across all quintiles of the expenditure distribution, as seen in Figure 3.3. This in turn implies that increases in the body weight are by no means proportional to increases in income. We also see that obesity is not only a problem of the richer quintiles but is a problem for the whole population. But still prevalence rates are highest among the richest $20 \%$ of the population. To conclude, although income is highly unequally distributed among the South African population, we see a relatively equally distributed (high) share of obese people in the whole population.

\footnotetext{
${ }^{31}$ We adjust the calculated NIDS data by using the CPI of the Statistical Office of South Africa (Available at: http://www.statssa.gov.za/?page_id=1854\&PPN=P0141\&SCH=6039).

${ }^{32}$ The poverty line is the upper bound poverty line calculated in the Poverty Trends Report of 2014, which resulted in $57 \%$ of the population living below it (Statistics South Africa, 2014). In this paper it is only indicative and does not reflect the extent of poverty in South Africa because the methodologies differ.
} 
Chapter 3: Understanding the Drivers of Overweight and Obesity in Developing Countries: The Case of South Africa

Figure 3.3 Share of $\mathrm{BMI}>30$ over expenditure quintiles

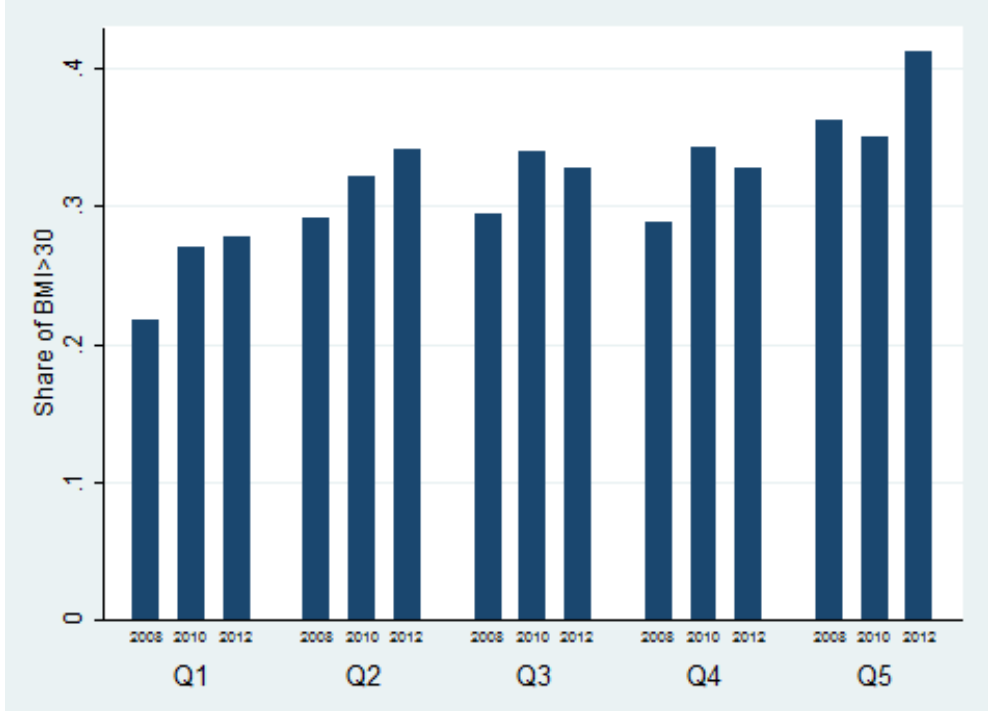

Source: Own calculations using NIDS data. The quintiles are calculated on total household expenditure per capita.

\subsection{Empirical Results}

This section of the paper presents the empirical results of our analysis. We use a dummy for being obese as the dependent variable in our probability models, while we also include linear regressions on the Body Mass Index itself. Moreover, we run separate regressions for males and females and also add other definitions of obesity as robustness checks. All the results shown use heteroscedasticity robust standard errors clustered at the household level.

\subsubsection{Obesity}

The regression results for the Pooled Probit regression on the probability of a person being obese are shown in Table 3.3. The other two specifications take advantage of the panel dimension of the data in order to account for time invariant characteristics and explore the within variance across observations. The fixed effects model is in this case preferred over the random effects model according to the Hausman test. Although the linear probability model lacks in precision, we feel that the number of observations is high enough to give useful insight into the within variation and the direction of the coefficient signs and the level of significance (Wooldridge, 2002). It also serves as a benchmark for the Mundlak Approach. The latter can be seen in the third column and is the preferred way to model fixed effects in a Probit model, where many of the covariates are binary variables and exhibit very little variation. 
Chapter 3: Understanding the Drivers of Overweight and Obesity in Developing Countries: The Case of South Africa

Table 3.3 Regressions on the probability of a person being obese

\begin{tabular}{|c|c|c|c|c|}
\hline VARIABLES & ed Probit & Linear Prob. FE & Mundla & Ieans \\
\hline Total Household Expenditure, p.c. (log) & $\begin{array}{l}0.1171 * * * \\
(4.58)\end{array}$ & $\begin{array}{l}0.0215^{* * * *} \\
(2.78)\end{array}$ & $\begin{array}{l}0.0796^{* * * *} \\
(3.63)\end{array}$ & $\begin{array}{l}0.0112 \\
(0.19)\end{array}$ \\
\hline Household Food Expenditure, p.c. (log) & $\begin{array}{l}0.0483 \\
(1.63)\end{array}$ & $\begin{array}{l}-0.0056 \\
(-0.70)\end{array}$ & $\begin{array}{l}-0.0165 \\
(-0.71)\end{array}$ & $\begin{array}{l}0.1583 * * \\
(2.23)\end{array}$ \\
\hline Urban & $\begin{array}{l}0.1690 * * * \\
(3.59)\end{array}$ & $\begin{array}{l}0.0129 \\
(0.39)\end{array}$ & $\begin{array}{l}0.0721 \\
(0.70)\end{array}$ & $\begin{array}{l}0.0867 \\
(0.76)\end{array}$ \\
\hline Age & $\begin{array}{l}0.0088 * * * \\
(10.75)\end{array}$ & $\begin{array}{l}0.0023 * * \\
(2.06)\end{array}$ & $\begin{array}{l}0.0094 * * * \\
(3.01)\end{array}$ & $\begin{array}{l}-0.0007 \\
(-0.22)\end{array}$ \\
\hline $\mathrm{Age}^{2}$ & $\begin{array}{l}-0.0000 * * * \\
(-8.54)\end{array}$ & $\begin{array}{l}-0.0000 * * * \\
(-4.03)\end{array}$ & $\begin{array}{l}-0.0000 * * * \\
(-6.04)\end{array}$ & $\begin{array}{l}0.0000 \\
(1.20)\end{array}$ \\
\hline Male & $\begin{array}{l}-1.0258 * * * \\
(-22.77)\end{array}$ & & & $\begin{array}{l}-0.9774 * * * \\
(-19.99)\end{array}$ \\
\hline Education & $\begin{array}{l}0.0660 * * * \\
(3.56)\end{array}$ & $\begin{array}{l}-0.0028 \\
(-0.29)\end{array}$ & $\begin{array}{l}-0.0055 \\
(-0.19)\end{array}$ & $\begin{array}{l}0.0583 \\
(1.59)\end{array}$ \\
\hline Living with Partner & $\begin{array}{l}0.2322 * * * \\
(6.19)\end{array}$ & $\begin{array}{l}0.0068 \\
(0.44)\end{array}$ & $\begin{array}{l}0.0142 \\
(0.32)\end{array}$ & $\begin{array}{l}0.2386 * * * \\
(3.81)\end{array}$ \\
\hline Feeling Depressed & $\begin{array}{l}-0.1032 * * * \\
(-2.93)\end{array}$ & $\begin{array}{l}-0.0106 \\
(-1.08)\end{array}$ & $\begin{array}{l}-0.0220 \\
(-0.77)\end{array}$ & $\begin{array}{l}-0.2211 * * \\
(-2.45)\end{array}$ \\
\hline Smoking & $\begin{array}{l}-0.4592 * * * \\
(-8.16)\end{array}$ & $\begin{array}{l}-0.0102 \\
(-0.75)\end{array}$ & $\begin{array}{l}-0.0401 \\
(-0.69)\end{array}$ & $\begin{array}{l}-0.5556 * * * \\
(-5.97)\end{array}$ \\
\hline Exercise & $\begin{array}{l}-0.1091 * * * \\
(-2.68)\end{array}$ & $\begin{array}{l}0.0039 \\
(0.43)\end{array}$ & $\begin{array}{l}0.0108 \\
(0.32)\end{array}$ & $\begin{array}{l}-0.3025 * * * \\
(-3.34)\end{array}$ \\
\hline Heavy Labour & $\begin{array}{l}-0.0392 \\
(-1.00)\end{array}$ & $\begin{array}{l}0.0054 \\
(0.47)\end{array}$ & $\begin{array}{l}0.0154 \\
(0.45)\end{array}$ & $\begin{array}{l}-0.0885 \\
(-1.21)\end{array}$ \\
\hline TV & $\begin{array}{l}0.1715 * * * \\
(4.74)\end{array}$ & $\begin{array}{l}0.0003 \\
(0.02)\end{array}$ & $\begin{array}{l}0.0015 \\
(0.04)\end{array}$ & $\begin{array}{l}0.2926 * * * \\
(4.19)\end{array}$ \\
\hline Household Size & $\begin{array}{l}0.0169 * * * \\
(2.61)\end{array}$ & $\begin{array}{l}0.0026 \\
(1.10)\end{array}$ & $\begin{array}{l}0.0070 \\
(0.98)\end{array}$ & $\begin{array}{l}0.0139 \\
(1.30)\end{array}$ \\
\hline African & $\begin{array}{l}0.4655 * * * \\
(2.93)\end{array}$ & & & $\begin{array}{l}0.4512 * * * \\
(2.71)\end{array}$ \\
\hline Colored & $\begin{array}{l}0.3641 * * \\
(2.10)\end{array}$ & & & $\begin{array}{l}0.3834 * * \\
(2.13)\end{array}$ \\
\hline Asian & $\begin{array}{l}-0.4446 * \\
(-1.77)\end{array}$ & & & $\begin{array}{l}-0.5104 * * \\
(-2.03)\end{array}$ \\
\hline Year 2010 & $\begin{array}{l}-0.0090 \\
(-0.37)\end{array}$ & $\begin{array}{l}0.0083 \\
(0.32)\end{array}$ & $\begin{array}{l}0.0733 \\
(1.10)\end{array}$ & \\
\hline Year 2012 & $\begin{array}{l}-0.0268 \\
(-1.01)\end{array}$ & $\begin{array}{l}0.0039 \\
(0.08)\end{array}$ & $\begin{array}{l}0.0936 \\
(0.74)\end{array}$ & \\
\hline Western Cape & $\begin{array}{l}0.2917 * * * \\
(2.70)\end{array}$ & $\begin{array}{l}0.1735 \\
(1.49)\end{array}$ & $\begin{array}{l}0.8158 * * \\
(2.27)\end{array}$ & $\begin{array}{l}-0.5250 \\
(-1.38)\end{array}$ \\
\hline Eastern Cape & $\begin{array}{l}0.1478^{*} \\
(1.87)\end{array}$ & $\begin{array}{l}-0.0055 \\
(-0.06)\end{array}$ & $\begin{array}{l}0.0244 \\
(0.08)\end{array}$ & $\begin{array}{l}0.1361 \\
(0.45)\end{array}$ \\
\hline Northern Cape & $\begin{array}{l}0.1866^{*} \\
(1.71)\end{array}$ & $\begin{array}{l}-0.0080 \\
(-0.14)\end{array}$ & $\begin{array}{l}-0.0515 \\
(-0.31)\end{array}$ & $\begin{array}{l}0.2215 \\
(1.09)\end{array}$ \\
\hline Free State & $\begin{array}{l}0.1606^{*} \\
(1.87)\end{array}$ & $\begin{array}{l}0.0240 \\
(0.25)\end{array}$ & $\begin{array}{l}0.1643 \\
(0.48)\end{array}$ & $\begin{array}{l}0.0331 \\
(0.09)\end{array}$ \\
\hline KwaZulu-Natal & $\begin{array}{l}0.3339 * * * \\
(4.60)\end{array}$ & $\begin{array}{l}0.0309 \\
(0.45)\end{array}$ & $\begin{array}{l}0.1050 \\
(0.43)\end{array}$ & $\begin{array}{l}0.2308 \\
(0.90)\end{array}$ \\
\hline North West & $\begin{array}{l}0.1239 \\
(1.34)\end{array}$ & $\begin{array}{l}-0.0461 \\
(-1.12)\end{array}$ & $\begin{array}{l}-0.2022 \\
(-1.54)\end{array}$ & $\begin{array}{l}0.3431 * * \\
(2.08)\end{array}$ \\
\hline Mpumalanga & $\begin{array}{l}0.0609 \\
(0.69)\end{array}$ & $\begin{array}{l}0.0172 \\
(0.36)\end{array}$ & $\begin{array}{l}0.0751 \\
(0.45)\end{array}$ & $\begin{array}{l}-0.0125 \\
(-0.06)\end{array}$ \\
\hline
\end{tabular}


Chapter 3: Understanding the Drivers of Overweight and Obesity in Developing Countries: The Case of South Africa

\begin{tabular}{|c|c|c|c|c|}
\hline \multirow{2}{*}{$\begin{array}{l}\text { VARIABLES } \\
\text { (continued) }\end{array}$} & \multirow[t]{2}{*}{ Pooled Probit } & \multirow[t]{2}{*}{ Linear Prob. FE } & \multicolumn{2}{|c|}{$\begin{array}{c}\text { Mundlak } \\
\text { Means }\end{array}$} \\
\hline & & & & \\
\hline Limpopo & $\begin{array}{l}-0.0882 \\
(-1.00)\end{array}$ & $\begin{array}{l}-0.0217 \\
(-0.46)\end{array}$ & $\begin{array}{l}-0.0680 \\
(-0.40)\end{array}$ & $\begin{array}{l}-0.0274 \\
(-0.14)\end{array}$ \\
\hline Constant & $\begin{array}{l}-4.7274 * * * \\
(-14.87) \\
\end{array}$ & $\begin{array}{l}-0.4711 \\
(-0.99) \\
\end{array}$ & $\begin{array}{l}-5.0874 * * * \\
(-12.88) \\
\end{array}$ & \\
\hline Observations & 13775 & 13775 & 13775 & \\
\hline Individuals & 4651 & 4651 & 4651 & \\
\hline R-squared (pseudo) & 0.1873 & 0.0136 (within) & 0.1948 & \\
\hline Rho & & 0.6788 & & \\
\hline
\end{tabular}

Robust absolute values of t-statistics in parentheses, using clustered standard errors at the household level. $* * * \mathrm{p}<0.01, * * \mathrm{p}<0.05, * \mathrm{p}<0.1$. Left out province is Gauteng and left out ethnic dummy is White.

Source: own calculations using NIDS sample.

Moreover, the Mundlak approach allows us to distinguish between short- and long-term effects. One can argue that the coefficient of $x_{i t}$ depicts the within variation or short-term effect, whereas the $\bar{x}_{i}$ component can be seen as the between variation or long-term effect (Wooldridge, 2002; Egger and Pfaffermayr, 2005). Although this method does not allow us to perfectly distinguish between the unobserved heterogeneity and the long term effect, we feel that it is the appropriate model for our analysis.

The first thing to notice in the Pooled Probit regression is that we are able to confirm a positive non-linear relationship between income or household expenditure per capita and increased body weight, ${ }^{33}$ i.e. the higher a person's income the higher the body weight. However, the transmission channel does not seem to be food expenditure, since the coefficient is not statistically different from zero. This implies that individuals do not gain weight through increased spending on food items caused by higher incomes. ${ }^{34}$ One could thus argue that higher incomes do not necessarily lead to a higher body weight, but that we merely observe a spurious correlation.

We also find that residing in an urban environment is associated with an increase in the probability of being obese. From the literature we expected this, since living in urban areas can increase the probability of gaining weight due to a higher density of fast food restaurants, higher fat-food availability, an increased use of vehicles and public transport, and other factors.

We are able to confirm a positive non-linear relationship between age and the probability of being obese; however this probability seems to be lower for males. We moreover find a positive relationship between education and increased body weight, which comes in stark contrast to the findings of other studies in developed countries. One interpretation could be that higher body weights are indeed regarded as a status symbol (Puoane et al., 2002).

\footnotetext{
${ }^{33}$ The variable used is the natural logarithm of Total Household Expenditure per capita adjusted by the CPI. We also run separate regressions including the squared term, which can be seen in the Appendix in Table A3.3. ${ }^{34}$ A more detailed discussion on the impact of increased food expenditure can be found in the Appendix.
} 
Chapter 3: Understanding the Drivers of Overweight and Obesity in Developing Countries: The Case of South Africa

Another explanation could be that better educated individuals have less free time to prepare healthier meals at home and prefer to consume meals outside the home which tend to be higher in calories. This argument applies mostly to developed countries. It does not seem to be the case here, since we find very little spending on ready meals and meals consumed away from home in our data. ${ }^{35}$ A third explanation might be that school education does not necessarily imply health education and that the concept of "benign obesity" still exists in peoples' minds among all education groups.

Furthermore, we find a positive relationship between the dummy for being married or living with one's partner and a higher Body Mass Index. Another expected relationship concerns smoking. Smokers have a lower probability of being obese and the same applies to individuals that reported feelings of depression. Both factors are known to influence appetite. Finally, we find an expected negative coefficient for the dummy on whether an individual exercises regularly. However, we do not have information on either the duration or the intensity of the exercise, in order to fully capture high physical activity that directly leads to increased calorie expenditure. The dummy on engaging in heavy labor, on the other hand, is statistically insignificant. The reasoning behind this can be a misspecification of the variable, since we only have broad categories for occupation. ${ }^{36}$

Moving on to the rest of the household characteristics, we find a positive relationship between owning a television set and the probability of being obese. This seems to be a good proxy for leading a more sedentary lifestyle, although we do not have information on the use of television (e.g. time spent watching etc.). The size of the household also has a positive and significant sign on said probability. An explanation for this could be economies of scale within the household and the allocation of resources.

We also find some significant differences across ethnic groups on increased body weight, which in turn might be an indication for cultural or genetic differences across ethnic groups, as discussed in Section 3.4.1.

The year dummies are insignificant. ${ }^{37}$ Our model is thus able to explain the differences in overweight rates between 2008 and 2012. Finally, there are some regional differences, especially in Western Cape and KwaZulu-Natal where people have a higher probability of being obese in comparison to Gauteng.

The linear probability fixed effects specification ${ }^{38}$ shows once again that increases in total expenditure can increase the probability of becoming obese. However, the story remains the same with regard to food expenditure. Here again, we find that the transmission channel is

\footnotetext{
${ }^{35}$ Not shown. The accuracy of the data may be a subject here, especially in the third wave.

${ }^{36}$ This changes if we replace the variable with a dummy for agriculture. The coefficient of the dummy variable agriculture is then negative and significant.

${ }^{37}$ The significance weakens with the introduction of the education and exercise variables. Naturally, there is also a high correlation with age.

${ }^{38}$ Note, that all Mundlak Probit regressions also include dummies for gender and ethnicity as part of the fixed effect.
} 
Chapter 3: Understanding the Drivers of Overweight and Obesity in Developing Countries: The Case of South Africa

not the increase in food expenditure, which leads us to the conclusion that unobserved factors correlated with income may be behind this finding. We moreover find that all other variables do not have a significant effect on the probability of becoming obese, except for age. The signs remain largely the same, but none of the coefficients are significant. The explanation for this with regard to some of the factors like urbanization is that we have a relatively short panel that spans over 4 years and in many cases their effects follow a rather slow process, while other factors like education exhibit very little variation over time. Thus, they are captured by the fixed effects component. It seems that the largest part of the variation stems from this component and short-term changes in our explanatory variables do not seem to change the weight status of individuals. This is underlined by the high rho, which indicates that close to $70 \%$ of the error term stems from the differences between observations.

The Mundlak specification confirms the fact that short-term changes do not seem to matter much, with the exception of the natural logarithm of total expenditure per capita. The coefficient is positive and significant, whereas the one for food expenditure is not. Nearly all other explanatory variables are insignificant. The inclusion of time means, however, allows us to interpret their coefficients as long-term effects. Here we obtain a picture very similar to the Pooled Probit. As expected, most of our explanatory variables resemble the results of the Pooled Probit, with some exceptions. Firstly, we find that total expenditure is insignificant, but long-term higher food expenditure is significant, which is also what one would expect.

We moreover observe that the coefficients of the time means for our other explanatory variables are somewhat larger compared to those in the first column. Although some part of the unobserved factors may contaminate the coefficients, we can gain some useful insight. This is especially the case for behavioral variables that can affect calorie intake and expenditure, like living with the partner, feeling depressed and owning a TV. Adapting to a certain lifestyle for long periods of time seems to affect the probability of an individual being obese. This is an indication that certain behavioral patterns over longer periods of time are mainly responsible for weight gain.

This is also confirmed by the fact that the explanatory power of the Mundlak specification is only marginally higher than that of the Pooled Probit, which means that the largest part of the observed differences across individuals stems from the time invariant component and the between variation. An interpretation of this finding could be that lifestyle choices over longer periods of time, which are nested within a culture or society and do not change over short periods of time, contribute to higher obesity rates. This leads us to believe that it is a slow process and that time invariant characteristics like traditions, culture or the standing of obesity in South African society have shaped clear preferences towards a higher body weight. Short term changes do not seem have a significant effect on the probability of being obese. 
Chapter 3: Understanding the Drivers of Overweight and Obesity in Developing Countries: The Case of South Africa

\section{$3.6 .2 \quad$ BMI}

The general picture obtained in our binary choice models is to a large extent replicated in Table 3.4, where we show the results for the BMI regressions. Here we simply use the BMI as the dependent variable, which allows us to run a simple Pooled OLS, another Pooled OLS with the lag of the BMI as an additional explanatory variable, as well as a fixed effects model to account for unobserved heterogeneity. Using the BMI as a dependent variable may not be appropriate, since an increasing BMI does not necessarily pose a problem, especially in a country where undernutrition is still prevalent. We therefore exclude individuals with a BMI below 18.5 and end up with 13,020 observations for all years.

Table 3.4 Regressions on the Body Mass Index

\begin{tabular}{|c|c|c|c|c|}
\hline VARIABLES & & Pooled OLS & Pooled OLS & Fixed Effects \\
\hline BMI lagged & & & $\begin{array}{l}0.6821 * * * \\
(51.138)\end{array}$ & \\
\hline $\begin{array}{l}\text { Total Household } \\
\text { p.c. }(\log )\end{array}$ & Expenditure, & $\begin{array}{l}0.5631 * * * \\
(5.23)\end{array}$ & $\begin{array}{l}0.3331 * * * \\
(4.326)\end{array}$ & $\begin{array}{l}0.3596 * * * \\
(4.20)\end{array}$ \\
\hline $\begin{array}{l}\text { Household Food } \\
\text { p.c. }(\log )\end{array}$ & Expenditure, & $\begin{array}{l}0.1075 \\
(0.90)\end{array}$ & $\begin{array}{l}-0.0598 \\
(-0.642)\end{array}$ & $\begin{array}{l}-0.1067 \\
(-1.16)\end{array}$ \\
\hline Urban & & $\begin{array}{l}0.7006^{* * *} \\
(3.25)\end{array}$ & $\begin{array}{l}0.1615 \\
(1.498)\end{array}$ & $\begin{array}{l}0.1159 \\
(0.33)\end{array}$ \\
\hline Age & & $\begin{array}{l}0.0380 * * * \\
(11.17)\end{array}$ & $\begin{array}{l}0.0082 * * * \\
(4.612)\end{array}$ & $\begin{array}{l}0.0488 * * * \\
(3.24)\end{array}$ \\
\hline $\mathrm{Age}^{2}$ & & $\begin{array}{l}-0.0000 * * * \\
(-8.46)\end{array}$ & $\begin{array}{l}-0.0000 * * * \\
(-4.211)\end{array}$ & $\begin{array}{l}-0.0000 * * * \\
(-7.10)\end{array}$ \\
\hline Male & & $\begin{array}{l}-4.4587 * * * \\
(-28.18)\end{array}$ & $\begin{array}{l}-1.4179 * * * \\
(-14.110)\end{array}$ & \\
\hline Education & & $\begin{array}{l}0.2713^{* * *} \\
(3.21)\end{array}$ & $\begin{array}{l}0.0593 \\
(1.401)\end{array}$ & $\begin{array}{l}0.0198 \\
(0.15)\end{array}$ \\
\hline Living with Partner & & $\begin{array}{l}0.9626 * * * \\
(5.26)\end{array}$ & $\begin{array}{l}0.3658 * * * \\
(3.879)\end{array}$ & $\begin{array}{l}0.0980 \\
(0.52)\end{array}$ \\
\hline Feeling Depressed & & $\begin{array}{l}-0.5179 * * * \\
(-3.44)\end{array}$ & $\begin{array}{l}-0.1798 \\
(-1.408)\end{array}$ & $\begin{array}{l}-0.1209 \\
(-0.98)\end{array}$ \\
\hline Smoking & & $\begin{array}{l}-2.1140 * * * \\
(-10.84)\end{array}$ & $\begin{array}{l}-0.7006^{* * *} \\
(-6.262)\end{array}$ & $\begin{array}{l}-0.1953 \\
(-0.92)\end{array}$ \\
\hline Exercise & & $\begin{array}{l}-0.3563 * * \\
(-2.47)\end{array}$ & $\begin{array}{l}-0.0963 \\
(-0.842)\end{array}$ & $\begin{array}{l}0.0233 \\
(0.21)\end{array}$ \\
\hline Heavy Labour & & $\begin{array}{l}-0.2396 \\
(-1.44)\end{array}$ & $\begin{array}{l}-0.0280 \\
(-0.252)\end{array}$ & $\begin{array}{l}-0.0062 \\
(-0.05)\end{array}$ \\
\hline TV & & $\begin{array}{l}0.8494 * * * \\
(5.53)\end{array}$ & $\begin{array}{l}0.1679 \\
(1.440)\end{array}$ & $\begin{array}{l}0.2023 \\
(1.44)\end{array}$ \\
\hline Household Size & & $\begin{array}{l}0.0753 * * * \\
(2.69)\end{array}$ & $\begin{array}{l}0.0322 * * \\
(2.025)\end{array}$ & $\begin{array}{l}0.0386 \\
(1.33)\end{array}$ \\
\hline African & & $\begin{array}{l}1.8489 * * \\
(2.50)\end{array}$ & $\begin{array}{l}0.4650 \\
(1.618)\end{array}$ & \\
\hline Colored & & $\begin{array}{l}1.1142 \\
(1.41)\end{array}$ & $\begin{array}{l}0.0698 \\
(0.226)\end{array}$ & \\
\hline Asian & & $\begin{array}{l}-1.5837 \\
(-1.49)\end{array}$ & $\begin{array}{l}-0.6545^{*} \\
(-1.784)\end{array}$ & \\
\hline
\end{tabular}


Chapter 3: Understanding the Drivers of Overweight and Obesity in Developing Countries: The Case of South Africa

\begin{tabular}{|c|c|c|c|}
\hline VARIABLES & Pooled OLS & Pooled OLS & Fixed Effects \\
\hline \multicolumn{4}{|l|}{ (continued) } \\
\hline \multirow[t]{2}{*}{ Year 2010} & -0.0921 & & 0.1558 \\
\hline & $(-0.97)$ & & $(0.46)$ \\
\hline \multirow{2}{*}{ Year 2012} & $-0.2143 * *$ & $-0.2533 * *$ & 0.1386 \\
\hline & $(-2.11)$ & $(-2.440)$ & $(0.21)$ \\
\hline \multirow[t]{2}{*}{ Western Cape } & $1.6985 * * *$ & $0.5433 * *$ & 0.7731 \\
\hline & $(3.41)$ & $(2.301)$ & $(0.65)$ \\
\hline \multirow[t]{2}{*}{ Eastern Cape } & $0.8944 * *$ & 0.1864 & 0.2679 \\
\hline & $(2.55)$ & (1.078) & $(0.29)$ \\
\hline \multirow[t]{2}{*}{ Northern Cape } & $0.9462 *$ & 0.1613 & 0.4374 \\
\hline & $(1.88)$ & $(0.623)$ & $(0.51)$ \\
\hline \multirow[t]{2}{*}{ Free State } & $0.7484 *$ & 0.2292 & 0.2407 \\
\hline & $(1.95)$ & $(1.324)$ & $(0.27)$ \\
\hline \multirow[t]{2}{*}{ KwaZulu-Natal } & $1.5288 * * *$ & $0.3495 * *$ & 0.6155 \\
\hline & $(4.84)$ & $(2.212)$ & $(0.84)$ \\
\hline \multirow[t]{2}{*}{ North West } & 0.3668 & $0.3310^{*}$ & -0.6988 \\
\hline & $(0.94)$ & $(1.666)$ & $(-1.64)$ \\
\hline \multirow[t]{2}{*}{ Mpumalanga } & 0.3546 & 0.1336 & 0.7507 \\
\hline & $(0.94)$ & $(0.726)$ & $(1.28)$ \\
\hline \multirow[t]{2}{*}{ Limpopo } & -0.5014 & 0.0656 & 0.2367 \\
\hline & $(-1.43)$ & $(0.354)$ & $(0.42)$ \\
\hline \multirow[t]{2}{*}{ Constant } & $10.3466 * * *$ & $4.9190 * * *$ & $12.0178 *$ \\
\hline & $(8.11)$ & $(6.846)$ & $(1.84)$ \\
\hline Observations & 13020 & 8802 & 13020 \\
\hline Individuals & 4574 & 4554 & 4574 \\
\hline R-squared (pseudo) & 0.2569 & 0.6278 & 0.0365 (within) \\
\hline Rho & & & 0.7836 \\
\hline
\end{tabular}

Robust absolute values of t-statistics in parentheses, using clustered standard errors at the household level. Excluding individuals with $\mathrm{BMI}<18.5$. $* * * \mathrm{p}<0.01, * * \mathrm{p}<0.05, * \mathrm{p}<0.1$. Left out province is Gauteng. Source: own calculations using NIDS sample.

This exercise allows us to overcome some of the problems associated with binary choice models and also allows us to better interpret the coefficients. Nevertheless, the results remain largely unchanged. ${ }^{39}$ In the second column, we add the lagged BMI as an explanatory variable. This way we lose the first wave of our dataset, but we add some more time depth to the Pooled OLS regression. The results are rather interesting. The coefficient of the lagged BMI is naturally very large and highly significant. It is however significantly different from 1. This means that the BMI of the past does not fully explain the BMI in the present. However, all the other coefficients become significantly smaller, which in turn implies that the factors under investigation matter less in the short run. Furthermore, it suggests that the effects of these factors are cumulative over longer periods of time. Another interesting finding is that the coefficients for owning a TV set, exercising and feeling depressed are no longer significant. These variables capture lifestyle and long term behavioral factors and their effects seem to have been absorbed by the lagged BMI. One could therefore assume that these factors act slowly, are deeply rooted in behavioral patterns

\footnotetext{
${ }^{39}$ We repeat the same exercise with the natural logarithm of the BMI as our dependent variable. The results do not differ largely and can be seen in the Appendix in Table A3.4.
} 
Chapter 3: Understanding the Drivers of Overweight and Obesity in Developing Countries:

The Case of South Africa

that lead to increased body weight and that long term decisions are the main source of high obesity rates. Finally, the fixed effects specification in column 3 allows us to more accurately model fixed effects and account for unobserved heterogeneity, but the results remain largely unchanged compared to the binary choice models. Once again the Rho is very high and accounts for nearly $80 \%$ of the error term, reflecting the idiosyncratic error between individuals.

The fixed effects specifications for overweight, obesity and the BMI itself have the positive and significant non-linear relationship between total household expenditure and the dependent variable in common. Since we are looking at the within variation, one could come to the conclusion that increases in income lead to increases in the BMI. We have discussed, however, that this does not happen through increased food consumption. ${ }^{40}$

In the literature on obesity in industrialized countries, the relation and the transmission channels are clear. Most studies find a negative relationship between obesity and income and the theoretical justification is that "healthy living" has become very expensive, both in terms of money and time, so that not everybody can afford it. Moreover, richer individuals tend to care more about their own health. In developing countries, on the other hand, the main argument was that increase in income would allow individuals to afford more food (Philipson and Posner, 2003; Römling and Qaim, 2012). However, this does not seem to be the case in South Africa, and although the weight increase of the population could be attributed to shifts in diets and the availability of low cost energy dense food items that replaced traditional diets, the fact that the positive relationship between income and BMI seems to be robust raises new questions as to what exactly it captures. Answering these questions is essential to designing the appropriate policies. The answers may be found in the arguments of Brown (1991), Case and Menendez (2009) and Wittenberg (2013). Increased body weight seems to be viewed as a positive outcome in the society, especially after experiencing deprivations in recent memory. Income growth may not necessarily directly affect this outcome, but what we merely observe is a spurious correlation that could be interpreted as the reflection and validation of the perceived or desired social status in South Africa.

\subsection{Conclusions}

In all estimated models - namely Pooled Probit, Linear Probability Model (LPM) with fixed effects, and the Mundlak Approach - we find positive significant effects for expenditure on the probability of being overweight or obese. For this positive relationship we can think about the different transmission channels of income/expenditure on body weight. As we could rule out that the increased expenditure is due to rises in food expenditure and hence directly related to increased food intake, we find that in the South African society high

\footnotetext{
${ }^{40}$ This also applies for the poorest $20 \%$ of the population, as can be seen in Figure A3.3 in the Appendix.
} 
Chapter 3: Understanding the Drivers of Overweight and Obesity in Developing Countries:

The Case of South Africa

income is highly correlated with higher body weight. High body weight is still seen as a sign of wealth and also promises a good health constitution. Behind these patterns are the negative image of slim people that is associated with the "slim disease" (HIV/AIDS) which often affects poor people and is not a sign of wealth and power. Since white people are still richer and heavier than African people in South Africa, it is possible that African people take it as an example and also alter their preferences towards higher weights to represent their social status. The same argument can be used to explain the positive relationship between education and BMI. The mentality regarding high body weight seems to be positive, at least among black South Africans and among females. Females have a much higher probability of becoming overweight or obese compared to males.

This line of thinking is also strengthened by the fact that we find time invariant characteristics and long-term effects as mattering the most. These seem to be deeply rooted in the South African society and further explain the observed behavioral patterns.

It seems that there are mentalities that are translated into behavior which have to be changed in order to initiate a rethinking regarding health issues. Patterns and mentalities influence an individual's behavior. We are hence convinced that a changing of these patterns (though it might take a long time) will lead to a modification in behavior regarding calorie intake and calorie expenditure and subsequently lead to a healthier lifestyle.

For implementing strategies that seduce people to healthier lifestyles governments of different countries have tried several programs with different outcomes regarding success. It is necessary to identify the risk of being overweight and obesity in children and adults and addressing it early. There are several reasons why women should be in the focus of health programs. They are more likely to have high body weights that are too high compared to men, they are more often the caretakers of children and hence, have an influence on their eating behavior and on their perception of a healthy lifestyle. The last argument is that more often women are responsible in food preparation and have an influence on the food composition of the other household members. According to our findings, we find it most important to increase awareness of negative health impacts of obesity which finally changes preferences for larger body sizes. As long as a high body weight seems to reflect a high social status (as does education) the most important strategy to convince people that losing weight is good for their health might be an extensive program that covers health knowledge involving mass media and schools. This might adjust people's (especially women's) perceptions of an ideal body shape. Measuring and reporting, learning from successful initiatives is essential for target-oriented strategies.

Several governmental programs have been evaluated as being successful, thus we would recommend implementing programs that change people's attitudes and behavior regarding food intake and physical activity. In Section 3.2 we discussed some programs that have been evaluated as having shown success in reducing obesity prevalence rates. Keeping this in mind, we conclude that a taxation of unhealthy food and drinks would need to be 
Chapter 3: Understanding the Drivers of Overweight and Obesity in Developing Countries: The Case of South Africa

relatively high (at least $20 \%$ according to (Mytton et al., 2012)) to have significant effects. But this would be difficult for policymakers to implement. This is even of greater relevance as there is a time-lag between the implementation of measures and first measurable success, thus election periods might be too short. Norum (1997) suggests a mix of food price interventions and food education programs. Increasing health knowledge would hopefully have long-term effects on people's perceptions of a healthy body. Katz (2012), the founding director of Yale University's Prevention Research Center, at least has hope that humans can change culture and can overcome the curse of having food available everywhere that according to him leads to overweight and obesity.

In a nutshell, the most important lesson we learn is that policies should focus on long-term measures. People adapt to short-term policies and after a while might customize undesired effects, e.g. too low fat taxes. It is more important that people change their mentality and finally their behavior in the long-run. 
Chapter 3: Understanding the Drivers of Overweight and Obesity in Developing Countries: The Case of South Africa

\section{Appendix}

Table A3.1 Variable definitions

\begin{tabular}{|c|c|}
\hline VARIABLES & Description \\
\hline Household Expenditure & $\begin{array}{l}\text { The natural logarithm of total household expenditure, as } \\
\text { calculated by the SALDRU, adjusted by the CPI and } \\
\text { divided per household resident. }\end{array}$ \\
\hline Household Food Expenditure & $\begin{array}{l}\text { The natural logarithm of total household expenditure for } \\
\text { food, as calculated by the SALDRU, adjusted by the } \\
\text { FoodCPI and divided per household resident. }\end{array}$ \\
\hline Urban & $\begin{array}{l}\text { Dummy variable, which takes the value, if the } \\
\text { household resides in urban or peri-urban areas (incl. } \\
\text { unofficial urban areas), as defined by the NIDS. }\end{array}$ \\
\hline Age & The age of the respondent at the time of the interview. \\
\hline Gender & Dummy variable, which takes the value 1 for males. \\
\hline Education & $\begin{array}{l}\text { Categorical variable, which takes values } 0-4 \\
0: \text { No education } \\
\text { 1: Primary education (until } 7^{\text {th }} \text { grade) } \\
\text { 2: Some secondary education (until } 11^{\text {th }} \text { grade, NTC1 } \\
\text { (National Technical Certificates), NTC2, certificates and } \\
\text { diplomas below } 12^{\text {th }} \text { grade) } \\
\text { 3: Completed secondary education }\left(12^{\text {th }} \text { grade, NTC3) }\right. \\
\text { 4: Tertiary education }\end{array}$ \\
\hline Living with partner & $\begin{array}{l}\text { Dummy variable, which takes the value } 1 \text {, if an } \\
\text { individual lives with spouse or partner. }\end{array}$ \\
\hline Feeling Depressed & $\begin{array}{l}\text { Dummy variable, which takes the value } 1 \text {, if an } \\
\text { individual reported feeling depressed more than } 3 \text { days a } \\
\text { week. }\end{array}$ \\
\hline Smoking & $\begin{array}{l}\text { Dummy variable, which takes the value } 1 \text {, if an } \\
\text { individual reported smoking regularly. }\end{array}$ \\
\hline Exercise & $\begin{array}{l}\text { Dummy variable, which takes the value } 1 \text {, if an } \\
\text { individual reported doing exercise more than once per } \\
\text { week. }\end{array}$ \\
\hline Heavy Labor & $\begin{array}{l}\text { Dummy variable, which takes the value } 1 \text {, if an } \\
\text { individual reported working as skilled agricultural or } \\
\text { fishery worker, craft and trade related worker, plant and } \\
\text { machinery operator and assembler, elementary } \\
\text { occupations, or reported engaging in personal } \\
\text { agriculture. }\end{array}$ \\
\hline TV & $\begin{array}{l}\text { Dummy variable, which takes the value } 1 \text {, if the } \\
\text { household owns a television set }\end{array}$ \\
\hline
\end{tabular}


Chapter 3: Understanding the Drivers of Overweight and Obesity in Developing Countries: The Case of South Africa

Table A3.2 Summary Statistics for NIDS data

\begin{tabular}{l|ll|ll|ll}
\hline & Total & & Females & & Males & \\
\hline VARIABLES & Obs & Mean & Obs & Mean & Obs & Mean \\
\hline Male & 13,968 & 0.343 & 9,180 & 0 & 4,788 & 1 \\
Age & 13,968 & 40.39 & 9,180 & 41.44 & 4,788 & 38.39 \\
BMI & 13,968 & 27.41 & 9,180 & 29.36 & 4,788 & 23.67 \\
Weight & 13,968 & 71.72 & 9,180 & 73.76 & 4,788 & 67.80 \\
Height & 13,968 & 1.62 & 9,180 & 1.584 & 4,788 & 1.69 \\
Married & 13,968 & 0.40 & 9,180 & 0.394 & 4,783 & 0.42 \\
Employment & 13,953 & 0.30 & 9,170 & 0.25 & 4,771 & 0.39 \\
Own PC & 13,917 & 1.95 & 9,146 & 1.96 & 4,767 & 1.93 \\
School grade & 13,927 & 7.974 & 9,160 & 7.75 & 4,769 & 8.41 \\
Diabetes & 13,910 & 0.044 & 9,141 & 0.049 & 4,759 & 0.034 \\
Depressed & 13,890 & 1.67 & 9,131 & 1.70 & 4,779 & 1.61 \\
Smoking & 13,947 & 0.18 & 9,168 & 0.08 & 4,768 & 0.37 \\
Exercise & 13,925 & 0.19 & 9,157 & 0.11 & 4,275 & 0.33 \\
HH Expend & 12,398 & 1997 & 8,123 & 2005 & 3,979 & 1982 \\
HH TotInco & 11,559 & 3807 & 7,580 & 3893 & 4,457 & 3644 \\
HH FoodExp & 12,986 & 940.6 & 8,529 & 959.9 & 4,783 & 903.6 \\
Urban & 13,947 & 0.40 & 9,164 & 0.38 & 4,788 & 0.42 \\
HH Size & 13,968 & 5.25 & 9,180 & 5.57 & 3,182 & 4.64 \\
Sport Member & 9,283 & 0.05 & 6,101 & 0.016 & 4,788 & 0.12 \\
\hline Sor Ong
\end{tabular}

Source: Own calculations using NIDS data.

\section{Comment 1: On the relationship between total expenditure and food expenditure}

Including food expenditure along with total expenditure does not likely cause any problems with serial correlation, as can be seen in Figure A3.1.

Figure A3.1 Total and Food Expenditure (2008-2012)

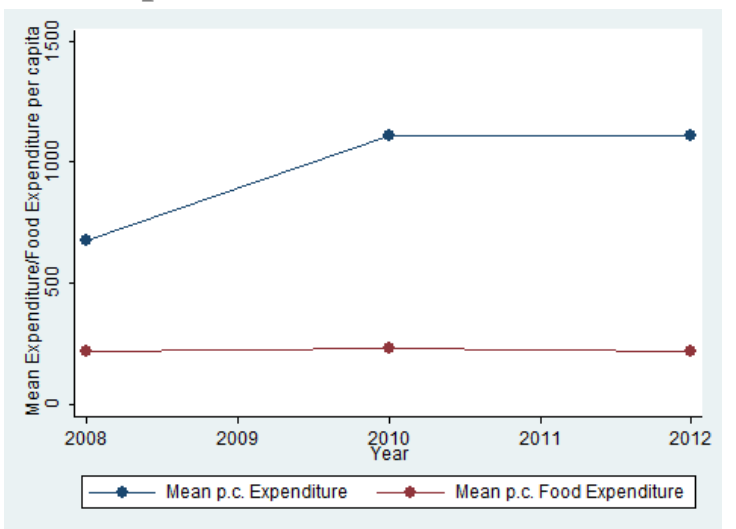

Source: Own calculations using NIDS data. Mean Total and Food Expenditure per capita, deflated by the CPI and the Food CPI, respectively.

Mean per capita expenditure on food items has remained constant over the time period, while total expenditure has increased. However, it may be the case that preferences and diets have shifted towards equally priced calorie intense items. People could consume more food items that have a higher energy density but pay the same prices as for the previously 
Chapter 3: Understanding the Drivers of Overweight and Obesity in Developing Countries: The Case of South Africa

consumed food and hence, consume more kilocalories for the same price.

A glimpse behind this can be seen in Figure A3.2, where we show the average spending on dairy products and vegetables, for example, in comparison to their mean prices. ${ }^{41} \mathrm{~A}$ slight drop in the price of dairy products seems to be associated with an over-proportional increase in spending, while it took a much higher price increase in 2012 to reduce spending to its original levels. For vegetables, on the other hand, prices kept increasing, which seems to be correlated with a reduction in spending between 2008 and 2010, while expenditure increased very slightly in the next period. Unfortunately, the dataset at hand does not offer detailed consumption and price data, in order to fully investigate this side of the relationship between expenditure and increased body weight, but we can get an idea of the mechanisms behind the phenomenon.

Figure A3.2 Expenditure on high- and low-fat food (2008-2012)

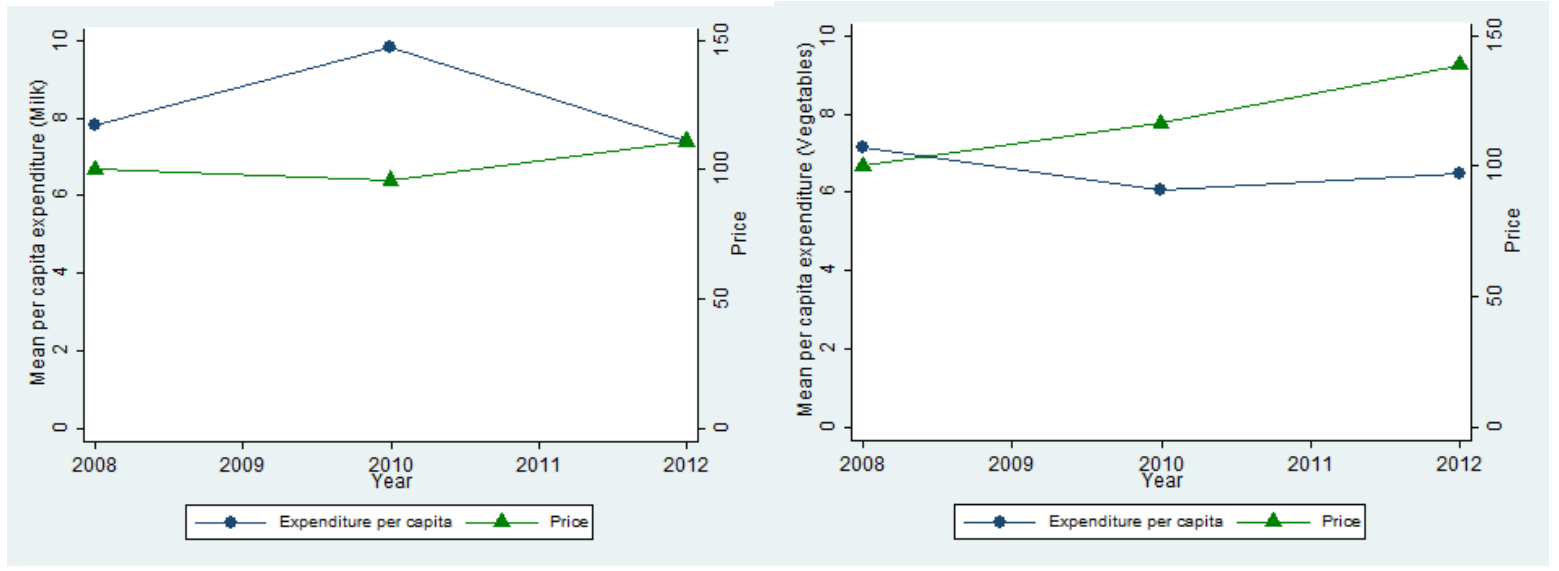

Source: Own calculation using NIDS data. Mean Expenditure per capita for dairy products and vegetables, deflated by the respective mean FAO prices. The prices are depicted by the FAO producer price index with the base year being 2008 .

Increases in total per capita expenditure do not necessarily imply a higher expenditure for food items as well. This also holds for the poorest $20 \%$ of households (see Figure A3.3). While total expenditure (or income) increased in the observed period by more than $50 \%$ on average, food expenditure remained largely constant over the period and even dropped slightly between 2008 and 2010.

\footnotetext{
${ }^{41}$ One should be cautious with these results, since detailed expenditure data are only available for a fraction of the households in the $3^{\text {rd }}$ wave. Although we did not find any obvious systematic bias, caution is still advised.
} 
Chapter 3: Understanding the Drivers of Overweight and Obesity in Developing Countries: The Case of South Africa

Figure A3.3 Total and Food Expenditure for the lowest quintile

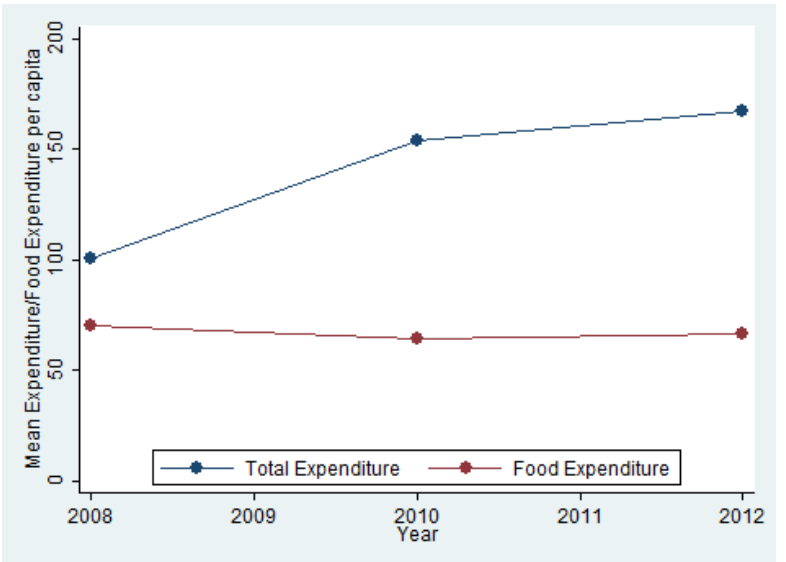

Source: Own calculations using NIDS data. Mean Total and Food Expenditure per capita for the poorest 20\% in terms of total expenditure deflated by the CPI and the Food CPI respectively. 
Chapter 3: Understanding the Drivers of Overweight and Obesity in Developing Countries: The Case of South Africa

Table A3.3 Regressions on the probability of a person being obese (Exp. squared)

\begin{tabular}{|c|c|c|}
\hline VARIABLES & Overweight & Obesity \\
\hline \multirow[t]{2}{*}{ Total Household Expenditure, p.c. (log) } & $0.2179 *$ & $0.3398 * *$ \\
\hline & (1.70) & $(2.53)$ \\
\hline \multirow[t]{2}{*}{ Total Household Expenditure, p.c. ${ }^{2}(\log )$} & -0.0044 & $-0.0164 *$ \\
\hline & $(-0.45)$ & $(-1.65)$ \\
\hline \multirow[t]{2}{*}{ Household Food Expenditure, p.c. (log) } & 0.0027 & 0.0368 \\
\hline & (0.09) & $(1.22)$ \\
\hline \multirow[t]{2}{*}{ Urban } & 0.0709 & $0.1678 * * *$ \\
\hline & (1.57) & $(3.57)$ \\
\hline \multirow[t]{2}{*}{ Age } & $0.0072 * * *$ & $0.0088 * * *$ \\
\hline & $(9.81)$ & $(10.83)$ \\
\hline \multirow{2}{*}{$\operatorname{Age}^{2}$} & $-0.0000 * * *$ & $-0.0000 * * *$ \\
\hline & $(-7.02)$ & $(-8.61)$ \\
\hline \multirow[t]{2}{*}{ Male } & $-0.7984 * * *$ & $-1.0226 * * *$ \\
\hline & $(-21.37)$ & $(-22.73)$ \\
\hline \multirow[t]{2}{*}{ Education } & $0.1053 * * *$ & $0.0674 * * *$ \\
\hline & $(5.85)$ & $(3.63)$ \\
\hline \multirow[t]{2}{*}{ Living with Partner } & $0.2062 * * *$ & $0.2295 * * *$ \\
\hline & $(5.65)$ & (6.14) \\
\hline \multirow[t]{2}{*}{ Feeling Depressed } & $-0.1193 * * *$ & $-0.1022 * * *$ \\
\hline & $(-3.61)$ & $(-2.90)$ \\
\hline \multirow[t]{2}{*}{ Smoking } & $-0.5504 * * *$ & $-0.4609 * * *$ \\
\hline & $(-11.57)$ & $(-8.20)$ \\
\hline \multirow[t]{2}{*}{ Exercise } & $-0.1408 * * *$ & $-0.1081 * * *$ \\
\hline & $(-4.08)$ & $(-2.66)$ \\
\hline \multirow[t]{2}{*}{ Heavy Labour } & 0.0072 & -0.0422 \\
\hline & $(0.20)$ & $(-1.08)$ \\
\hline \multirow[t]{2}{*}{ TV } & $0.1756^{* * *}$ & $0.1642 * * *$ \\
\hline & $(5.13)$ & $(4.52)$ \\
\hline \multirow[t]{2}{*}{ Household Size } & $0.0243 * * *$ & $0.0181 * * *$ \\
\hline & $(4.01)$ & $(2.78)$ \\
\hline \multirow[t]{2}{*}{ African } & 0.1824 & $0.4111 * *$ \\
\hline & (1.09) & $(2.55)$ \\
\hline \multirow[t]{2}{*}{ Colored } & 0.1987 & $0.3088 *$ \\
\hline & (1.13) & (1.76) \\
\hline \multirow[t]{2}{*}{ Asian } & -0.3038 & $-0.4784^{*}$ \\
\hline & $(-1.07)$ & $(-1.92)$ \\
\hline \multirow[t]{2}{*}{ Year 2010} & 0.0094 & -0.0180 \\
\hline & (0.39) & $(-0.74)$ \\
\hline \multirow[t]{2}{*}{ Year 2012} & 0.0003 & -0.0380 \\
\hline & $(0.01)$ & $(-1.41)$ \\
\hline \multirow[t]{2}{*}{ Western Cape } & $0.2074 * *$ & $0.2887 * * *$ \\
\hline & $(2.00)$ & $(2.68)$ \\
\hline \multirow[t]{2}{*}{ Eastern Cape } & $0.1557 * *$ & $0.1464 *$ \\
\hline & $(2.09)$ & $(1.86)$ \\
\hline \multirow[t]{2}{*}{ Northern Cape } & -0.0481 & $0.1855^{*}$ \\
\hline & $(-0.47)$ & $(1.71)$ \\
\hline Free State & 0.1001 & $0.1607 *$ \\
\hline & (1.20) & $(1.87)$ \\
\hline KwaZulu-Natal & $0.3292 * * *$ & $0.3340 * * *$ \\
\hline
\end{tabular}


Chapter 3: Understanding the Drivers of Overweight and Obesity in Developing Countries: The Case of South Africa

\begin{tabular}{lll}
\hline VARIABLES & Overweight & Obesity \\
\hline (continued) & & 0.1241 \\
North West & 0.0114 & $(1.34)$ \\
& $(0.14)$ & 0.0618 \\
Mpumalanga & 0.1050 & $(0.70)$ \\
Limpopo & $(1.230)$ & -0.0851 \\
& -0.0635 & $(-0.97)$ \\
Constant & $(-0.78)$ & $-5.3575 * * *$ \\
& & $(-11.20)$ \\
\hline Observations & $-3.6330 * * *$ & 13775 \\
Individuals & $(-7.87)$ & 4651 \\
R-squared (pseudo) & 13775 & 0.1671 \\
\hline \hline
\end{tabular}

Robust absolute values of t-statistics in parentheses, using clustered standard errors at the household level. $* * * \mathrm{p}<0.01, * * \mathrm{p}<0.05, * \mathrm{p}<0.1$. Left out province is Gauteng. Source: own calculations using NIDS sample. 
Chapter 3: Understanding the Drivers of Overweight and Obesity in Developing Countries: The Case of South Africa

Table A3.4 Regressions on the natural logarithm of the Body Mass Index

\begin{tabular}{|c|c|c|c|}
\hline VARIABLES & Pooled OLS & Pooled OLS & Fixed Effects \\
\hline ln (BMI) lagged & & $\begin{array}{l}0.6405 * * * \\
(57.68)\end{array}$ & \\
\hline $\begin{array}{l}\text { Total Household Expenditure, } \\
\text { p.c. (log) }\end{array}$ & $\begin{array}{l}0.0207 * * * \\
(5.74)\end{array}$ & $\begin{array}{l}0.0123 * * * \\
(4.61)\end{array}$ & $\begin{array}{l}0.0125 * * * \\
(4.25)\end{array}$ \\
\hline $\begin{array}{l}\text { Household Food Expenditure, } \\
\text { p.c. (log) }\end{array}$ & $\begin{array}{l}0.0035 \\
(0.87)\end{array}$ & $\begin{array}{l}-0.0032 \\
(-0.96)\end{array}$ & $\begin{array}{l}-0.0038 \\
(-1.22)\end{array}$ \\
\hline Urban & $\begin{array}{l}0.0225 * * * \\
(3.13)\end{array}$ & $\begin{array}{l}0.0059 \\
(1.57)\end{array}$ & $\begin{array}{l}0.0067 \\
(0.52)\end{array}$ \\
\hline Age & $\begin{array}{l}0.0013 * * * \\
(11.77)\end{array}$ & $\begin{array}{l}0.0003 * * * \\
(4.67)\end{array}$ & $\begin{array}{l}0.0018 * * * \\
(3.27)\end{array}$ \\
\hline $\mathrm{Age}^{2}$ & $\begin{array}{l}-0.0000 * * * \\
(-8.91)\end{array}$ & $\begin{array}{l}-0.0000 * * * \\
(-4.12)\end{array}$ & $\begin{array}{l}-0.0000 * * * \\
(-7.71)\end{array}$ \\
\hline Male & $\begin{array}{l}-0.1560 * * * \\
(-28.38)\end{array}$ & $\begin{array}{l}-0.0528 * * * \\
(-14.69)\end{array}$ & \\
\hline Education & $\begin{array}{l}0.0106 * * * \\
(3.86)\end{array}$ & $\begin{array}{l}0.0026^{*} \\
(1.74)\end{array}$ & $\begin{array}{l}0.0022 \\
(0.505)\end{array}$ \\
\hline Living with Partner & $\begin{array}{l}0.0346 * * * \\
(5.80)\end{array}$ & $\begin{array}{l}0.0138 * * * \\
(4.22)\end{array}$ & $\begin{array}{l}0.0028 \\
(0.42)\end{array}$ \\
\hline Feeling Depressed & $\begin{array}{l}-0.0182 * * * \\
(-3.58)\end{array}$ & $\begin{array}{l}-0.0063 \\
(-1.42)\end{array}$ & $\begin{array}{l}-0.0038 \\
(-0.91)\end{array}$ \\
\hline Smoking & $\begin{array}{l}-0.0779 * * * \\
(-11.39)\end{array}$ & $\begin{array}{l}-0.0282 * * * \\
(-6.50)\end{array}$ & $\begin{array}{l}-0.0086 \\
(-1.12)\end{array}$ \\
\hline Exercise & $\begin{array}{l}-0.0149 * * * \\
(-3.04)\end{array}$ & $\begin{array}{l}-0.0055 \\
(-1.36)\end{array}$ & $\begin{array}{l}0.0004 \\
(0.09)\end{array}$ \\
\hline Heavy Labour & $\begin{array}{l}-0.0062 \\
(-1.13)\end{array}$ & $\begin{array}{l}-0.0016 \\
(-0.41)\end{array}$ & $\begin{array}{l}0.0001 \\
(0.01)\end{array}$ \\
\hline TV & $\begin{array}{l}0.0301 * * * \\
(5.81)\end{array}$ & $\begin{array}{l}0.0045 \\
(1.11)\end{array}$ & $\begin{array}{l}0.0074 \\
(1.57)\end{array}$ \\
\hline Household Size & $\begin{array}{l}0.0027 * * * \\
(2.91)\end{array}$ & $\begin{array}{l}0.0011^{* *} \\
(1.98)\end{array}$ & $\begin{array}{l}0.0012 \\
(1.25)\end{array}$ \\
\hline African & $\begin{array}{l}0.0593 * * \\
(2.43)\end{array}$ & $\begin{array}{l}0.0153 \\
(1.55)\end{array}$ & \\
\hline Colored & $\begin{array}{l}0.0372 \\
(1.43)\end{array}$ & $\begin{array}{l}0.0038 \\
(0.35)\end{array}$ & \\
\hline Asian & $\begin{array}{l}-0.0544 \\
(-1.47)\end{array}$ & $\begin{array}{l}-0.0241 * \\
(-1.78)\end{array}$ & \\
\hline Year 2010 & $\begin{array}{l}-0.0013 \\
(-0.41)\end{array}$ & & $\begin{array}{l}0.0087 \\
(0.71)\end{array}$ \\
\hline Year 2012 & $\begin{array}{l}-0.0055 \\
(-1.620)\end{array}$ & $\begin{array}{l}-0.0097 * * * \\
(-2.78)\end{array}$ & $\begin{array}{l}0.0094 \\
(0.40)\end{array}$ \\
\hline Western Cape & $\begin{array}{l}0.0557 * * * \\
(3.40)\end{array}$ & $\begin{array}{l}0.0195^{* *} \\
(2.34)\end{array}$ & $\begin{array}{l}0.0254 \\
(0.63)\end{array}$ \\
\hline Eastern Cape & $\begin{array}{l}0.0299 * * * \\
(2.58)\end{array}$ & $\begin{array}{l}0.0074 \\
(1.22)\end{array}$ & $\begin{array}{l}0.0085 \\
(0.26)\end{array}$ \\
\hline Northern Cape & $\begin{array}{l}0.0251 \\
(1.48)\end{array}$ & $\begin{array}{l}0.0032 \\
(0.35)\end{array}$ & $\begin{array}{l}0.0146 \\
(0.51)\end{array}$ \\
\hline Free State & $\begin{array}{l}0.0228 * \\
(1.78)\end{array}$ & $\begin{array}{l}0.0074 \\
(1.20)\end{array}$ & $\begin{array}{l}0.0087 \\
(0.28)\end{array}$ \\
\hline KwaZulu-Natal & $\begin{array}{l}0.0538 * * * \\
(5.10)\end{array}$ & $\begin{array}{l}0.0144 * * \\
(2.54)\end{array}$ & $\begin{array}{l}0.0233 \\
(0.86)\end{array}$ \\
\hline North West & $\begin{array}{l}0.0096 \\
(0.73)\end{array}$ & $\begin{array}{l}0.0129 * \\
(1.81)\end{array}$ & $\begin{array}{l}-0.0215 \\
(-1.36)\end{array}$ \\
\hline
\end{tabular}


Chapter 3: Understanding the Drivers of Overweight and Obesity in Developing Countries: The Case of South Africa

\begin{tabular}{llll}
\hline VARIABLES & Pooled OLS & Pooled OLS & Fixed Effects \\
\hline (continued) & & & \\
Mpumalanga & 0.0121 & 0.0051 & 0.0351 \\
& $(0.97)$ & $(0.76)$ & $(1.62)$ \\
Limpopo & -0.0170 & 0.0020 & 0.0163 \\
& $(-1.42)$ & $(0.29)$ & $(0.78)$ \\
& & & \\
Constant & $2.6864 * * *$ & $2.7382 * * *$ & $1.0498 * *$ \\
& $(63.46)$ & $(11.66)$ & $(27.52)$ \\
\hline Observations & 13020 & 8802 & 13020 \\
Individuals & 4574 & 4554 & 4574 \\
R-squared (pseudo) & 0.2799 & 0.6156 & 0.0448 (within) \\
Rho & & & 0.7841 \\
\hline \hline
\end{tabular}

Robust absolute values of t-statistics in parentheses, using clustered standard errors at the household level. Excluding individuals with $\mathrm{BMI}<18.5$. $* * * \mathrm{p}<0.01, * * \mathrm{p}<0.05, * \mathrm{p}<0.1$. Left out province is Gauteng. Source: own calculations using NIDS sample. 


\title{
4 Regional Agreements to Address Climate Change: Scope, Promise, Funding, and Impacts*
}

\begin{abstract}
A large number of regional agreements is concerned with greenhouse gas (GHG) emissions reductions, often linked to other regional integration agreements. The most successful one in reducing carbon emissions has been the Emission Trading System by the European Union (EU ETS). Apart from this exceptional agreement there are many others which either focus directly on reducing GHG emissions or were embedded in other agreements. Little is known about the type, the design or funding of those agreements. We therefore illuminate the potential contribution those agreements could have had in reducing GHG emissions and give an overview of the nature of those agreements in evaluating their success. We classify 16 agreements by their subject (technology/R\&D, trade and finance) and examine their record to date. We find that the impact on mitigating climate change has been negligible to date since in all agreements clear reduction targets or compliance mechanisms were missing. Especially, knowledge sharing seems to be of high relevance for countries and regions that are affected by climate change.
\end{abstract}

Keywords: regional cooperation, climate change, mitigation

JEL Codes: Q54, Q58, Q55

* This chapter is co-authored with Nicole Grunewald and Stephan Klasen, University of Goettingen. 
Chapter 4: Regional Climate Agreements to Address Climate Change: Scope, Promise, Funding, and Impacts

\subsection{Introduction}

urrent negotiations on a global agreement on climate change mitigation have only very recently (with the Paris Agreement) yielded concrete outcomes and prospects for an all-encompassing global agreement long time have been very unlikely (Uekötter, 2011; Weingart et al., 2008). Long time, commitment and burden sharing seem to be hard to negotiate on a global level due to systematic differences in interests between groups of countries (Uekötter, 2015). Conversely, national action is more feasible but carries its own risks and problems as strong climate action using regulation or taxes by one country might lead to competitive disadvantages. Also, national action might fail to capitalize on opportunities for more cost-effective mitigation action through international cooperation. Between the national and the global level are (supra-national) regions that might be able to effectively straddle the respective problems of national and global action. Regional agreements are easier to implement and monitor because regions are already engaged in a range of cooperation activities. Also there can be a higher level of trust, willingness to cooperate, and greater homogeneity of conditions, thus avoiding the difficult questions global agreements face. Regional mitigation initiatives might additionally circumvent some of the problems of national actions by exploiting more cost-effective regional initiatives and reducing the competitive disadvantages of national action. The IPCC has consequently decided to include a chapter on regional development and cooperation in its recently published Fifth Assessment Report to investigate the scope and limits of regional cooperation (IPCC, 2015).

Given the potential opportunities of cooperation at the regional level, many regional initiatives have been developed to help countries better cooperate on reducing GHG emissions. The members share common interests and in many cases common borders. The proximity and adjacency between neighboring countries translate to higher levels of familiarity and cooperation (Balsiger and Prys, 2014). We are, however, aware that this might not be true for every neighboring country. In recent years several regional climate agreements have been founded such as the Carbon Sequestration Leadership Forum (CSLF), or the Asia-Pacific Partnership on Clean Development and Climate (APPCDC). These are trade and technology agreements, which reduce emissions as a secondary interest. We differentiate the agreements into different types: trade, technology and $R \& D$ or financial agreement. We analyze the range of designs in their programs or initiatives, e.g. members, size of funding and compliance mechanisms and liability.

The European Union has gone further in developing mechanisms to address climate change at the regional level, including various binding directives on energy efficiency or biofuels as well as a cap-and-trade system to control emissions called the EU-Emission Trading System. The EU is a special case as it is the only region where there has been a substantial transfer of sovereignty from nation states to regional institutions, including the EU Council, the EU 
Chapter 4: Regional Climate Agreements to Address Climate Change: Scope, Promise, Funding, and Impacts

Commission, and the EU parliament. In some sense these EU institutions operate like a nation state, including in areas of trade and the environment. For these reasons, we do not analyze the EU initiatives that combat climate change as they have already been extensively covered in the literature (Convery, 2009; Lohmann, 2011). We instead try to fill the gap of missing literature on the many other regional agreements on climate change apart from the initiatives within the European Union.

To our knowledge there are only a few studies, which aim to categorize and evaluate regional agreements. Bäckstrand (2008) analyses the accountability of regional climate partnerships. She first divides the partnerships into trans-governmental or private networks as well as technology cooperations. A key question when analyzing partnerships such as the Asia Pacific Partnership on Clean Development and Climate (APPCDC) is whether they complement or substitute global international climate agreements such as the Kyoto Protocol. The analysis focuses on the legal character of the agreements such as transparency, monitoring, representation of the stakeholders and the accountability mechanism. Bäckstrand (2008) concludes that those climate partnerships led to a transformation in the climate policy agenda towards a more complex multilateralism.

De Coninck et al. (2008) focus on 16 technology-oriented climate agreements such as the Global Methane Initiative (GMI) and the Carbon Sequestration Leadership Forum (CSLF). They analyze whether those agreements could address climate change. De Coninck et al. (2008) therefore choose a set of criteria such as environmental and technological effectiveness as well as economic efficiency and incentives for compliance. They find that all technologyoriented agreements are potentially valuable to climate change, specifically in terms of mitigation. The agreements can also contribute to long run development as they improve cost efficiency through higher technological effectiveness and may thus potentially reduce environmental damage.

Balsiger and Prys (2014) give an overview of the nature and role of regional agreements in environmental politics. They classify agreements by their dimension and scope. In 2001 regional agreements already made up for $70 \%$ of multilateral environmental agreements (UNEP, 2001). Balsiger and Prys (2014) perform an accounting of agreements and find the differences between those agreements whose members are neighboring countries and the agreements whose member countries are not neighbors. They find that spatial proximity plays a major role in the development of regional agreements. Unfortunately, hardly any climate change agreement appears in the database Balsiger and Prys (2014) use for their analysis, namely the International Environmental Agreements (IEA) Database Project (Mitchell, 2013). We searched in the IEA Database for keywords (climate, carbon, energy, $\mathrm{CO} 2$, emissions, methane, mitigation, adaptation, greenhouse gas) and names of climate change agreements and found hardly any agreement related to climate change with the exception of the UNFCCC. 
Chapter 4: Regional Climate Agreements to Address Climate Change: Scope, Promise, Funding, and Impacts

Our analysis differs from the three studies mentioned as we give a specific overview of current regional climate agreements concluded on the government level. We therefore analyze the type and motivation as well as the nature of those agreements. To our knowledge, we consider all agreements, as identified by certain classifications specified in section 4.2, which currently exist. We set up certain evaluation criteria such as: (1) type, dimension and age; (2) goals and compliance/reduction mechanisms; (3) incentives and funding. In this way we try to analyze the mitigation potential within the construction of the agreements. We are well aware that regional agreements are only second best compared to global agreements due to carbon leakage. The best mitigation results can only be achieved through a global agreement which sets obligations to all member countries. A regional agreement can contribute to mitigation, however countries outside the agreement can offset the reduction in Carbon Dioxide (CO2) emissions. Nevertheless, regional agreements account for a large share of current GHG mitigation efforts and may be substantially easier to implement than the currently elusive global deal. We analyze the potential of regional agreements as an intermediate solution on the way to a global agreement, as global efforts are still out of reach due to the difficulties of negotiations and power constrictions within the single countries. The Paris Agreement from 2015 is a great step towards a global legally binding agreement. Still, although most of the world's countries emphasized its global necessity, it is not clear whether it becomes effective or not. To enter into force, 55 parties who produce $55 \%$ of the world's GHG have to ratify it by April 2017.

\subsection{Research Scope}

A growing interest in the need for an effective instrument to address climate change has led to the emergence of many programs, initiatives, and agreements related to the mitigation and adaptation of climate change. We have selected those agreements that have been implemented since the turn in the millennium and focus on those which fulfill the conditions we discuss here. Furthermore, the agreements we discuss here have not yet been greatly discussed.

We first classify the geographical settings of the initiative and focus exclusively on regional agreements and initiatives. This refers to initiatives implemented by a group of countries, consisting of at least three partner countries in geographic proximity. National, bilateral or global agreements are excluded. ${ }^{42}$ As regions that are primarily characterized by proximity and adjacency are introduced here, we assume high levels of familiarity and cooperation and argue that there is thus a "true" intention to arrange joint mitigation activities. But we are aware that regional proximity also can involve feelings of insecurity (Balsiger and Prys, 2014). Regional is hence understood as aiming at the regional effects of climate change. Partner

\footnotetext{
${ }^{42}$ Some agreements have the term "global" in their name, but the focus still lies on geographical regions. They are called "global" mainly because there is often one main donor (from an industrialized country) that supports a region (of mainly developing countries).
} 
Chapter 4: Regional Climate Agreements to Address Climate Change: Scope, Promise, Funding, and Impacts

countries of the agreements can be, but are not necessarily, neighboring countries. Regional in our case thus means focusing on regional effects with agreements bigger than bilateral and below the global level. We focus on initiatives that address mitigation not adaptation. There is a long history and track record of regional agreements on mitigation which are also linked to a longer-standing international focus on mitigation. The Fifth Assessment Report from the IPCC and the Stern Review conclude that mitigation strategies are more economic than adaptation strategies, meaning they are less costly for governments (Stern, 2006; IPCC, 2015). Nevertheless, the theoretical separation between adaptation and mitigation is often blurred. Some agreements are thus included in this analysis despite carrying the term "adaptation" in their goals as well. We refer to agreements when the titles name constructions such as "agreement", "initiative", "partnership", "program”, or "project". All of these terms address climate change mitigation with a regional focus, but with different ideas concerning goals, membership liability or compliance mechanisms. Also, the symbolic character of political actions may differ from case to case. This often leads to a situation where adaptation and mitigation are both implicitly addressed in the goals of an agreement.

We separate climate change agreements from other environmental agreements (e.g. on air or water pollution and acid rain) to only capture initiatives with a clear climate-related focus and a goal of climate change mitigation. We distinguish between technology agreements that primarily range from research and development $(\mathrm{R} \& \mathrm{D})$ platforms to technology transfers, financial agreements, and agreements that are borne out of trade agreements but put their emphasis on climate-related issues in an additional and separate initiative. These three groups of agreements represent different approaches towards mitigation strategies. We show where the agreements differ from each other and ask whether some are more likely to be successful than others.

\subsection{Evaluation Criteria}

Within the literature on the evaluation of climate policies, various criteria have been identified to evaluate current policies, such as the Kyoto Protocol, or potential future policies, such as a global carbon tax (de Coninck et al., 2008; Aldy et al., 2003). We choose three criteria for our analysis: (1) type, member size and age of the initiative; (2) goals and the compliance/reduction mechanism; (3) incentives and funding.

We are only able to evaluate the charters, program outlines and a small number of papers, which discuss the initiatives, as reliable data on concrete impacts and evaluations of regional climate agreements is very scarce and sometimes non-existing.

\subsubsection{Type, Member Size and Age of the Initiative}

We first classify the examined agreement by type, i.e. whether it arises from a trade agreement or if it is explicitly set up for dealing with climate change issues. Technology 
Chapter 4: Regional Climate Agreements to Address Climate Change: Scope, Promise, Funding, and Impacts

oriented agreements could be classified by their levels of cooperation and stage of technology, as Uneo (2006) does. We then identify the date the program or initiative was launched and check whether it is still in effect. We list the members and note how the number of members has changed. The member size, in terms of number of participating countries, and "age" of the initiative give us insights on how well the initiative has been accepted. A large member size tells us about the relevance of the initiative, although we are aware that a smaller member size does not necessarily reflect a lower interest in the initiative. It is also possible that a smaller member size might be due to a more binding character of the regulatory framework and higher requirements for compliance. The stability of membership might give us information about the initiative's entry conditions and incentives for participation. If the agreement has been designed with enough flexibility towards new information, then additional information can be incorporated into the regulatory framework (de Coninck et al., 2008). This might seem welcoming to potential members. A high attrition rate, on the contrary, might also give us some relevant information about the topicality of an initiative.

\subsubsection{Goals and Compliance/Reduction Mechanisms}

The compliance/reduction mechanisms and goals differ greatly among the initiatives. These could be clear reduction targets, such as a cap-and-trade system or a carbon tax which aim to reduce emissions directly. On the other hand, there are indirect reductions from agreements which focus on the transfer of climate friendly technology and knowledge as well as the provision of financial means to invest in climate change mitigation and adaptation projects. The overall GHG reducing effect of the agreements is hard to quantify, as they are not usually binding and the GHG reducing effect only occurs in the long run (de Coninck et al., 2008). Still, this effect should not be underestimated as technology and knowledge transfers can create positive spillovers from one industry to another and usually go in line with higher cost effectiveness due to lower energy intensity levels. We investigate whether an agreement postulates a voluntary or a compulsory commitment. This is of even greater interest in capand-trade programs as these are where specific goals are set and hence, members can be judged by the fulfillment of these goals. Since we consider regional initiatives (not national) the problem of compliance mechanisms arises as there is no national law that the members can refer to. Countries face the free rider problem because marginal mitigation costs are increasing. Each country can only benefit from a small fraction of the global mitigation benefit which thereby significantly reduces the incentive for countries to mitigate climate change (Barrett and Stavins, 2003). Thus, well established compliance mechanism and goals are of key importance.

\subsubsection{Incentives and Funding}

Incentives and funding are important evaluation criteria because we believe that the higher the funding of an initiative is, the more likely its goals will be potentially reached. The first 
Chapter 4: Regional Climate Agreements to Address Climate Change: Scope, Promise, Funding, and Impacts

argument that supports this assumption is that accessibility of funds is an incentive to participate in itself. Second, some of the agreements are borne out of already existing trade agreements and members enter the climate agreement automatically. Third, other agreements are based on the exchange of technology and the access to state-of-the-art research. Finance climate agreements additionally provide an incentive through the access to funds.

As very few papers have addressed construction, type and mechanisms of a set of regional agreements/initiatives, we - to the best of our knowledge - are currently the first to give an overview of several regional agreements dealing with climate change. Papers by Bulkeley et al. (2012), Bäckstrand (2008), and Balsiger and Prys (2014) have more of an overview character but no systematic examination of implicit characteristics and mechanisms of regional climate change mitigation efforts.

\subsection{Evaluation of the Agreements}

We divide the agreements into groups based on their type, as this is the major driver of different characteristics (see Table 4.1). Most of the agreements are technology and R\&D related, some are finance mechanisms and a few were added to or originated from regional trade agreements. This is not surprising as technology agreements promise benefits of technological progress to all participating parties. In terms of climate change mitigation, however, these agreements are the least ambitious type of agreements we examine here. Technology and R\&D agreements often only facilitate cooperation that might actively contribute to climate change mitigation in the future (de Coninck et al., 2008).

Financial agreements, on the other hand, are either driven by international organizations such as the United Nations and the World Bank ${ }^{43}$, or are of bilateral nature and thus not considered here. Different bodies of the United Nations (UN) apply different finance mechanisms such as Global Environmental Facility (GEF) or the UN-Reducing Emissions from Deforestation and Forest Degradation (REDD) program.

Regional financial agreements exist almost only between the European Union (EU) and other countries. The European Commission initiated different types of climate funds. First, there is the Global Climate Change Alliance (GCCA) which provides finance for regional climate change mitigation projects in least developed countries. Second, there is the Global Energy Efficiency and Renewable Energy Fund (GEEREF), which is a public-private investment fund to improve energy efficiency in developing countries and also focuses on particular regions. There are more than seven funds for REDD with approved projects worth 95.38 Mio. USD in 2010, supporting regional projects located mostly in Guyana, Brazil,

\footnotetext{
${ }^{43}$ The World Bank administers various climate investment funds such as the Clean Technology Fund or the Strategic Climate Fund. Several countries such as Germany and the United Kingdom run national initiatives such as the International Climate Initiative (ICI) or the Environmental Transformation Fund, International Window (ETF-IW).
} 
Chapter 4: Regional Climate Agreements to Address Climate Change: Scope, Promise, Funding, and Impacts

Indonesia or Mexico. There is only one regional REDD fund in South America under the Central American Commission on Environment and Development. All other REDD funds are bilateral between the donor and the recipient countries.

\section{Table 4.1 Overview of the Analyzed Agreements}

\begin{tabular}{ll}
\hline TYPE & Name of the Agreement \\
\hline Technology, & 1. Carbon Sequestration Leadership Forum (CSLF) \\
R\&D & 2. International Partnership for the Hydrogen Economy (IPHE) \\
3. Methane to Markets Partnership (M2M) \\
4. Mediterranean Climate Change Initiative (MCCI) \\
5. Arab Climate Resilience Initiative (ACRI) \\
6. ASEAN Multi-Sectoral Framework on Climate Change (AFCC) \\
7. Asia Pacific Partnership on Clean Development and Climate (APPCDC) \\
8. Pacific Climate Change Science Program (PCCSP) \\
9. Energy and Climate Partnership of the Americas (ECPA) \\
10. G-20 Fossil Fuel Subsidies Elimination Agreement (G-20 FFSEA) \\
11. APEC Fossil Fuel Subsidies Elimination Agreement (APEC FFSEA) \\
12. The Global Energy Efficiency and Renewable Energy Fund (GEEREF) \\
13. Global Climate Change Alliance (GCCA) \\
14. Regional Reducing Emissions from Deforestation and forest Degradation \\
(REDD) \\
15. Common Market for Eastern and Southern Africa (COMESA) Climate \\
Initiative \\
16. North American Agreement on Environmental Cooperation (NAAEC) \\
Commission for Environmental Cooperation (CEC)
\end{tabular}

Source: Authors' own composition.

Trade agreements with additional climate agreements are still relatively rare. The North American Free Trade Agreement (NAFTA) and the Common Market for Eastern and South Africa (COMESA) are currently the only free trade agreements which have launched specific climate initiatives. Those initiatives focus mostly on the knowledge sharing and could be exploited much more to protect the climate. At the same time, as shown by Baghdadi et al., (2013), a rising number of free trade agreements include environmental agreements. They show that those trade pacts with such environmental agreements lead to a conversion of emissions within the countries covered and to a (slightly) lower absolute level than without the agreement. This means environmental provisions have a direct harmonization effect on pollution. Building on this, existing initiatives could be enhanced to address mitigation using cap-and-trade such as the EU-ETS or coordinated carbon taxes within a trading bloc (Schott and Fickling, 2010). 
Chapter 4: Regional Climate Agreements to Address Climate Change: Scope, Promise, Funding, and Impacts

\subsubsection{Type, Member Size and Age}

\subsubsection{Technology and Research \& Development Agreements}

Most of the knowledge and technology-related agreements share a joint motivation. Countries group together because they are jointly affected by severe climate-related impacts like water scarcity, rising sea levels, floods, droughts, and desertification. Most of the knowledge agreements are implemented to cooperatively address these questions.

The Carbon Sequestration Leadership Forum (CSLF) is a framework for international cooperation in researching the areas of separating, capturing and storing $\mathrm{CO}_{2}$ emissions. It was launched in 2003 and currently counts 25 member countries (see Table A 4.1 in Appendix). Just like the CSLF, the International Partnership for the Hydrogen Economy is an international partnership for alternative fuels such as hydrogen. It was established in 2003 and the member countries are committed to sharing information on hydrogen and fuel cell technologies as well as cooperating with one another in the early adaptation of the technologies. The Global Methane Initiative, which originated under the name Methane to Markets, was founded in 2004. Currently the GMI compromises 40 partner countries.

The Arab Climate Resilience Initiative is an initiative within Arab countries ${ }^{44}$, the implementing partner the UNOPS (United Nations Office for Project Services) and the responsible party the UNDP (United Nations Development Program). After three regional consultative events, lots of presentations, speeches, and background papers, the program has started its activities. The fourth meeting in 2010 in Morocco brought together more than 150 stakeholders, experts and policymakers who agreed on an inter-country collaboration in the Arab region. The program period lasts for four years, from 2012 to 2016 . It was launched in 2010 but has only recently been implemented (UNDP, 2011). Oil-producing countries have not signed the ACRI project document yet because they feel they would lose out from any policy aimed at reducing oil consumption, yet they are also vulnerable to at least some aspects of climatic variations (UNDP, 2013).

Ensuring long-term food security is one of the main goals of the ASEAN organization and its member states. This does not just improve farmers' livelihoods (by sustainable food production) but also improves the living conditions of all people living in the ASEAN countries (ASEAN, 2011). Hence, in November 2009 the ASEAN Ministers of Agriculture and Forestry adopted the ASEAN Multi-sectoral Framework on Climate Change. The focus still lies on food security for the AFCC, but emphasizes the meaning of "sustainable and efficient use of land and water resources by minimizing the impacts of and the contributions to climate change" (Vichitlekarn, 2010; FAO, 2011). The AFCC is an initiative under AIFS framework (ASEAN Integrated Food Security, also implemented in 2009) and makes information available to ASEAN Climate Change Initiative which serves as a platform for

\footnotetext{
${ }^{44}$ The meetings take place in Syria, Egypt and Bahrain.
} 
Chapter 4: Regional Climate Agreements to Address Climate Change: Scope, Promise, Funding, and Impacts

coordination and cooperation (Vichitlekarn, 2011). ACCI was approved in 2009 by ASEAN Environment Ministers and serves as a platform to address the particular vulnerability of the region to climate change. ACCI is planned to prepare "policy and strategy formulation", for "information sharing", and "capacity building and technology transfer" among the member countries (Letchumanan, 2010). Letchumanan (2010) and Trevisan (2013) give a broad overview of established programs related to climate change in ASEAN member countries. Partnerships also exist with other countries (ASEAN Plus - Australia, USA, Korea, China, Japan) and development partners (e.g. GIZ, FAO, IDB) (Vichitlekarn, 2011). In May 2013 representatives of the AFCC, GIZ, FAO, and SDC grouped together to form a "Regional Expert Forum on Climate Change, Agriculture, and Food Security in ASEAN" in Bangkok, Thailand. They emphasize the necessity to develop guidelines and design a concrete plan of action for the ASEAN member states (AFCC, 2013).

The Asia-Pacific Partnership on Clean Development and Climate held its inaugural meeting in January 2006 in Sydney, Australia. Member countries are Australia, China, India, Japan, the Republic of Korea, and the USA (APPCDC, 2006). In October 2007, Canada entered the partnership (Fujiwara, 2007). The main goal of the APPCDC is to secure reliable access to affordable and clean energy. This becomes even more apparent after having a closer look at the approved public-private sector task forces (covering Aluminum, Buildings and Appliances, Cement, Cleaner Fossil Energy, Coal Mining, Power Generation and Transmission, Renewable Energy and Distributed Generation, and Steel) (APPCDC, 2013). Thus, the task forces refer predominantly to energy intensive sectors. The character of the partnership is non-legally binding and on a voluntary basis. It is organized by two main bodies (a Policy and Implementation Committee and an Administrative Support Group), however a permanent secretariat does not exist. After establishing several task forces and flagship projects the APPCDC formally concluded its joint work as of April 2011 (APPCDC, 2013). Fujiwara (2007; 2012) gives a broad overview of the projects of the APPCDC and their public's perception of them. The initiative was "build up on the foundation of bilateral and multilateral partnerships" and therefore finds connecting factors that help achieve the UNFCCC objectives via progress in technological research (Fujiwara, 2007).

The Pacific Climate Change Science Program counts as a knowledge program, as it is part of the much larger International Climate Change Adaptation Initiative (ICCAI) program, which is funded by the Australian government (Power et al., 2011). The PCCSP includes 14 Pacific island countries and East Timor in conducting research in order to advise the policymakers of their countries on climate change mitigation and adaptation (Australian Bureau of Meteorology and CSIRO, 2009). The ICCAI was launched in 2008 and is still ongoing. The first Annual Report 2009 for the PCCSP summarizes progress over the period July 2009 to June 2010. 
Chapter 4: Regional Climate Agreements to Address Climate Change: Scope, Promise, Funding, and Impacts

The Energy and Climate Partnership for the Americas is a technology partnership between the countries of the Americas and was established in 2009. It covers several initiatives that are developed by the recipient countries themselves (Energy and Climate Partnership of the Americas, 2011). Like Marcellino and Gerstetter point out, the idea behind this partnership is promising: it is not a "one-size-fits-all" program that encompasses more than 30 member countries; instead a country proposes an initiative which is then joined and supported by other countries, NGOSs, and technical and financial support (2011).

Both Fossil Fuel Subsidies Elimination Agreements, by the G-20 (G-20 FFSEA) and by APEC (APEC FFSEA), reference climate change as key motivation and have the aim of reducing GHG emissions. G-20 FFSEA is part of the 2009 Pittsburgh G-20 leaders declaration.

An example for mere symbolic action of a more declaratory character is the Mediterranean Climate Change Initiative, which has been reviewed by several scientific articles (see Cantore et al., 2011; Brauch, 2012; Ahmed and Dougherty, 2012; Galeotti and Roson, 2011). All these articles and several environmental-related websites refer to the launch event of the MCCI, however afterwards there has been hardly any information about the initiative. It can be classified as a network that initiates, coordinates and distributes climate impact studies. The MCCI has 21 member countries and was launched in October 2010 in Athens, Greece. Brauch (2012) refers to a second annual meeting being held in late 2011 which might give some hints about the age of the initiative, but unfortunately it was not possible for the author to find out more about the continuity of the initiative. Judging from recent information on the initiative, it appears that the network is no longer active.

\subsubsection{Climate Finance Agreements}

There are only a few regional agreements concerning climate finance. We analyze three different funds which were issued by the EU and serve developing countries as well as one fund which was issued by Germany. Generally, these funds were catalyzed by the UNFCCC climate negotiations.

The Global Climate Change Alliance (GCCA) originated from an initiative by the European Commission as "an answer to the development dimension of climate change" in 2008 (Bird and Brown 2010,11). The GCCA did not set up an administrative body and uses the existing channels of official development assistance by the member countries. The funds are reserved for the most vulnerable countries, which are categorized as least developed countries and the small island developing states (Klein and Möhner, 2011). The Global Energy Efficiency and Renewable Energy Fund (GEEREF) is a risk capital fund, which is managed by the European Investment Bank and was set up in 2008. It aims to transfer energy efficient techniques to developing countries. It thus contributes to climate change mitigation by providing equity finance for small regional projects of up to 10 Mio. EUR. Behrens (2009) states that the first 
Chapter 4: Regional Climate Agreements to Address Climate Change: Scope, Promise, Funding, and Impacts

two projects which were financed were located in Africa and have a volume of 22 Mio. EUR. These agreements on climate finance by the European Commission were predominantly established in 2008 and are arranged between the member countries of the EU and developing countries such as Guyana, Mauritius, Rwanda and Seychelles. The GCCA was extended by the Declaration on Climate Change between the Pacific Islands Forum and the EU in 2008.

Yet another financial tool is represented by the Reducing Emissions from Deforestation and forest Degradation funds. The Kyoto Protocol did not recognize emission reductions from REDD, but at the Conference of the Parties in Copenhagen in 2009 it was accepted after several forest rich developing countries made their voice heard. Industrialized countries invest in projects against deforestation and forest degradation in developing countries and can buy the certified emission reductions to fulfill their own commitments. REDD therefore represents a mechanism to reduce emissions from deforestation by providing financial incentives to preserve rather than harvest forests. There is one regional REDD project in Central America, which has a regional character and shall be discussed here. This Regional REDD project evolved between Germany and Belize, Costa Rica, El Salvador, Guatemala, Honduras, Nicaragua, Panamá and the Dominican Republic. It was established in 2010 and will last for six years. The advantage in regional REDD programs is that participating countries share forests and can implement joint strategies against deforestation. The Congo Basin is another potential regional REDD area, however the current projects are not transboundary ones.

\subsubsection{Trade Agreements}

One of the two climate agreements arising from trade agreements is the Commission for Environmental Cooperation, which was created in 1994 under the North American Agreement on Environmental Cooperation as a side agreement to North American Free Trade Agreement. The CEC addresses regional environmental concerns and aims to prevent trade and environmental conflicts between the NAFTA partner countries. The CEC was founded in the same year as when the adjunct trade agreement NAFTA was signed in 1994. The members include Canada, Mexico and the United States. Since 2009 climate change has been more strongly incorporated in the agenda of the NAFTA.

The Common Market for Eastern and Southern Africa Climate Initiative consists currently of a roundtable process to share knowledge in order to promote sustainable landscapes and livelihoods. The COMESA Climate Initiative has no specific date for its foundation. The members are 19 East and South African Countries. 
Chapter 4: Regional Climate Agreements to Address Climate Change: Scope, Promise, Funding, and Impacts

\subsubsection{Goals and Compliance/Reduction Mechanism}

\subsubsection{Technology and Research \& Development Agreements}

The Carbon Sequestration Leadership Forum is a climate initiative which meets at ministerial level with the goal of facilitating new technologies for the capture and storage of $\mathrm{CO}_{2}$ emissions. In particular it aims to identify obstacles in achieving improved technologies and identifies areas of multilateral cooperation on carbon separation and fosters research in the participating countries. The CSLF hence does not reduce emissions directly and does not set any reductions target. The CSLF meets in workshops and aims to disseminate new technologies (Carbon Sequestration Leadership Forum, 2011). The International Partnership for the Hydrogen Economy has very similar goals in order to facilitate research and the use of fuel cells and hydrogen among the member countries. It also aims to establish a conducive policy and regulatory environment for the application of the technology. We yet again cannot find a defined mechanism to reduce $\mathrm{CO}_{2}$ emissions; still the IPHE can contribute to reducing $\mathrm{CO}_{2}$ emissions indirectly through the replacement of fossil fuel technologies (International Partnership for Hydrogen and Fuel Cells in the Economy, 2010). The Global Methane Initiative is more action oriented than the CSLF and the IPHE. The goal of GMI is to reduce global methane emissions while enhancing economic growth and promoting energy security. GMI targets three major sources of methane emissions such as landfills, coalmines and natural gas systems. Just like CLSF and IPHE, the GMI does not have a clear reduction target. Member countries are required to develop and share national actions plans to coordinate methane reduction efforts (Global Methane Initiative, 2010).

The Mediterranean Climate Change Initiative aims to initiate, coordinate, and distribute climate change impact studies across the Mediterranean region as well as provide the underlying data. There is no information about timelines for the presentation of results. The administrative bodies can act as a mechanism that ensures compliance. In the case of the MCCI there are three administrative bodies: a central facility, which produces operational climate projections, a science steering committee, which promotes multi-national, interdisciplinary collaboration and a governing body with representatives from all participating countries (Mediterranean Climate Change Initiative, 2010).

For the Arab Climate Resilience Initiative, the expected outcome is very similar to all other initiatives that we have categorized as being technology as well as research \& development related projects. An extensive consultative process has led to a well prepared project document, which points out the following output goals: building institutional capacity to address climate change adaptation and mitigation; creating opportunities to improve the production and use of sustainable energy; and strengthening knowledge management, advocacy, and awareness in the Arab countries (UNDP, 2011; UNDP, 2013). A technical support group will provide technical support and guidance in accessing and analyzing available data on climate variability and impacts to key ministries and stakeholders involved 
Chapter 4: Regional Climate Agreements to Address Climate Change: Scope, Promise, Funding, and Impacts

in the implementation of ACRI activities (UNDP, 2011). The UNDP Regional Bureau for Arab States evaluated several programs in the area. To the evaluators the ACRI project appears "too ambitious technically". They therefore recommend asking the UNDP Bureau for Development Policy and/or the UNDP Global Environment Facility for "structured, periodic technical assistance" (UNDP, 2013).

The AFCC "covers the agriculture, fisheries, livestock and forestry sectors and will coordinate with the environment, health and energy sectors" (ASEAN AFCC, no date). The concept note for the AFCC considers following objectives: to coordinate "on the development of adaptation and mitigation strategies" and to cooperate "on the implementation of integrated adaptation and mitigation measures". By means of 4 main goals subdivided into several "strategic thrusts", the ASEAN members attempt to address the special needs of their countries to better counter the consequences of climate change (ASEAN AFCC, no date).

Member countries explicitly emphasized that the APPCDC should "complement but not replace the Kyoto Protocol" (APPCDC, 2006). The APPCDC neither includes any caps, nor detailed target setting. It was supposed to serve as a platform for information sharing and exchange, implementation of bilateral and multilateral cooperative activities, among others (APPCDC, 2006). Through knowledge sharing the established task forces try to improve the technologies used to reduce emissions. In some task forces, as Fujiwara (2007) points out, mandatory indices of $\mathrm{CO} 2$ emission intensities are used to control emissions in some sectors.

The Pacific Climate Change Science Program objectives are: "to provide meteorological, climatological, and oceanographic information (...), to build the capacity of partner country scientific organizations (...), and [the] dissemination of the climate science information to partner countries and other stakeholders (...)" (Australian Bureau of Meteorology and CSIRO, 2009). In 2011 the program published a 560 pages strong report on its scientific assessment and research results, which includes a regional overview as well as several country reports (Australian Bureau of Meteorology and CSIRO, 2011). We interpret the report as a successful achievement of the above-mentioned objectives, as it points out that members are engaged in making progress.

The ECPA aims to contribute to energy efficiency projects and supports several initiatives that are proposed by the member countries (Marcellino and Gerstetter, 2011). Initiatives address: Energy efficiency, renewable energy, cleaner and more efficient use of fossil fuels, energy infrastructure, energy poverty, sustainable forest and land use, and adaptation (ECPA, 2015).

Both, the G-20 FFSEA and APEC FFSEA want to "phase out over the medium term fossil fuel subsidies (that) encourage wasteful consumption" (Merrill, 2015). These commitments have been reconfirmed several times (e.g. the G-20 in November 2014, and the APEC in 2009) (Merrill, 2015). As the OECD calculate (2009) GHG emissions could be reduced by $10 \%$ by 
Chapter 4: Regional Climate Agreements to Address Climate Change: Scope, Promise, Funding, and Impacts

2050 compared to baseline through eliminating fossil fuel subsidies by 2020 in developing countries.

To conclude, through our findings on knowledge and research agreements as well as technology agreements we see that none of the investigated agreements has a binding character in terms of compliance mechanisms. After several official meetings and conferences, the responsibility of making progress in designing climate mitigation and adaptation measures seems to yet again end up at the national level.

\subsubsection{Climate Finance Agreements}

The compliance and reduction mechanisms of financial agreements do differ, however the goal is common. All the agreements have the goal of reducing greenhouse gas emissions and supporting low-income countries in their mitigation and adaptation efforts.

The Global Climate Change Alliance has been designed to particularly help least developed countries and small-island developing states to improve their capacity to adapt to the negative effects of climate change and develop sustainable development strategies. Bird and Brown (2010) criticize the compliance of the GCCA as the recipient country selection did not follow climate finance principles but were instead internal decisions of the European Commission. Klein and Möhner (2011) describe the selection process category approach to vulnerability. In this approach only the least developed countries and the small island developing states are eligible for funding. Meanwhile the GCCA focuses on adaptation, especially for small island developing states, while the Global Energy Efficiency and Renewable Energy Fund clearly focuses more on mitigation through improving energy efficiency and thus lowering energy intensity in emerging countries. It focuses on the promotion of energy efficiency and renewable energy through equity finance rather than debts in emerging countries.

The regional REDD fund aims to support the dialog between different sectors, develop national REDD strategies and compensation instruments including the indigenous population.

\subsubsection{Trade Agreements}

The two climate programs from trade agreements did not install a specific mechanism to mitigate climate change. The goal of the Council for Environmental Cooperation (CEC) "is to promote policies and actions that provide mutual benefits for the environment, trade and the economy" (CEC, 2012). This goal is realized by projects in different areas such as information and decision-making, trade and the environment and specifically the renewable energy expert committee, which analyses the feasibility of small-scale renewable energy projects. It is interesting to note that Baghdadi et al. (2013) show that in the case of NAFTA, there has been a particularly strong emission convergence and reduction of absolute emissions among member countries of all trade agreements even when environmental provisions are considered. At the same time, it is not clear (and not investigated in that study) whether these 
Chapter 4: Regional Climate Agreements to Address Climate Change: Scope, Promise, Funding, and Impacts

results were obtained largely as a bi-product of the non-emission related provisions of the environmental provisions that provided emission reducing co-benefits (e.g. by mandating cleaning production technologies and better regulations that also reduce emissions) or whether the CEC has played a role in this.

The COMESA Climate Initiative targets knowledge and capacity building for climate change mitigation. The framework and tools pillar aim to build institutions to monitor and measure climate change. The best practice toolbox aims to collect knowledge and experience on sustainable land use and carbon sequestration in order to support climate change mitigation and adaptation. The COMESA Climate Initiative has two pillars: the first is directed at the framework and tools and the second at applications and learning. It consists of the secretariat of the New Partnership for Africa's Development and the heads of the member states. A country based round table process has all been initiated.

\subsubsection{Incentives and Funding}

\subsubsection{Technology and Research \& Development Agreements}

The Carbon Sequestration Leadership Forum supports projects concerned with researching the capture and storage of $\mathrm{CO}_{2}$ emissions. It currently recognizes 32 projects. The technical group proposes projects for recognition based on their information exchange, collaboration, road mapping and research and development potential. Once the policy group approves the proposed projects they are officially recognized. The International Partnership for the Hydrogen Economy in 2010 has had a research budget of over $1 \mathrm{Bn}$. USD for research and development financed by all members (IPHE, 2011). Incentives are very much in line with the incentives of the CSLF. Both agreements provide access to information on state-of-the-art research in the field of fuel cells and hydrogen and aim to disseminate this information among the member countries. Those who participate could become market leaders in fuel cells and hydrogen. Again, the incentives to join the Global Methane Initiative are similar to the ones of the CSLF and IPHE. Each member country gets access to the methane mitigation strategies of the other member countries. There is thus an incentive to get access to new technologies. Funding of the GMI is voluntary; each member country can provide funding. Last but not least, all the costs have to be incurred by the country to which they arise.

The Mediterranean Climate Change Initiative incentives countries to participate because of the benefits that knowledge on climate change projections could have for member countries. Member countries are able to take action after analyzing the information they get from the initiative. We have no information regarding the funding of MCCI.

The Arab Climate Resilience Initiative project has declared the UNOPS responsible for the use of project funds. For projects like the 'Nile coastal adaptation project in Egypt' or 'Resilience building of the rain fed farmers and pastoral communities in Sudan' the budgets 
Chapter 4: Regional Climate Agreements to Address Climate Change: Scope, Promise, Funding, and Impacts

have already been allocated through the Special Climate Change Fund (SCCF) or the Least Developed Countries Fund (LDCF), respectively. The total resources required are 9.3 Mio. USD with total allocated resources of 2.5 Mio. USD. For the missing amount of 6.8 Mio. USD, donors have yet to be found (Owaygen, 2012; UNDP, 2013).

In March 2011 the AFCC held a workshop in Beijing and discussed the topic of financing the framework as well as several other mechanisms for regional cooperation. The idea was to get funding from GEF and CDM, but a regional fund to finance research on climate adaptation and mitigation strategies has also been discussed (FAO, 2011).

The charter of the APPCDC (2006) stresses the voluntary basis of the partnership. As no common fund exists, the partners agreed that the partner that has induced the costs carries them himself. But each partner may contribute funds, personnel and other resources to the partnership for the APP. Fujiwara (2007) names the total amount of around 170 Mio. USD committed by Australia and the USA to several projects operating under Task Forces.

The member countries in the Pacific Climate Change Science Program, namely the Pacific island countries, lies in its name. There is thus not any strong incentive for other countries to join the program. It is a voluntary initiative and has a legally non-binding character. But the knowledge gain for the member countries seems to be high, as the science program holds workshops and training events on a regular basis (Power et al., 2011). The PCCSP has a budget of 20.5 Mio: USD; it is part of the larger ICCAI (150 Mio. USD program).

For the ECPA, the USA invested \$60 million in fiscal years 2009 and 2010; however all participating governments and the public and private sector partners also contribute resources to implement the suggested initiatives (ECPA, 2015).

For the G-20 FSSEA and APEC FSSEA, implementation plans and medium-term timelines are prepared to phase-out inefficient fossil fuel subsidies. For the G-20 FFSEA the finance and energy ministers are in close collaboration. For the APEC FSSEA the member countries in 2011 decided to establish a voluntary reporting mechanism in order to monitor progress towards achieving their goals of reducing fuel subsidies and energy waste (APEC Energy Working Group, 2012).

\subsubsection{Climate Finance Agreements}

The incentives of the regional finance agreements are manifold, but all focus on the development of adaptation and mitigation potential in the recipient countries. By providing climate change adaptation measures with the GCCA, energy efficiency with the REDD or alternative income sources to deforestation with the Regional REDD positive side effects are generated. One of these effects could be the transfer of new technologies or job creation. There are no sanctions in those finance mechanisms. 
Chapter 4: Regional Climate Agreements to Address Climate Change: Scope, Promise, Funding, and Impacts

The sources of funding of the regional finance agreements differ. The GCCA is financed through the channels of official development assistance from the member states. By 2011 one regional group and 17 countries had received support from the GCCA (Klein and Möhner, 2011). The GEEREF had a volume of 113 Mio. EUR in equity finance for the period of 2007 to 2011 and is not limited to developing countries (Behrens, 2009). The Regional REDD received 12 Mio. EUR from the German Federal Ministry of Economic Cooperation and Development.

\subsubsection{Trade Agreements}

Trade agreements provide incentives through harmonized products and the option of receiving funding for projects as well as through the knowledge exchange. The climate initiative from COMESA receives funding through the Global Environmental Facility and World Bank for projects providing sustainable land use and carbon sequestration.

\subsection{Summary Assessment}

Based on our evaluation criteria we find that most existing agreements in the field of climate change mitigation originate in the field of technology and R\&D. The exchange of technology and $R \& D$ offers long-term returns in terms of knowledge exchange. And since no country wants to be left behind, technology agreements have become rampant. Those agreements are also the largest in terms of member size. Trade based climate agreements in comparison are born out of existing trade agreements. The member countries are hence pre-determined. Since member countries are intertwined in commercial operations already and might have a joint interest in certain standards, the implementation of trade-related climate agreements are a logical step towards gaining benefits from collaboration in other important fields (like climate change mitigation). Finance based climate agreements originate mostly between a donor country and a group of countries which apply for funding for their climate projects. The oldest agreement is the Council of Environmental Cooperation, which was created in 1994 and is a side agreement of the North American Free Trade Agreement (NAFTA). Technology and $R \& D$ agreements are on average much younger and were mostly created around 2010.

The goals of the different types of agreements are of course also different; and none of the investigated agreements name any specific or concrete goal of $\mathrm{CO}_{2}$ emission reductions. The technology and R\&D agreements, however, make clear statements on the goals they aim to achieve. The dissemination of new low carbon technologies and enforcement of research cooperation are the center of attention. Financial agreements aim to support low-income countries in their climate mitigation and adaptation efforts. Climate agreements from trade do not mention clear goals. In fact, agreements from trade firstly aim to support environmental friendly policies. All agreements lack a clear compliance mechanism. There is no evidence of a mechanism to punish member countries that do not fulfill their goals. Last but not least, the goals are defined so vaguely that it is hard to measure performance against these goals. 
Chapter 4: Regional Climate Agreements to Address Climate Change: Scope, Promise, Funding, and Impacts

Concerning the incentives to join an agreement, there is a strong incentive for neighboring countries to join the same agreement as countries face similar risks from climate change and also often bring in similar external preconditions. Furthermore, there is an incentive to join technology and R\&D agreements in order to not be left behind when other countries introduce new technologies. The implementation of advanced technologies, e.g. regarding energy efficiency, would generate a competitive advantage for the country. Finance agreements are a lucrative option since they provide funding for mitigation and adaptation projects and countries do not have to raise funds on their own. This is of special interest for developing countries that do not have a lot of funding at their disposal but are often hit hard by the consequences of climate change. Technology and R\&D agreements obviously inherit the biggest funds followed by finance agreements, which may play a bigger role in the near future. Since budgets have been approved, stakeholders are clearly interested in seeing constructive measures towards climate change mitigation.

Since eliminating fossil-fuel subsidies carries several benefits (sometimes even called a winwin policy) such as protecting the environment and saving governmental spending, it is worth asking why the elimination of these subsidies has not yet taken place. Victor (2009) describes how political stakeholders shy away from eliminating fossil-fuel subsidies; re-election, lobbyism of well-organized interest groups, and "populist" subsidies are some of the reasons the author mentions.

When taking all of our criteria together and accessing the outlines of the agreements, it is clear that none of the agreements have had much impact as most lack clear goals, quantifiable and stringent compliance mechanisms, and reliably associated financial resources. Within this rather sobering assessment, the agreements concentrating on technology and R\&D seem to be the most promising ones to date. Climate agreements associated with trade agreements are hard to evaluate, as they do not have clear commitments nor progress reports. They may contribute to setting common environmental standards among the member countries however their contribution to climate change mitigation or adaptation cannot be quantified. Finance agreements such as the Regional REDD, on the other hand, have a clear project goal that could even lead to quantifiable reduction in $\mathrm{CO}_{2}$ emissions.

At the same time, the climate change mitigation potential of those agreements, especially the finance agreements, is much larger than realized. Nevertheless, the effect of the assessed agreements could be much higher if they were equipped with stringent compliance mechanisms to ensure that countries fulfill their commitments. Last but not least, the goals of all the above examined agreements toned to be outlined more clearly. Climate change mitigation and adaptation could move to the center of those agreements and do not have to be a side effect of casual collaboration in other fields. 
Chapter 4: Regional Climate Agreements to Address Climate Change: Scope, Promise, Funding, and Impacts

\subsection{Conclusion}

Most of the investigated agreements are based on voluntary commitments and are of a legally non-binding character. The agreements and programs have been established with lofty motivations but few clear targets, compliance mechanisms, or funding. Monitoring and rigorous evaluations are largely absent. Some, e.g. the MCCI, even appear to be more of a symbolic political deal. Others organize access to information and new technologies as well as access to financial funds, which are potential benefits. Still others build on existing treaties such as trade agreements. We currently observe more agreements on a regional level than on an international level since all members share another important motivation to join an agreement.

Many of the member countries in the above described agreements face similar climate change related risks since they are neighboring countries and will be jointly affected. Those risks include rising sea levels, flooding, water scarcity and sustainable and reliable access to energy. Climate change has transboundary impacts; neighbored countries thus share a joint motivation to confront similar challenges together. On the global level, there is much information about the effects of climate change, but less on the regional specifics. This might be one reason why many nations group together to identify shared necessities and efforts, which could mitigate the harmful consequences of climate change.

Neighboring countries or countries which border the same sea profit from grouping together in order to gain and share information and knowledge about effects from climate change. Since they share similar needs, they might be willing to make commitments which would allow them to share the burden of identifying appropriate measures. The expected outcome or goal of most regional agreements is better knowledge about the requirements of potential mitigation and adaptation strategies.

Nevertheless, the concrete impact of these agreements thus far is negligible. While the main potential outcome may be found in the field of information sharing, they have achieved little else to date. Furthermore, it is hardly possible to identify a clear cause-and-effect chain between a regional organization and mitigation success in the area of climate change. Any evaluation is limited to an understanding of the regional driven (political) behavior to firmly address measures leading towards mitigation efforts. Measuring mitigation success will always be blurred by hundreds of local to global impact factors and can only be identified by a quantitative analysis of a cross-regional or global database. In this paper we are limited to a more systematic approach of identifying potential outcomes or flaws. To increase any impact it is necessary to enforce a stronger commitment to clear and quantifiable goals, compliance mechanisms and funding. Since monitoring mechanisms and clear compliance goals are often lacking, member countries cannot be recognized for their achievement (neither for progress nor for passive membership). Ultimately, this could involve a transfer of sovereignty to 
Chapter 4: Regional Climate Agreements to Address Climate Change: Scope, Promise, Funding, and Impacts

achieve real impact. Outside the EU, such a transfer of sovereignty has, however, proven rather difficult. Bäckstrand additionally states that "the increased use of partnerships in transnational governance should [...] be interpreted as [...] a replacement of sovereign authority" (2008). Thus, while the potential for regional agreements on climate change is substantial, the existing record suggests that fundamental changes are required to ensure they play a significant role in the global architecture on climate change mitigation. 


\section{Appendix}

Table A4.1a Overview on Regional Technology and R\&R Agreements Concerning Climate Change

\begin{tabular}{|c|c|c|c|c|c|c|}
\hline Agreement & Year & Type & Budget & Members & $\begin{array}{l}\text { Compliance } \\
\text { Mechanism }\end{array}$ & $\begin{array}{l}\mathrm{CO}_{2} \text { reduction and } \\
\text { Goals }\end{array}$ \\
\hline $\begin{array}{l}\text { Carbon } \\
\text { Sequestration } \\
\text { Leadership } \\
\text { Forum }(\text { CSLF) }\end{array}$ & 2003 & Technology & $\begin{array}{l}\text { Each } \\
\text { member } \\
\text { carries } \\
\text { own costs }\end{array}$ & $\begin{array}{l}\text { Australia, Brazil, Canada, China, } \\
\text { Colombia, European Union, France, } \\
\text { Germany, Greece, India, Italy, Japan, } \\
\text { Luxembourg, , Mexico, New Zealand, } \\
\text { Norway, Poland, Russia, Saudi Arabia, } \\
\text { South Africa, South Korea Uganda, } \\
\text { United Arab Emirates, United Kingdom, } \\
\text { United States. }\end{array}$ & Voluntary & $\begin{array}{l}\text { Technologies for } \\
\text { separating and storing } \\
\text { carbon; several CSLF } \\
\text { recognized projects in } \\
\text { member countries (in } \\
\text { total } 34 \text { by } 09 / 2012 \text { ). }\end{array}$ \\
\hline $\begin{array}{l}\text { International } \\
\text { Partnership for } \\
\text { the Hydrogen } \\
\text { Economy } \\
\text { (IPHE) }\end{array}$ & 2003 & Technology & $\begin{array}{l}\text { Each } \\
\text { member } \\
\text { carries } \\
\text { own costs }\end{array}$ & $\begin{array}{l}\text { Australia, Brazil, Canada, China, France, } \\
\text { Germany, Iceland, India, Italy, Japan, } \\
\text { New Zealand, Norway, Republic of } \\
\text { Korea, Russia, United Kingdom, United } \\
\text { States of America, and the European } \\
\text { Commission }\end{array}$ & Voluntary & $\begin{array}{l}\text { Research on hydrogen } \\
\text { and fuel cell } \\
\text { technology, also } \\
\text { commercial utilization } \\
\text { activities. }\end{array}$ \\
\hline $\begin{array}{l}\text { Global Methane } \\
\text { Initiatiave (GMI) } \\
\text { [Formerly: } \\
\text { Methane to Markets } \\
\text { Partnership (M2M)] }\end{array}$ & 2010 & Technology & $\begin{array}{l}\text { Each } \\
\text { member } \\
\text { carries } \\
\text { own costs }\end{array}$ & $\begin{array}{l}\text { Australia, Argentina, Brazil, Bulgaria, } \\
\text { Chile, China, Colombia, Dominican } \\
\text { Republic, Ecuador, Ethiopia, India, Italy, } \\
\text { Japan, Mexico, Mongolia, Nicaragua, } \\
\text { Nigeria, Pakistan, Peru, Philippines, } \\
\text { Poland, Russia, Serbia, South Korea, } \\
\text { Thailand, Turkey, Ukraine, United } \\
\text { Kingdom, United States, Vietnam. }\end{array}$ & Voluntary & $\begin{array}{l}\text { Technology for } \\
\text { recovering and using } \\
\text { methane. }\end{array}$ \\
\hline
\end{tabular}

Source: Authors' own elaboration. 
Chapter 4: Regional Climate Agreements to Address Climate Change: Scope, Promise, Funding, and Impacts

Table A4.1b Overview on Regional Technology and R\&R Agreements Concerning Climate Change

\begin{tabular}{|c|c|c|c|c|c|c|}
\hline Agreement & Year & Type & Budget & Members & Compliance Mechanism & $\begin{array}{lll}\text { CO2 } & \text { reduction and } \\
\text { Goals } & & \end{array}$ \\
\hline $\begin{array}{l}\text { Mediterranean } \\
\text { Climate Change } \\
\text { Initiative } \\
\text { (MCCI) }\end{array}$ & 2010 & Knowledge & $\mathrm{n} / \mathrm{a}$ & $\begin{array}{l}\text { Albania, Bulgaria, } \\
\text { Croatia, Cyprus, Egypt, the } \\
\text { Former Yugoslav Republic of } \\
\text { Macedonia, France, Greece, } \\
\text { Israel, } \\
\text { Italy, Libya, Malta, Mauritania, } \\
\text { the Palestinian National } \\
\text { Authority, Romania, Serbia, } \\
\text { Slovenia, Syria, Tunisia and } \\
\text { Spain, } \\
\text { Turkey. }\end{array}$ & Voluntary & $\begin{array}{l}\text { Sharing best practice, } \\
\text { experience and tools to } \\
\text { adapt to changes already } \\
\text { being observed; reducing } \\
\text { GHG emissions; and } \\
\text { pursuing opportunities } \\
\text { for common low-carbon } \\
\text { development strategies. }\end{array}$ \\
\hline $\begin{array}{l}\text { Arab Climate } \\
\text { Resilience } \\
\text { Initiative (ACRI) }\end{array}$ & 2010 & Knowledge & $\mathrm{n} / \mathrm{a}$ & Arab countries & Voluntary & $\begin{array}{l}\text { Connecting scientific } \\
\text { research and technology } \\
\text { transfer. }\end{array}$ \\
\hline $\begin{array}{l}\text { ASEAN Mulit- } \\
\text { Sectoral } \\
\text { Framework on } \\
\text { Climate Change } \\
\text { (AFCC) }\end{array}$ & 2009 & & $\begin{array}{l}\text { Support } \\
\text { from } \\
\text { GIZ } \\
(3 \mathrm{Mio} \text {. } \\
\text { EUR for } \\
2011- \\
2013)\end{array}$ & $\begin{array}{|lr|}\text { Part of ACCI } & \\
\text { Indonesia, } & \text { Malaysia, } \\
\text { Philippines, } & \text { Singapore, } \\
\text { Thailand, Vietnam } & \end{array}$ & Voluntary & $\begin{array}{l}\text { Minimize the risks and } \\
\text { impacts of and the } \\
\text { contribution to climate } \\
\text { change. }\end{array}$ \\
\hline
\end{tabular}

Source: Authors' own elaboration. 
Chapter 4: Regional Climate Agreements to Address Climate Change: Scope, Promise, Funding, and Impacts

Table A4.1c Overview on Regional Technology and R\&R Agreements Concerning Climate Change Continued

\begin{tabular}{|c|c|c|c|c|c|c|}
\hline Agreement & Year & Type & Budget & Members & Compliance Mechanism & $\begin{array}{lll}\mathrm{CO2} & \text { reduction } & \text { and } \\
\text { Goals } & & \end{array}$ \\
\hline $\begin{array}{l}\text { Asia Pacific } \\
\text { Partnership on } \\
\text { Clean } \\
\text { Development and } \\
\text { Climate } \\
\text { (APPCDC) }\end{array}$ & $\begin{array}{l}2005- \\
2011\end{array}$ & Technology & $\begin{array}{l}\text { Australia will } \\
\text { provide } \\
\text { resources to } \\
\text { establish and } \\
\text { maintain the } \\
\text { program. }\end{array}$ & $\begin{array}{l}\text { Australia, China, India, Japan } \\
\text { and South Korea, USA } \\
\text { (2005), Canada (2007) }\end{array}$ & Voluntary & $\begin{array}{l}\text { Climate change mitigation, } \\
\text { energy security, air } \\
\text { pollution. }\end{array}$ \\
\hline $\begin{array}{l}\text { Pacific Climate } \\
\text { Change Science } \\
\text { Program } \\
\text { (PCCSP) }\end{array}$ & $\begin{array}{l}2008- \\
2011\end{array}$ & Knowledge & $\mathrm{n} / \mathrm{a}$ & $\begin{array}{l}\text { Australia and } 15 \text { more } \\
\text { (Pacific Islands) }\end{array}$ & Voluntary & $\begin{array}{l}\text { Improves the } \\
\text { understanding of climate } \\
\text { change science. }\end{array}$ \\
\hline $\begin{array}{l}\text { Energy and } \\
\text { Climate } \\
\text { Partnership for } \\
\text { the Americas } \\
\text { (EPCA) }\end{array}$ & 2009 & Technology & $\begin{array}{l}\text { US invested } \\
\$ 60 \text { million } \\
\text { in fiscal years } \\
2009 \text { and } \\
2010\end{array}$ & $\begin{array}{l}\text { Argentina, Bolivia, Brazil, } \\
\text { Chile, Colombia, Paraguay, } \\
\text { Peru, Uruguay, Costa Rica, El } \\
\text { Salvador, Guatemala, } \\
\text { Honduras, Nicaragua, } \\
\text { Panama, Canada, Mexico, } \\
\text { USA, Antigua and Barbuda, } \\
\text { Barbados, Belize, Dominica, } \\
\text { Dominican Republic, } \\
\text { Grenada, Guyana, Haiti, } \\
\text { Jamaica, Saint Kitts and } \\
\text { Nevis, Saint Lucia, Saint } \\
\text { Vincent and the Grenadines, } \\
\text { Suriname, Trinidad and } \\
\text { Tobago, The Bahamas }\end{array}$ & Voluntary & $\begin{array}{l}\text { Umbrella of } 16 \text { initiatives } \\
\text { in North America, } \\
19 \text { initiative in Central } \\
\text { America, } 30 \text { initiatives in } \\
\text { South America, } \\
22 \text { initiatives in the } \\
\text { Caribbean }\end{array}$ \\
\hline
\end{tabular}

Source: Authors' own elaboration. 
Table A4.1d Overview on Regional Financial Agreements Concerning Climate Change

\begin{tabular}{|c|c|c|c|c|c|c|}
\hline Agreement & Year & Type & Budget & Members & Compliance Mechanism & $\mathrm{CO}_{2}$ reduction and Goals \\
\hline $\begin{array}{l}\text { G-20 Fossil Fuel } \\
\text { Elimination } \\
\text { Subsidies } \\
\text { Agreement } \\
\text { (G-20 FFESA) }\end{array}$ & 2009 & Technology & & $\begin{array}{l}\text { Argentina, Australia, Brazil, } \\
\text { Canada, China, France, } \\
\text { Germany, India, Indonesia, } \\
\text { Italy, Japan, South Korea, } \\
\text { Mexico, Russia, Saudi } \\
\text { Arabia, South Africa, } \\
\text { Turkey, the United } \\
\text { Kingdom, the United States }\end{array}$ & voluntary & $\begin{array}{l}\text { Climate change mitigation by } \\
\text { phasing out fossil fuel } \\
\text { subsidies over the medium- } \\
\text { term }\end{array}$ \\
\hline $\begin{array}{l}\text { APEC Fossil Fuel } \\
\text { Elimination } \\
\text { Subsidies } \\
\text { Agreement } \\
\text { (APEC FFESA) }\end{array}$ & 2009 & Technology & & $\begin{array}{l}\text { Australia, Brunei, Canada, } \\
\text { Chile, China, Indonesia, } \\
\text { Japan, South Korea, } \\
\text { Malaysia, Mexico, New } \\
\text { Zealand, Papua New } \\
\text { Guinea, Peru, The } \\
\text { Philippines, Russia, } \\
\text { Singapore, Chinese Taipei, } \\
\text { Thailand, the United States, } \\
\text { Vietnam }\end{array}$ & $\begin{array}{l}\text { voluntary } \\
\text { (voluntary reporting } \\
\text { mechanism since 2011) }\end{array}$ & $\begin{array}{l}\text { Climate change mitigation by } \\
\text { phasing out fossil fuel } \\
\text { subsidies over the medium- } \\
\text { term }\end{array}$ \\
\hline $\begin{array}{l}\text { The Global } \\
\text { Energy } \\
\text { Efficiency and } \\
\text { Renewable } \\
\text { Energy Fund } \\
\text { (GEEREF) }\end{array}$ & 2008 & $\begin{array}{l}\text { Fund-of- } \\
\text { Funds }\end{array}$ & $\begin{array}{l}200-250 \\
\text { Mio. } \\
\text { EUR } \\
\text { target; } \\
108 \text { Mio. } \\
\text { EUR } \\
\text { secured } \\
\text { (2007- } \\
2011: \\
113 \text { Mio. E } \\
\text { UR) }\end{array}$ & $\begin{array}{l}\text { EU and Developing } \\
\text { Countries }\end{array}$ & No sanctions & $\begin{array}{l}\text { "aims to accelerate the transfer, } \\
\text { development, use and } \\
\text { enforcement of } \\
\text { environmentally sound } \\
\text { technologies for the world's } \\
\text { poorer regions, helping to } \\
\text { bring secure, clean and } \\
\text { affordable energy to local } \\
\text { people." (GEEREF, 2012) }\end{array}$ \\
\hline
\end{tabular}


Chapter 4: Regional Climate Agreements to Address Climate Change: Scope, Promise, Funding, and Impacts

Table A4.1e Overview on Regional Trade Agreements Concerning Climate Change

\begin{tabular}{|c|c|c|c|c|c|c|}
\hline Agreement & Year & Type & Budget & Members & Compliance Mechanism & CO2 reduction and Goals \\
\hline $\begin{array}{l}\text { Global Climate } \\
\text { Change Alliance } \\
\text { (GCCA) }\end{array}$ & 2007 & Financial & $\begin{array}{l}55 \text { Mio. } \\
\text { EUR }\end{array}$ & $\begin{array}{l}\text { EU and Developing } \\
\text { Countries }\end{array}$ & No sanctions & Mainly adaptation \\
\hline $\begin{array}{l}\text { Forest/REDD } \\
\text { agreements } \\
\text { (project in } \\
\text { Central America) }\end{array}$ & $\begin{array}{l}2010- \\
2016\end{array}$ & Financial & $\begin{array}{l}12 \text { Mio. E } \\
\text { UR }\end{array}$ & $\begin{array}{l}\text { Belize, Costa Rica, El } \\
\text { Salvador, Germany, } \\
\text { Guatemala, Honduras, } \\
\text { Nicaragua, Panamá and the } \\
\text { Dominican Republic }\end{array}$ & No sanctions & $\begin{array}{l}\text { Emissions reduction from } \\
\text { deforestation }\end{array}$ \\
\hline $\begin{array}{l}\text { Common Market } \\
\text { for Eastern and } \\
\text { Southern Africa } \\
\text { (COMESA) } \\
\text { Climate Initiative }\end{array}$ & 2007 & Trade & $\mathrm{n} / \mathrm{a}$ & $\begin{array}{l}\text { Burundi, Comoros, } \\
\text { Democratic Republic of } \\
\text { Congo (DRC), Djibouti, } \\
\text { Egypt, Eritrea, Ethiopia, } \\
\text { Kenya, Libya, Madagascar, } \\
\text { Malawi, Mauritius, Rwanda, } \\
\text { Seychelles, Sudan, } \\
\text { Swaziland, Uganda, Zambia } \\
\text { and Zimbabwe. }\end{array}$ & $\begin{array}{l}\text { The goal is "achieving } \\
\text { economic prosperity and } \\
\text { climate change protection" }\end{array}$ & $\begin{array}{l}\text { - no direct } \mathrm{CO}_{2} \text { reductions } \\
\text { - potential emission reductions } \\
\text { through } \mathrm{R} \& \mathrm{D} \text { spillovers }\end{array}$ \\
\hline $\begin{array}{l}\text { North American } \\
\text { Agreement on } \\
\text { Environmental } \\
\text { Cooperation } \\
\text { (NAAEC) } \\
\text { Commission for } \\
\text { Environmental } \\
\text { Cooperation } \\
\text { (CEC) }\end{array}$ & 1994 & Trade & $\begin{array}{l}9.36 \text { Mio. } \\
\text { USD } \\
\text { (NAFEC) }\end{array}$ & Canada, Mexico and USA & $\begin{array}{l}\text { The goal is to facilitate } \\
\text { collaboration and public } \\
\text { participation to foster nature } \\
\text { preservation in the context } \\
\text { of increasing economic, } \\
\text { trade, and social. } \\
\text { The mechanism is to give } \\
\text { project funding through the } \\
\text { North American Fund for } \\
\text { Environmental Cooperation } \\
\text { (NAFEC) }\end{array}$ & $\begin{array}{l}\text { - no direct } \mathrm{CO}_{2} \text { reductions } \\
\text { - some of the projects concern } \\
\text { climate change and the } \\
\text { transition into a low carbon } \\
\text { economy }\end{array}$ \\
\hline
\end{tabular}

Source: Authors' own elaboration. 
Chapter 4: Regional Climate Agreements to Address Climate Change: Scope, Promise, Funding, and Impacts

\section{References}

Adler, N. E., and J. Stewart. 2009. "Reducing Obesity: Motivating Action While Not Blaming the Victim." The Milbank Quarterly 87 (1): 49-70.

AFCC. 2013. "Regional Expert Forum on Climate Change, Agriculture and Food Security in ASEAN." Bangkok, Thailand.

Ahmed, S. M., and W. Dougherty. 2012. "Climate Change and the Environment." In Unlocking North Africa's Potential through Regional Integration: Challenges and Oppportunities, edited by Emanuele Santi, Saoussen Ben Romdhane, and William Shaw, 54-83. Tunis Belvédère, TUNISIA: African Development Bank (AfDB) Group, Temporary Relocation Agency (TRA).

Aldy, J. E., S. Barrett, and R. N. Stavins. 2003. "Thirteen plus One: A Comparison of Global Climate Policy Architectures." Climate Policy 3 (4): 373-97.

Antipatis, V. J., and T. P. Gill. 2001. "Obesity as a Global Problem." In International Textbook of Obesity, edited by Per Björntorp, 1-22. John Wiley \& Sons, Ltd.

APEC Energy Working Group. 2012. "Reforming Fossil-Fuel Subsidies to Reduce Waste and Limit CO2 Emissions While Protecting the Poor." APEC Project EWG11/2010. Singapore.

APPCDC, (Asia-Pacific Partnership on Clean Development and Climate). 2006. "APPCDC Charter."

- 2013. "Asia-Pacific Partnership on Clean Development and Climate." Accessed October 2. http://www.asiapacificpartnership.org/english/default.aspx.

ASEAN AFCC. unknown date. "ASEAN Multi-Sectoral Framework on Climate Change: Agriculture and Forestry towards Food Security (AFCC)." concept note. http://aseanfoodsecurity.asean.org/wp-content/uploads/2011/08/afcc.pdf.

ASEAN, Secretariat. 2011. ASEAN Economic Community Factbook. Jakarta, Indonesia.

Asfaw, A. 2007. "Do Government Food Price Policies Affect the Prevalence of Obesity? Empirical Evidence from Egypt." World Development 35 (4): 687-701.

Australian Bureau of Meteorology and CSIRO. 2009. "Pacific Climate Change Science Program - Annual Report." 1. PCCSP.

- 2011. "Climate Change in the Pacific: Scientific Assessment and New Research. Volume 1: Regional Overview. Volume 2: Country Reports." PCCSP.

Bäckstrand, K. 2008. "Accountability of Networked Climate Governance: The Rise of Transnational Climate Partnerships." Global Environmental Politics 8 (3): 74-102.

Baghdadi, L., I. Martinez-Zarzoso, and H. Zitouna. 2013. "Are RTA Agreements with Environmental Provisions Reducing Emissions?" Journal of International Economics 90 (2): 378-90.

Ball, K., and D. Crawford. 2005. "Socioeconomic Status and Weight Change in Adults: A Review." Social Science \& Medicine 60 (9): 1987-2010.

Ball, K., G. Mishra, and D. Crawford. 2011. "Which Aspects of Socioeconomic Status Are Related to Obesity among Men and Women?" International Journal of Obesity 26 (4): 559-65.

Balsiger, J., and M. Prys. 2014. "Regional Agreements in International Environmental Politics." International Environmental Agreements: Politics, Law and Economics, May, 1-22.

Barrett, S., and R. Stavins. 2003. "Increasing Participation and Compliance in International Climate Change Agreements." International Environmental Agreements: Politics, Law and Economics 3 (4): 349-76.

Baum, C. L., and S.-Y. Chou. 2011. "The Socio-Economic Causes of Obesity." Working Paper 17423. National Bureau of Economic Research. 
Chapter 4: Regional Climate Agreements to Address Climate Change: Scope, Promise, Funding, and Impacts

Behrens, A. 2009. "The Financing of the Global Energy Efficiency and Renewable Energy Fund (GEEREF)." 190. CEPS Policy Brief.

Bel i Queralt, G., and S. Joseph. 2015. "Certificate Oversupply in the European Union Emission Trading System and Its Impact on Technological Change."

Bennett, M. K. 1941. "International Contrasts in Food Consumption." Geographical Review 31 (3): 365-76.

Bird, N., and J. Brown. 2010. "International Climate Finance: Principles for European Support to Developing Countries." EDC2020 working paper.

Black, R. E., L. H. Allen, Z. A. Bhutta, L. E. Caulfield, M. de Onis, M. Ezzati, C. Mathers, and J. Rivera. 2008. "Maternal and Child Undernutrition: Global and Regional Exposures and Health Consequences." The Lancet 371 (9608): 243-60.

Bleich, S., D. Cutler, C. Murray, and A. Adams. 2008. "Why Is The Developed World Obese?" Annual Review of Public Health 29: 273-95.

Böhringer, C. 2003. "The Kyoto Protocol: A Review and Perspectives." Oxford Review of Economic Policy 19 (3): 451-66.

Bourne, L. T., E. V. Lambert, and K. Steyn. 2002. "Where Does the Black Population of South Africa Stand on the Nutrition Transition?" Public Health Nutrition 5 (1a): 15762.

Brauch, H. G. 2012. "Policy Responses to Climate Change in the Mediterranean and MENA Region during the Anthropocene." In Climate Change, Human Security and Violent Conflict, edited by J. Scheffran, M. Brzoska, H. G. Brauch, P. M. Link, and J. Schilling, 719-94. Hexagon Series on Human and Environmental Security and Peace 8. Springer Berlin Heidelberg.

Brown, P. J. 1991. "Culture and the Evolution of Obesity." Human Nature 2 (1): 31-57.

Buckley, R. M., and J. Kalarickal. 2006. Thirty Years of World Bank Shelter Lending: What Have We Learned? World Bank Publications.

Bulkeley, H., L. Andonova, K. Bäckstrand, M. Betsill, D. Compagnon, R. Duffy, A. Kolk, et al. 2012. "Governing Climate Change Transnationally: Assessing the Evidence from a Database of Sixty Initiatives." Environment and Planning C: Government and Policy 30 (4): 591-612.

Burns, C. 2004. "Poverty, Food Insecurity and Obesity - A Review of the Literature Describing the Link between Poverty, Food Insecurity and Obesity." Victorian Health Promotion Foundation: Centre for Physical Activity and Nutrition Research School of Exercise and Nutrition Sciences, Deakin University.

Caballero, B. 2007. "The Global Epidemic of Obesity: An Overview." Epidemiologic Reviews 29 (1): $1-5$.

Cabello, D., F. Sekulova, and D. Schmidt. 2008. "World Bank \& Conditionalities: Poor Deal for Poor Countries." Amsterdam: A SEED Report.

Campbell, K. J., D. A. Crawford, and K. Ball. 2006. "Family Food Environment and Dietary Behaviors Likely to Promote Fatness in 5-6 Year-Old Children." International Journal of Obesity 30 (8): 1272-80.

Cantore, N., C. George, and D. Willem Velde te. 2011. "Assessment on the Implementation of the Mediterranean Strategy for Sustainable Development (MSSD) for the Period 2005-2010." Overseas Development Institute.

Caprio, S., S. R. Daniels, A. Drewnowski, F. R. Kaufman, L. A. Palinkas, A. L. Rosenbloom, and J. B. Schwimmer. 2008. "Influence of Race, Ethnicity, and Culture on Childhood Obesity: Implications for Prevention and Treatment A Consensus Statement of Shaping America's Health and the Obesity Society." Diabetes Care 31 (11): 2211-21.

Carbon Sequestration Leadership Forum, CSLF. 2011. "Charter for the Carbon Sequestration Leadership Forum: A Carbon Capture and Storage Technology Initiative (Revised)." 
Chapter 4: Regional Climate Agreements to Address Climate Change: Scope, Promise, Funding, and Impacts

Case, A., and A. Menendez. 2009. "Sex Differences in Obesity Rates in Poor Countries: Evidence from South Africa." Economics \& Human Biology 7 (3): 271-82.

Cawley, J. H. 2006. "Markets and Childhood Obesity." The Future of Children 16 (1): 69-88.

CEC. 2012. "Annual Report." Commission for Environmental Cooperation.

Chopra, M., S. Galbraith, and I. Darnton-Hill. 2002. "A Global Response to a Global Problem: The Epidemic of Overnutrition." Bulletin of the World Health Organization 80 (12): 952-58.

Collinson, M. A. 2010. "Striving against Adversity: The Dynamics of Migration, Health and Poverty in Rural South Africa." Global Health Action 3 (June).

Convery, F. J. 2009. "Origins and Development of the EU ETS." Environmental and Resource Economics 43 (3): 391-412.

Cornia, G. A. 1994. "Poverty, Food Consumption, and Nutrition During the Transition to the Market Economy in Eastern Europe.” The American Economic Review 84 (2): 297 302.

Crosnoe, R. 2007. “Gender, Obesity, and Education.” Sociology of Education 80 (3): 241-60.

Cutter, J., B. Yian and S. K. Chew. 2001. "Levels of Cardiovascular Disease Risk Factors in Singapore Following a National Intervention Programme." Bulletin of the World Health Organization 79 (10): 908-15.

Dammann, K. W., and C. Smith. 2009. "Factors Affecting Low-Income Women's Food Choices and the Perceived Impact of Dietary Intake and Socioeconomic Status on Their Health and Weight." Journal of Nutrition Education and Behavior 41 (4): 24253.

Davenport, C. 2015. "Nations Approve Landmark Climate Accord in Paris." The New York Times, December 12.

Deaton, A., and S. Zaidi. 2002. "Guidelines for Constructing Consumption Aggregates for Welfare Analysis." World Bank Publications. The World Bank.

de Coninck, H., C. Fischer, R. G. Newell, and T. Ueno. 2008. "International TechnologyOriented Agreements to Address Climate Change." Energy Policy 36 (1): 335-56.

Delisle, H. 2002. "Foetal programming of nutrition-related chronic diseases." Santé (Montrouge, France) 12 (1): 56-63.

Development Policy and Analysis Division (DPAD), Department of Economic and Social Affairs of the United Nations Secretariat (UN/DESA). 2012. "Country Classification Statistical Annex to World Economic Situation and Prospects."

Doak, C. M., L. S. Adair, M. Bentley, C. Monteiro, and B. M. Popkin. 2004. "The Dual Burden Household and the Nutrition Transition Paradox." International Journal of Obesity and Related Metabolic Disorders 29 (1): 129-36.

Doak, C. M., L. S. Adair, C. Monteiro, and B. M. Popkin. 2000. "Overweight and Underweight Coexist within Households in Brazil, China and Russia." The Journal of Nutrition 130 (12): 2965-71.

Dore, A. R., L. S. Adair, and B. M. Popkin. 2003. "Low Income Russian Families Adopt Effective Behavioral Strategies to Maintain Dietary Stability in Times of Economic Crisis." The Journal of Nutrition 133 (11): 3469-75.

Dowse, G. K., H. Gareeboo, K. G. M. M. Alberti, P. Zimmet, J. Tuomilehto, A. Purran, D. Fareed, P. Chitsono, V. R. Collins, and F. Hemraj. 1995. "Changes in Population Cholesterol Concentrations and Other Cardiovascular Risk Factor Levels after Five Years of the Non-Communicable Disease Intervention Programme in Mauritius." British Medical Journal 311 (7015): 1255-59.

Drewnowski, A. 2003. "Fat and Sugar: An Economic Analysis." The Journal of Nutrition 133 (3): $838 \mathrm{~S}-840 \mathrm{~S}$.

Drewnowski, A., and S. E. Specter. 2004. "Poverty and Obesity: The Role of Energy Density and Energy Costs." The American Journal of Clinical Nutrition 79 (1): 6-16. 
Chapter 4: Regional Climate Agreements to Address Climate Change: Scope, Promise, Funding, and Impacts

Drewnowski, A., and B. M. Popkin. 1997. "The Nutrition Transition: New Trends in the Global Diet." Nutrition Reviews 55 (2): 31-43.

Easterly, W. 2009. "How the Millennium Development Goals Are Unfair to Africa." World Development 37 (1): 26-35.

ECPA. 2015. “ECPA Website.” http://www.ecpamericas.org/.

Egger, P., and M. Pfaffermayr. 2005. "Estimating Long and Short Run Effects in Static Panel Models." Econometric Reviews 23 (3): 199-214.

Energy and Climate Partnership of the Americas, ECPA. 2011. "Fact Sheet."

European Commission. 2016. "The EU Emissions Trading System (EU ETS)." http://ec.europa.eu/clima/policies/ets/index_en.htm.

FAO, ASEAN+3, WMO. 2011. "Climate Change and Food Security - Workshop Summary." http://www.fao.org/fileadmin/templates/rap/files/meetings/2011/110329_summary.pdf.

Fernald, L. C. H. 2007. "Socio-Economic Status and Body Mass Index in Low-Income Mexican Adults." Social Science \& Medicine (1982) 64 (10): 2030-42.

Finn, A., M. Leibbrandt, and J. Levinsohn. 2012. "Income Mobility in South Africa: Evidence from the First Two Waves of the National Income Dynamics Study." NIDS Discussion Paper, Working Paper Series No. 82, 5.

Finucane, M. M., G. A. Stevens, M. J. Cowan, G. Danaei, J. K. Lin, C. J. Paciorek, G. M. Singh, et al. 2011. "National, Regional, and Global Trends in Body-Mass Index since 1980: Systematic Analysis of Health Examination Surveys and Epidemiological Studies with 960 Country-Years and 9.1 Million Participants." The Lancet 377 (9765): 557-67.

Fischer, S. 1991. "Growth, Macroeconomics, and Development." NBER Macroeconomics Annual 1991, MIT Press, 6: 329-79.

Ford, L. 2015. "Sustainable Development Goals: All You Need to Know." The Guardian, January 19, sec. Global development.

Fujiwara, N. 2012. "Sector-Specific Activities as the Driving Force towards a Low-Carbon Economy: From the Asia-Pacific Partnership to a Global Partnership." 262. CEPS Policy Brief. Brussles: CEPS.

Fujiwara, N. 2007. "The Asia-Pacific Partnership on Clean Development and Climate: What It Is and What It Is Not." SSRN eLibrary, November.

Galeotti, M., and R. Roson. 2011. "Economic Impacts of Climate Change in Italy and the Mediterranean: Updating the Evidence.” SSRN Scholarly Paper ID 1935280. Rochester, NY: Social Science Research Network.

GEEREF. 2012. "GEEREF - Global Energy Efficiency and Renewable Energy Fund." http://www.geeref.com/.

Gibson, J., S. Stillman, and T. Le. 2008. "CPI Bias and Real Living Standards in Russia during the Transition.” Journal of Development Economics 87 (1): 140-60.

Gilbert, L., T. A. Selikow, and L. Walker. 2010. "Society, Health and Disease in a Time of HIV/AIDS."

Gillis, L. J., and O. Bar-Or. 2003. "Food Away from Home, Sugar-Sweetened Drink Consumption and Juvenile Obesity." Journal of the American College of Nutrition 22 (6): 539-45.

Global Methane Initiative, GMI. 2010. "Terms of Reference for the Global Methane Initiative."

Gorodnichenko, Y., K. Sabirianova, and D. Stolyarov. 2010. "Inequality and Volatility Moderation in Russia: Evidence from Micro-Level Panel Data on Consumption and Income." Review of Economic Dynamics, Special issue: Cross-Sectional Facts for Macroeconomists, 13 (1): 209-37.

Grefe, C. 2015. "Hunger: 'Erfolge sind auf kosmetische Mathematik zurückzuführen."” Die Zeit, June 3, Section. Wirtschaft. 
Chapter 4: Regional Climate Agreements to Address Climate Change: Scope, Promise, Funding, and Impacts

Grossman, M., and N. Mocan. 2011. Economic Aspects of Obesity. University of Chicago Press.

Guo, X., B. M. Popkin, T. A. Mroz, and F. Zhai. 1999. "Food Price Policy Can Favorably Alter Macronutrient Intake in China." The Journal of Nutrition 129 (5): 994-1001.

Gupta, S., D. Tirpark, N. Burger, J. Gupta, N. Höhne, A. I. Boncheva, G. M. Kanoan, et al. 2007. "Policies, Instruments, and Co-Operative Arrangements." In Climate Change 2007: Mitigation. Contribution of Assessment Report of the Intergovernmental Panel on Climate Change, edited by B. Betz, O. R. Davidson, P. R. Bosch, R. Dave, and L. A. Meyer. Cambridge, UK and New York, USA: Cambridge University Press.

Halford, J. C. G., J. Gillespie, V. Brown, E. E. Pontin, and T. M. Dovey. 2004. "Effect of Television Advertisements for Foods on Food Consumption in Children." Appetite 42 (2): 221-25.

Hawkes, C. 2007. "Promoting Healthy Diets and Tackling Obesity and Diet-Related Chronic Diseases: What Are the Agricultural Policy Levers?" Food \& Nutrition Bulletin 28 (Supplement 2): 312S - 322S.

Hawley, K. L., C. A. Roberto, M. A. Bragg, P. J. Liu, M. B. Schwartz, and K. D. Brownell. 2013. "The Science on Front-of-Package Food Labels." Public Health Nutrition 16 (03): 430-39.

Hoffman, D. J. 2001. "Obesity in Developing Countries: Causes and Implications.” Web site. FAO.

Holt, E. 2011. "Hungary to Introduce Broad Range of Fat Taxes.” Lancet 378 (9793).

Houthakker, H. 1987. "Engel's Law." In The New Palgrave: A Dictionary of Economics, edited by M. Milgate and P. Newman, 2:143-44. London: The Macmillan Press.

Hovi, J., T. Skodvin, and S. Andresen. 2003. "The Persistence of the Kyoto Protocol: Why Other Annex I Countries Move on Without the United States." Global Environmental Politics 3 (4): 1-23.

Hovi, J., D. F. Sprinz, and G. Bang. 2010. "Why the United States Did Not Become a Party to the Kyoto Protocol: German, Norwegian and US Perspectives." European Journal of International Relations, December.

Huffman, S. K., and M. Rizov. 2007. "Determinants of Obesity in Transition Economies: The Case of Russia." Economics and Human Biology 5 (3): 379-91.

- 2010. "The Rise of Obesity in Transition: Theory and Empirical Evidence from Russia." Journal of Development Studies 46 (3): 574-94.

Human Development Reports, UN Development Programme. 2013. "Mean Years of Schooling (of Adults) (years) (HDR)." http://hdr.undp.org/en/content/mean-yearsschooling-adults-years.

Inglis, V., K. Ball, and D. Crawford. 2005. "Why Do Women of Low Socioeconomic Status Have Poorer Dietary Behaviours than Women of Higher Socioeconomic Status? A Qualitative Exploration." Appetite 45 (3): 334-43.

International Food Policy Research Institute (IFPRI). 2015. Global Nutrition Report 2015: Actions and Accountability to Advance Nutrition and Sustainable Development. Washington, D.C.

International Monetary Fund (IMF). 2015. "World Economic Outlook - Uneven GrowthShort- and Long-Term Factors." Washington D.C., USA.

International Partnership for Hydrogen and Fuel Cells in the Economy, IPHE. 2010. "Terms of Reference for the International Partnership for Hydrogen and Fuel Cells in the Economy (Revised)."

IPCC. 2015. Climate Change 2014: Mitigation of Climate Change: Working Group III Contribution to the IPCC Fifth Assessment Report. 1st ed. Cambridge University Press. 
Chapter 4: Regional Climate Agreements to Address Climate Change: Scope, Promise, Funding, and Impacts

IPHE, International Partnership for Hydrogen and Fuel Cells in the Economy. 2011. "Hydrogen and Fuel Cell Global Policies Update." http://iphe.net/resources/reports.html.

James, P. T., R. Leach, E. Kalamara, and M. Shayeghi. 2001. "The Worldwide Obesity Epidemic." Obesity Research 9 (S11): 228S - 233S.

Jeffery, R. W., S. A. French, J. L. Forster, and V. M. Spry. 1991. "Socioeconomic Status Differences in Health Behaviors Related to Obesity: The Healthy Worker Project." International Journal of Obesity 15 (10): 689-96.

Katz, D. L. 2012. "Is Obesity Cultural? - US News." US News \& World Report.

Kearney, J. 2010. "Food Consumption Trends and Drivers." Philosophical Transactions of the Royal Society B: Biological Sciences 365 (1554): 2793-2807.

Kingston, C., G. Jackson Irikana, V. Uchechukwu Dienye, and K. Gogo Kingston. 2011. "The Impacts of the World Bank and IMF Structural Adjustment Programmes on Africa: The Case Study of Cote D'Ivoire, Senegal, Uganda, and Zimbabwe." SSRN Scholarly Paper ID 2056391. Rochester, NY.

Klasen, S. 2012. "Policy Note: MDGs post-2015: What to Do?" 123. Courant Research Centre: Poverty, Equity and Growth - Discussion Papers.

Klasen, S., and S. Lange. 2012. "Getting Progress Right: Measuring Progress Towards the MDGs Against Historical Trends.” 87. Courant Research Centre: Poverty, Equity and Growth - Discussion Papers.

Kleinman, A., and P. Benson. 2006. "Anthropology in the Clinic: The Problem of Cultural Competency and How to Fix It." PLoS Med 3 (10): e294.

Klein, R. J. T., and A. Möhner. 2011. "The Political Dimension of Vulnerability: Implications for the Green Climate Fund." IDS Bulletin 42 (3): 15-22.

Kramer, C. K., B. Zinman, and R. Retnakaran. 2013. "Are Metabolically Healthy Overweight and Obesity Benign Conditions?: A Systematic Review and Meta-Analysis." Annals of Internal Medicine 159 (11): 758-69.

Kruger, H. S., T. Puoane, M. Senekal, and M.-T. van der Merwe. 2005. "Obesity in South Africa: Challenges for Government and Health Professionals." Public Health Nutrition 8 (05): 491-500.

Lakdawalla, D. N., D. Goldman, and B. Shang. 2005. "The Health And Cost Consequences Of Obesity Among The Future Elderly." Health Affairs 10.

Letchumanan, R. 2010. "Climate Change: Is Southeast Asia up to the Challenge?: Is There an ASEAN Policy on Climate Change?" SR004. LSE IDEAS. London, UK.

Levine, R., and D. Renelt. 1991. Cross-Country Studies of Growth and Policy: Methodological, Conceptual, and Statistical Problems. World Bank Publications.

Loewe, M. 2012. "Post 2015: How to Reconcile the Millennium Development Goals (MDGs) and the Sustainable Development Goals (SDGs)?" Briefing Paper 18/2012. Bonn, Germany: German Development Institute, Deutsches Institut für Entwicklungspolitik die.

Lohmann, L. 2011. "The Endless Algebra of Climate Markets." Capitalism Nature Socialism 22 (4): 93-116.

Lu, Y., and D. Goldman. 2010. "The Effects of Relative Food Prices on Obesity - Evidence from China: 1991-2006." Working Paper 15720. National Bureau of Economic Research.

Macdiarmid, J., and J. Blundell. 1998. "Assessing Dietary Intake: Who, What and Why of under-Reporting." Nutrition Research Reviews 11 (02): 231-53.

Manig, C., and A. Moneta. 2009. "More or Better? Measuring Quality versus Quantity in Food Consumption." Papers on Economics and Evolution 0913: 27.

Marcellino, D., and C. Gerstetter. 2011. "Financing Energy Efficiency Measures and R\&D in Emerging Economies - A Comparative Analysis EU-US.” Ecologic Institute, Berlin. 
Chapter 4: Regional Climate Agreements to Address Climate Change: Scope, Promise, Funding, and Impacts

Mbanya, J. C., S. B. Squire, E. Cazap, and P. Puska. 2011. "Mobilising the World for Chronic NCDs." The Lancet 377 (9765): 536-37.

McKibbin, W. J., and P. J. Wilcoxen. 2002. "The Role of Economics in Climate Change Policy." The Journal of Economic Perspectives 16 (2): 107-29.

Mediterranean Climate Change Initiative, MCCI, and George Tselioudis. 2010. "Draft Plan for a Mediterranean Climate Service Network."

Mendez, M. A., C. A. Monteiro, and B. M. Popkin. 2005. "Overweight Exceeds Underweight among Women in Most Developing Countries." The American Journal of Clinical Nutrition 81 (3): 714-21.

Merrill, L. 2015. "Eliminating Fossil Fuel Subsidies Still on the Agenda - The International Community Must Now Walk the Talk." Global Subsidies Initiative.

Michaelowa, A., and B. Müller. 2009. "The Clean Development Mechanism in the Future Climate Change Regime."

Minos, D. 2015. "'I'm Just Well Nourished' - A Study on Overweight and Obesity in Developing Countries." Göttingen.

Mitchell, R. B. 2013. "IEA Database." 2002.

Monteiro, C. A., E. C. Moura, W. L. Conde, and B. M. Popkin. 2004. "Socioeconomic Status and Obesity in Adult Populations of Developing Countries: A Review." Bulletin of the World Health Organization 82 (12): 940-46.

Montiel, P., and L. Servén. 2004. Macroeconomic Stability in Developing Countries: How Much Is Enough? World Bank Publications.

Montonen, J., R. Järvinen, M. Heliövaara, A. Reunanen, A. Aromaa, and P. Knekt. 2005. "Food Consumption and the Incidence of Type II Diabetes Mellitus." European Journal of Clinical Nutrition 59 (3): 441-48.

Mroz, T. A., and B. M. Popkin. 1995. "Poverty and the Economic Transition in the Russian Federation." Economic Development and Cultural Change 44 (1): 1-31.

Mundlak, Y. 1978. "On the Pooling of Time Series and Cross Section Data." Econometrica 46 (1): 69-85.

Mvo, Z., J. Dick, and K. Steyn. 1999. "Perceptions of Overweight African Women about Acceptable Body Size of Women and Children." Curationis 22 (2).

Mytton, O. T., D. Clarke, and M. Rayner. 2012. "Taxing Unhealthy Food and Drinks to Improve Health.” The British Medical Journal 344 (May): e2931.

Nande, P., M. Hussain, and S. Vali. 2010. "Influence of Obesity on Body Measurements and Composition in Adult Women Belonging to Minority Community." Indian Journal of Nutrition and Dietetics 47 (4): 137-51.

Ng, M., T. Fleming, M. Robinson, B. Thomson, N. Graetz, C. Margono, E. C Mullany, et al. 2014. "Global, Regional, and National Prevalence of Overweight and Obesity in Children and Adults during 1980-2013: A Systematic Analysis for the Global Burden of Disease Study 2013." The Lancet 384 (9945): 766-81.

Norum, K. R. 1997. "Some Aspects of Norwegian Nutrition and Food Policy." In Diet, Nutrition and Chronic Disease: Lessons from Contrasting Worlds, edited by P. Shetty and K. McPherson, 318. London: John Wiley \& Sons, Ltd.

Ocampo, J. A., and R. Vos. 2008. "Policy Space and the Changing Paradigm in Conducting Macroeconomic Policies in Developing Countries." BIS Papers chapters. Bank for International Settlements.

OECD. 2009. The Economics of Climate Change Mitigation: Policies and Options for Global Action Beyond 2012.

Osmani, S., and A. Sen. 2003. "The Hidden Penalties of Gender Inequality: Fetal Origins of Ill-Health." Economics \& Human Biology 1 (1): 105-21.

Owaygen, M. 2012. "Arab Climate Resilience Initiative." UNDP RBAS presented at the Expert Group Meeting, ESCWA. 
Chapter 4: Regional Climate Agreements to Address Climate Change: Scope, Promise, Funding, and Impacts

Patterson, S. 1953. Colour and Culture in South Africa: A Study of the Status of the Cape Coloured People Within the Social Structure of the Union of South Africa. Taylor \& Francis.

Petrukhin, I. S., and E. Y. Lunina. 2012. "Cardiovascular Disease Risk Factors and Mortality in Russia: Challenges and Barriers." Public Health Reviews 33 (2): 436-49.

Philipson, T. J., and R. A. Posner. 2003. "The Long-Run Growth in Obesity as a Function of Technological Change." Perspectives in Biology and Medicine 46 (3): S87-107.

Philipson, T. J., and R. A. Posner. 2008. "Is the Obesity Epidemic a Public Health Problem? A Decade of Research on the Economics of Obesity." Working Paper 14010. National Bureau of Economic Research.

Phillips, C. M., C. Dillon, J. M. Harrington, V. J. C. McCarthy, P. M. Kearney, A. P. Fitzgerald, and I. J. Perry. 2013. "Defining Metabolically Healthy Obesity: Role of Dietary and Lifestyle Factors." PLoS ONE 8 (10).

Popkin, B. M. 1993. "Nutritional Patterns and Transitions." Population and Development Review 19 (1): 138-57.

1999. "Urbanization, Lifestyle Changes and the Nutrition Transition." World Development 27 (11): 1905-16.

. 2004. "The Nutrition Transition: An Overview of World Patterns of Change." Nutrition Reviews 62 (7 Pt 2): S140-43.

Popkin, B. M., L. S. Adair, and S. W. Ng. 2012. "Global Nutrition Transition and the Pandemic of Obesity in Developing Countries." Nutrition Reviews 70 (1): 3-21. d

Popkin, B. M., W. Conde, N. Hou, and C. Monteiro. 2006. "Is There a Lag Globally in Overweight Trends for Children Compared with Adults?" Obesity 14 (10): 1846-53.

Popkin, B. M., S. Horton, S. Kim, A. Mahal, and J. Shuigao. 2001. "Trends in Diet, Nutritional Status, and Diet-Related Noncommunicable Diseases in China and India: The Economic Costs of the Nutrition Transition." Nutrition Reviews 59 (12): 379-90.

Popkin, B. M., and S. Wen Ng. 2007. "The Nutrition Transition in High- and Low-income Countries: What Are the Policy Lessons?" Agricultural Economics 37 (December): 199-211.

Popkin, B. M., and P. Gordon-Larsen. 2004. "The Nutrition Transition: Worldwide Obesity Dynamics and Their Determinants." International Journal of Obesity 28 (S3): S2-9.

Posel, D. 2001. "Who Are the Heads of Household, What Do They Do, and Is the Concept of Headship Useful? An Analysis of Headship in South Africa." Development Southern Africa 18 (5): 651-70.

Power, S. B., A. Schiller, G. Cambers, D. Jones, and K. Hennessy. 2011. "The Pacific Climate Change Science Program." Bulletin of the American Meteorological Society 92 (11): 1409-11.

Prentice, A. M. 2006. "The Emerging Epidemic of Obesity in Developing Countries." International Journal of Epidemiology 35 (1): 93-99.

Prins, G., and S. Rayner. 2007. “Time to Ditch Kyoto.” Nature 449 (7165): 973-75.

Puoane, T., K. Steyn, D. Bradshaw, R. Laubscher, J. Fourie, V. Lambert, and N. Mbananga. 2002. "Obesity in South Africa: The South African Demographic and Health Survey." Obesity Research 10 (10): 1038-48.

Puska, P., J. Tuomilehto, A. Nissinen, E. Vartiainen, and editors. 1995. The North Karelia Project: 20 Year Results and Experiences. Helsinki: Helsinki University Press.

Reyes, O. 2011. "EU Emissions Trading System: Failing at the Third Attempt." Corporate Europe Observatory and Carbon Trade Watch, Barcelona.

Rizov, M., T. Herzfeld, and S. K. Huffman. 2012. "The Russian Food, Alcohol and Tobacco Consumption Patterns during Transition." Collegium Antropologicum 36 (4): 1143-54.

Römling, C., and M. Qaim. 2012. "Obesity Trends and Determinants in Indonesia." Appetite 58 (3): 1005-13. 
Chapter 4: Regional Climate Agreements to Address Climate Change: Scope, Promise, Funding, and Impacts

Rtveladze, K. 2012. "Obesity Trends in Russia. The Impact on Health and Healthcare Costs." Health 04 (12): 1471-84.

Russian Geography. 2016. "Map of Russia." http://russiangeography.com/Map-of-Russia.gif.

Sachs, J. D. 2012. "From Millennium Development Goals to Sustainable Development Goals." The Lancet 379 (9832): 2206-11.

Sacks, G., J. L. Veerman, M. Moodie, and B. Swinburn. 2011. “"Traffic-Light' Nutrition Labelling and 'junk-Food' Tax: A Modelled Comparison of Cost-Effectiveness for Obesity Prevention.” International Journal of Obesity 35 (7): 1001-9.

Schmidhuber, J. 2004. "The Growing Global Obesity Problem: Some Policy Options to Address It." Electronic Journal of Agricultural and Development Economics 1 (2): 18.

Schmidhuber, J., and P. Shetty. 2005. "The Nutrition Transition to 2030. Why Developing Countries Are Likely to Bear the Major Burden." Food Economics - Acta Agriculturae Scandinavica, Section C 2 (3-4): 150-66.

Schott, J. J., and M. Fickling. 2010. "Revisiting the NAFTA Agenda on Climate Change." Peterson Institute for International Economics.

Schwaabe, C. 2006. "Die deutsche Modernitätskrise. Politische Kultur und Mentalität von der Reichsgründung bis zur Wiedervereinigung." Edited by Wolfgang Bergem. Politische Vierteljahresschrift 47 (4): 749-51.

Sinclair, M. 2009. "The Expensive Failure of the European Union Emissions Trading Scheme." London: TaxPayers' Alliance.

Smetanina, S. 2010. "Russians Must Go on a Diet | Russia Beyond The Headlines." Russia Beyond The Headlines.

Smuts, R.W. 1992. "Fat, Sex, Class, Adaptive Flexibility, and Cultural Change." Ethology and Sociobiology 13 (5-6): 523-42.

Sobal, J. 1991. "Obesity and Socioeconomic Status: A Framework for Examining Relationships between Physical and Social Variables." Medical Anthropology 13 (3): 231-47.

. 2001. "Social and Cultural Influences on Obesity." In International Textbook of Obesity, edited by Per Björntorp, 305-22. John Wiley \& Sons, Ltd.

Sobal, J., V. Nicolopoulos, and J. Lee. 1995. "Attitudes about Overweight and Dating among Secondary School Students." International Journal of Obesity and Related Metabolic Disorders: Journal of the International Association for the Study of Obesity 19 (6): 376-81.

Sobal, J., and A. J. Stunkard. 1989. "Socioeconomic Status and Obesity: A Review of the Literature." Psychological Bulletin 105 (2): 260-75.

Song, J. 2010. "The Road to the Successful Clean Development Mechanism : Lessons from the Past." PhD Thesis, Massachusetts Institute of Technology. http://dspace.mit.edu/handle/1721.1/62763.

Stanner, S. A., K. Bulmer, C. Andres, O. E. Lantseva, V. Borodina, V. V. Poteen, and J. S. Yudkin. 1997. "Does Malnutrition in Utero Determine Diabetes and Coronary Heart Disease in Adulthood? Results from the Leningrad Siege Study, a Cross Sectional Study." British Medical Journal 315 (7119): 1342-48.

Statistics South Africa. 2014. "Poverty Trends in South Africa: An Examination of Absolute Poverty between 2006 and 2011." Pretoria, South Africa.

Staudigel, M. 2011. "How (much) Do Food Prices Contribute to Obesity in Russia?" Economics \& Human Biology 9 (2): 133-47.

Staudigel, M., and R. Schröck. 2015. "Food Demand in Russia: Heterogeneous Consumer Segments over Time." Journal of Agricultural Economics 66 (3): 615-39.

Stern, N. 2006. "What Is the Economics of Climate Change?" World Economics 7 (2). 
Chapter 4: Regional Climate Agreements to Address Climate Change: Scope, Promise, Funding, and Impacts

Stewart, H. 2011. "Food Away from Home." In The Oxford Handbook of the Economics of Food Consumption and Policy, edited by J.L. Lusk, J. Roosen, and J.F. Shogren, 64766.

Stifel, D. C., and S. L. Averett. 2009. "Childhood Overweight in the United States: A Quantile Regression Approach.” Economics \& Human Biology 7 (3): 387-97.

Stillman, S., and D. Thomas. 2008. "Nutritional Status During an Economic Crisis: Evidence from Russia." The Economic Journal 118 (531): 1385-1417.

Stubbs, C. O., and A. J. Lee. 2004. "The Obesity Epidemic: Both Energy Intake and Physical Activity Contribute." The Medical Journal of Australia 181 (9): 489-91.

Subramanian, S. V., J. M. Perkins, and K. T. Khan. 2009. "Do Burdens of Underweight and Overweight Coexist among Lower Socioeconomic Groups in India?" The American Journal of Clinical Nutrition 90 (2): 369-76.

Suhrcke, M., L. Rocco, M. McKee, S. Mazzuco, D. Urban, A. Steinherr, European Observatory on Health Systems andPolicies, and OMS Regional Office for Europe. 2007. "Economic Consequences of Noncommunicable Diseases and Injuries in the Russian Federation."

Swafford, M., and M. Kosolapov. 2002. "Sample Design, Response Rates, and Weights in The Russi Longitudinal Monitoring Survey Rounds 5 to 10: An Abbreviated Description." Unpublished Technical Report. Paragon Research International, Inc. and Institute of Sociology of the Russian Academy of Sciences.

Swinburn, B., and G. Egger. 2002. "Preventive Strategies against Weight Gain and Obesity." Obesity Reviews: An Official Journal of the International Association for the Study of Obesity 3 (4): 289-301.

Tafreschi, D. 2014. "The Income Body Weight Gradients in the Developing Economy of China." Economics \& Human Biology.

The Economist. 2015. "The 169 Commandments." The Economist, March.

Tran, M. 2012. "Mark Malloch-Brown: Developing the MDGs Was a Bit like Nuclear Fusion." The Guardian, November 16, sec. Global development.

Trevisan, J., FEEM, and CMCC. 2013. "The Common Framework for Climate Policy in South-East Asia." International Center for Climate Governance, ICCG Reflection, 13: 7.

Tulchinsky, T. H., and E. A. Varavikova. 1996. "Addressing the Epidemiologic Transition in the Former Soviet Union: Strategies for Health System and Public Health Reform in Russia." American Journal of Public Health 86 (3): 313-20.

Uekötter, F. 2011. Am Ende Der Gewissheiten. Die ökologische Frage Im 21. Jahrhundert. Frankfurt a. M.: Campus.

-. 2015. "Paradoxien Der Klimadiplomatie, Welten Und Weltbilder Im Wandel." INDES. Zeitschrift Für Gesellschaft Und Wandel 4 (4): 135-42.

Ueno, T. 2006. "Reengineering the Climate Regime." 48. Discussion Paper. Washington, D.C.: Resources For the Future.

Ulijaszek, S. J., and H. Lofink. 2006. "Obesity in Biocultural Perspective.” Annual Review of Anthropology 35 (1): 337-60.

UN. 2015a. "The Millenium Development Goals Report." New York, USA.

UN, DESA. 2015b. "World Population Prospects: 2015 Revision.” New York, USA.

UNDP, RBAS. 2011. “ACRI (Arab Climate Resilience Initiative) - Project Document (20122016)." Project Document. UNDP.

. 2013. "Evaluation of the Regional Programme for Arab States." Evaluation Office. http://papersmart.unmeetings.org/media/3224308/rpe_rbas_2010_2013.pdf.

UNEP. 2001. "International Environmental Governance: Multilateral Environment Agreements." Intergovernmental Group of Ministers or Their Representatives on International Environmental Governance First Meeting. New York: United Nations. 
Chapter 4: Regional Climate Agreements to Address Climate Change: Scope, Promise, Funding, and Impacts

UNFCCC. 2016. “Kyoto Protocol.” http://unfccc.int/kyoto_protocol/items/2830.php.

United Nations. 1995. "World Summit for Social Development, Copenhagen 1995." http://www.un.org/esa/socdev/wssd/text-version/.

2015a. "Resolution Adopted by the General Assembly on 25 September 2015 Transforming Our World: The 2030 Agenda for Sustainable Development." New York, USA.

$2015 b$.

"Sustainable

Development

Knowledge

Platform." https://sustainabledevelopment.un.org/.

. 2015c. "The Millennium Development Goals Report." New York, USA.

. 2016. "The UN Climate Change Convention and the Kyoto Protocol." http://www.un.org/wcm/content/site/climatechange/pages/gateway/the-

negotiations/the-un-climate-change-convention-and-the-kyoto-protocol.

Upadhyaya, S. 2013. "Country Grouping in UNIDO Statistics." United Nations Industrial Development Organization, Development Policy, Statistics and Research Branch Working Paper, 1/2013: 36.

Van Der Merwe, M.-T., and M. S. Pepper. 2006. "Obesity in South Africa." Obesity Reviews 7 (4): 315-22.

Vichitlekarn, S. 2010. "ASEAN Policy and Cooperation on Food Security." Singapore. http://aseanfoodsecurity.asean.org/wp-content/uploads/2011/08/suriyan-st1.pdf. 2011. "ASEAN Multi-Sectoral Framework on Climate Change: Agriculture, Fisheries and Forestry towards Food Security (AFCC)." Beijing, China.

Victor, D. G. 2009. "The Politics of Fossil-Fuel Subsidies." SSRN Scholarly Paper ID 1520984. Rochester, NY: Social Science Research Network.

Villanueva, T. 2011. "European Nations Launch Tax Attack on Unhealthy Foods." Canadian Medical Association Journal 183 (17): E1229-30.

Walker, A. R. P., F. Adam, and B. F. Walker. 2001. "World Pandemic of Obesity: The Situation in Southern African Populations." Public Health 115 (6): 368-72.

Walker, A. R. P., D. Bhamjee, B. F. Walker, and A. P. Mart. 1979. "Serum High-Density Lipoprotein Cholesterol, Glucose Tolerance and Other Variables in Obese Black Adolescent." South African Medical Journal 56: 221.

Walker, A. R. P., and I. Segal. 1980. "The Puzzle of Obesity in the African Black Female." The Lancet 315 (8162): 263.

Walker, A. R. P., B. F. Walker, A. J. Walker, and H. H. Vorster. 1988. "Low Frequency of Adverse Sequelae of Obesity in South African Rural Black Women." International Journal for Vitamin and Nutrition Research 59 (2): 224-28.

Wardle, J., and A. Steptoe. 2003. "Socioeconomic Differences in Attitudes and Beliefs about Healthy Lifestyles." Journal of Epidemiology and Community Health 57 (6): 440-43.

Wie, M., J. B. Kampert, C. E. Barlow, et al. 1999. "Relationship between Low Cardiorespiratory Fitness and Mortality in Normal-Weight, Overweight, and Obese Men." Journal of the American Medical Association 282 (16): 1547-53.

Weingart, P., A. Engels, and P. Pansegrau. 2008. Von Der Hypothese Zur Katastrophe. Der Anthropogene Klimawandel Im Diskurs Zwischen Wissenschaft, Politik Und Massenmedien. Opladen and Farmington Hills: Leske \& Budrich.

WHO. 1995. "WHO | Physical Status: The Use and Interpretation of Anthropometry." Report of a WHO Expert Committe. Technical Report Series No. 854. Geneva. . 1998. "Obesity: Preventing and Managing the Global Epidemic. Report of a WHO Consultation." World Health Organization Technical Report Series 894: i - xii, 1-253. 2010a. "WHO Global Infobase: International Comparisons (Females)." https://apps.who.int/infobase/Comparisons.aspx?l=\&NodeVal=WGIE_BMI_5_cd.070 $4 \& D O=1 \& D D L R e g=A L L \& D D L S e x=2 \& D D L A g e G r p=15-$

$100 \& D D L Y e a r=2010 \& D D L M e t h o d=I N T M D C T M \& D D L C a t e N u m=6 \& T x t B x C t m N u$ 
Chapter 4: Regional Climate Agreements to Address Climate Change: Scope, Promise, Funding, and Impacts

$\mathrm{m}=20,35,50,65,80 \& \mathrm{CBLC} 1=\mathrm{ON} \& \mathrm{CBLC} 3=\mathrm{ON} \& \mathrm{CBLC} 4=\mathrm{ON} \& \mathrm{CBLC} 6=\mathrm{ON} \& \mathrm{CBLC}$ $8=\mathrm{ON} \& \mathrm{CBLC} 10=\mathrm{ON} \&$ DDLMapsize $=800 \mathrm{x} 480 \&$ DDLMapLabels $=$ none $\& D D L T m p R$ angBK=0\&DDLTmpColor $=-3342388$.

2010b. "WHO Global Infobase: International Comparisons (Males)." https://apps.who.int/infobase/Comparisons.aspx?l=\&NodeVal=WGIE_BMI_5_cd.070 $4 \& D O=1 \& D D L R e g=A L L \& D D L S e x=2 \& D D L A g e G r p=15-$

$100 \&$ DDLYear $=2010 \&$ DDLMethod $=$ INTMDCTM $\&$ DDLCateNum $=6 \& T x t B x C t m N u$ $\mathrm{m}=20,35,50,65,80 \& \mathrm{CBLC} 1=\mathrm{ON} \& \mathrm{CBLC} 3=\mathrm{ON} \& \mathrm{CBLC} 4=\mathrm{ON} \& \mathrm{CBLC} 6=\mathrm{ON} \& \mathrm{CBLC}$ $8=$ ON $\&$ CBLC $10=$ ON $\&$ DDLMapsize $=800 \times 480 \& D D L M a p L a b e l s=$ none $\& D D L T m p R$ angBK=0\&DDLTmpColor $=-3342388$.

2011a. "WHO | Global Status Report on Noncommunicable Diseases 2010."

2011b. "WHO | Noncommunicable Diseases Country Profiles 2011."

. 2014. Global Status Report on Noncommunicable Diseases 2014.

2015. "South Africa: Country

Profiles.” http://www.who.int/gho/countries/zaf/country_profiles/en/.

—. 2016. "Washington Consensus - Glossary." World Health Organization. http://www.who.int/trade/glossary/story094/en/.

WHO/FAO, joint expert consultation. 2003. "Diet, Nutrition and the Prevention of Chronic Diseases." No. 916 (TRS 916). WHO Technical Report Series.

Williams, L., J. Germov, and A. Young. 2007. "Preventing Weight Gain: A Population Cohort Study of the Nature and Effectiveness of Mid-Age Women's Weight Control Practices." International Journal of Obesity 31 (6): 978-86.

Wittenberg, M. 2013. "The Weight of Success: The Body Mass Index and Economic Well-

Wooldridge, J. 2002. Econometric Analysis of Cross Section and Panel Data. Cambridge, MA; London, England: MIT Press.

Wooldridge, J. M. 2002. Introductory Econometrics: A Modern Approach. 2nd ed. Mason, USA: South-Western.

Wooldridge, J. M. 2006. Introductory Econometrics - A Modern Approach. 3, International Student Edition. Thomson South-Western.

World Bank. 2012. "Women Are Less Likely than Men to Participate in the Labor Market in Most Countries | Data." http://data.worldbank.org/news/women-less-likely-than-mento-participate-in-labor-market.

Zohoori, N., T. A. Mroz, B. M. Popkin, E. Glinskaya, M. Lokshin, D. Mancini, P. Kozyreva, M. Kosolapov, and M. Swafford. 1998. "Monitoring the Economic Transition in the Russian Federation and Its Implications for the Demographic Crisis - the Russian Longitudinal Monitoring Survey." World Development 26 (11): 1977-93. 